\title{
Estudo e Avaliação de TÉCNICAS dE Processamento do Sinal Mioelétrico para o Controle de Sistemas de Reabilitação
}

\author{
Rodrigo Lício Ortolan
}

Dissertação apresentada à Escola de Engenharia de São Carlos da Universidade de São Paulo, como parte dos requisitos para obtenção do Título de Mestre em Engenharia Elétrica.

Orientador: Prof. Dr. Alberto Cliquet Jr. 


\section{DEDICATÓRIA}

"Quero a utopia quero tudo e mais, quero a felicidade nos olhos de um pai... ...quero que a justiça reine em meu país...

...Se o poeta é aquele que sonha o que vai ser real, vou sonhar coisas boas que o homem faz e esperar pelos frutos no quintal."

Milton Nascimento - (Coração Civil)

Dedico às duas pessoas, que muito me ensinaram e sempre me incentivaram a estudar e trabalhar honestamente: meus pais. 


\section{Agradecimentos}

Este trabalho não seria possível sem a valiosa contribuição de várias pessoas, às quais expresso minha sincera gratidão:

Aos meus pais, Roberto e Suzana pela minha formação pessoal e por terem me concedido a oportunidade de estudar, também por sempre apoiarem e incentivarem a realização dos meus sonhos. Aos meus irmãos Carolina e Danilo pela alegria e convivência e por compreenderem a necessidade da minha ausência.

À Beatriz pelo sorriso, carinho e força sempre presentes, pela sua incansável ajuda nas correções ortográficas e gramaticais do texto e também por estar sempre ao meu lado me apoiando e incentivando em minhas investidas, durante os últimos quatro anos.

Ao professor Dr. Alberto Cliquet Jr. pelo privilégio de sua orientação durante a elaboração deste trabalho, pelo incentivo, conselhos e amizade.

Aos professores Dr. Marcelo Basílio Joaquim e Dr. José Carlos Pereira pela valiosa contribuição nas dúvidas esclarecidas, pela boa vontade e atenção.

Aos funcionários do departamento de engenharia elétrica em especial à Marisa, Rosane, Xaraba e Zé Carlos pela eficiência, organização e atenção nos serviços prestados. Aos técnicos Zé Luiz, Alessandro, Petrussio, Gerson e Roseli pelo companheirismo, manutenção dos equipamentos e auxílio prestado.

Aos companheiros do LABCIBER pelas experiências compartilhadas, pelos trabalhos realizados em conjunto e pelos bons momentos nas viagens, bares, etc..., e especialmente ao Benigno e Maçaranduba pela leitura detalhada deste trabalho. 
Aos amigos e moradores da República dos "Cachassauros Largados", (Eng ${ }^{\text {os.: }}$ Maru, Bicudo, Spin, Fernandinho, Velinho e Sardinha), pelos momentos (etílicos ou não) de companhia, descontração e cumplicidade e também por compreenderem a minha ausência em algumas ocasiões. Aos amigos da graduação pelas lembranças e amizade sempre revigorada.

Ao Mestre Ricardo Naoki Mori, grande 'guru', pelas elucidantes conversas de caráter profissional e pessoal.

A família Gatti pela ótima recepção e constante apoio.

Aos Prof. Drs. participantes do Exame de Qualificação José Roberto Castilho Piqueira e José Carlos Pereira, e também aos Prof. Drs. José Roberto Castilho Piqueira, Marcelo Basílio Joaquim, Laécio Carvalho de Barros e José Carlos Sartori, pela boa vontade ao aceitar o convite para participar da Banca Examinadora Final, pela leitura criteriosa e contribuição neste trabalho.

À Fundação Coordenação de Aperfeiçoamento de Pessoal de Nível Superior (CAPES), pela bolsa de estudos concedida e à Fundação de Amparo à Pesquisa do Estado de São Paulo (FAPESP) pelo financiamento do projeto 96/12198-2.

Enfim sou imensamente grato a minha família, amigos e aqueles que contribuíram anonimamente na realização deste trabalho. 


\section{SUMÁRIO}

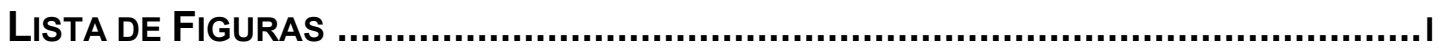

LISTA DE TABELAS ....................................................................................

ABREVIAÇÕES E SIGLAS ....................................................................... VII

RESUMO ................................................................................................ VIII

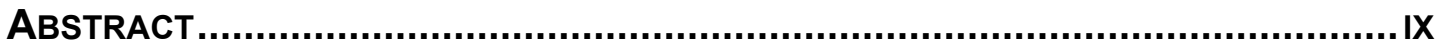

PREFÁCIO 1

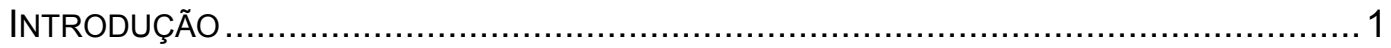

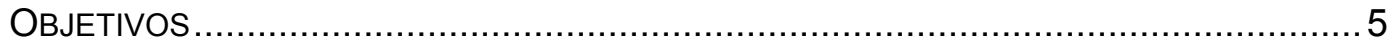

CAPÍTULO $1+6$

O SinAL Mioelétrico

1.1 O PROCESSO DE CONTRAÇÃO MUSCULAR. .................................................. 8

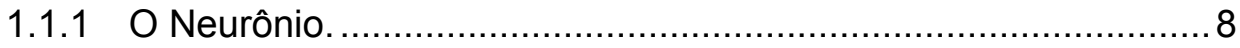

1.1.2 O Potencial de Ação Neural .................................................... 10

1.1 .3 Junção neuromuscular ................................................... 13

1.1.4 Fisiologia do Músculo Esquelético ....................................... 14

1.1.5 Unidade Motora ................................................................ 16

1.1.6 O Potencial de Ação da Unidade Motora (MUAP) .................... 18

1.2 FORMAS DE CAPTAÇÃO E CARACTERÍSTICAS DO SME ..................................20

1.2.1 Características do SME de Superfície .................................20

1.2.2 Eletrodos utilizados para captar o SME ................................23

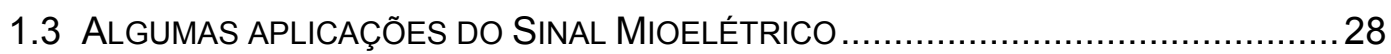

1.3.1 O uso do SME em próteses de mão ........................................29

1.3.2 Aplicação do SME em sistemas de Estimulação Elétrica Neuro-Muscular (EENM) ................................................ 31

1.3.3 Controle de ambiente de comunicação para pacientes com Traumatismo Crânio Encefálico 


\section{TÉCNICAS DE FILTRAGEM}

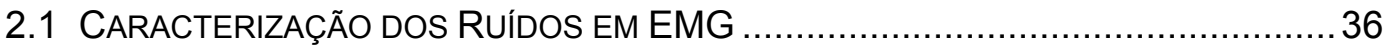

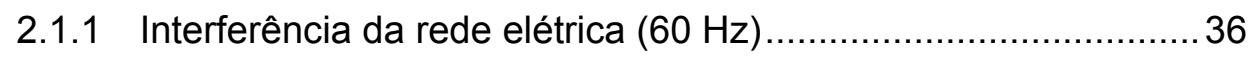

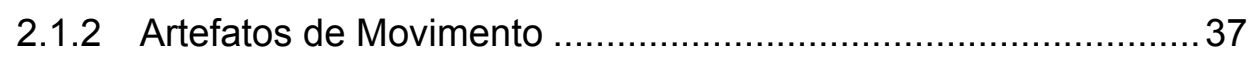

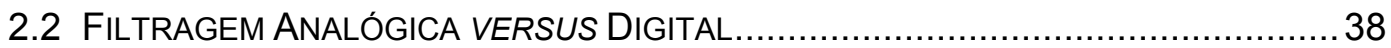

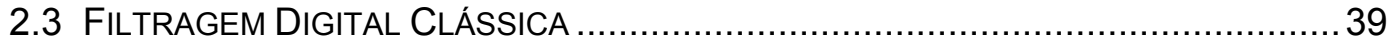

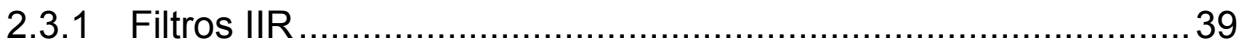

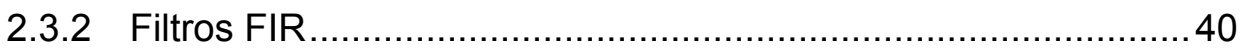

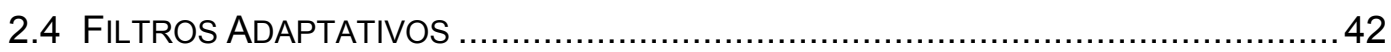

2.5 FILTRO DE WIENER (CANCELADOR DE Ruído ESTACIONÁRIO) .........................43

2.6 CANCELAMENTO DE RuÍDO AdAPTATIVO .................................................... 46

2.6.1 O algoritmo LMS ….......................................................... 47

2.6 .2 O algoritmo RLS ............................................................... 50

2.6.3 Efeito da Presença de Componentes do Sinal Desejado no Sinal de Referência ........................................................... 52

2.6.4 Cancelamento de Ruído Adaptativo Utilizando

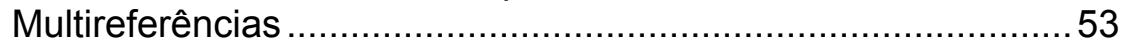

2.6.5 Filtro Notch com o Cancelamento de Ruído Adaptativo .............54

2.7 RECONSTRUÇÃO DO SINAL UTILIZANDO AS COMPONENTES DA

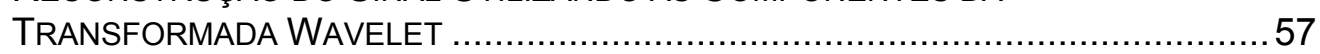

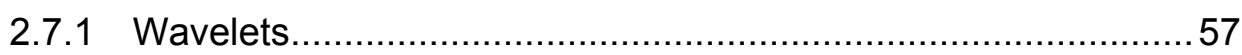

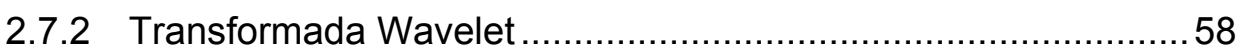

2.7.3 Análise Multiresolução ....................................................... 61

\section{CAPÍTULO 3}

\section{Avaliação de TÉCnicas de Filtragem Aplicadas ao SME}

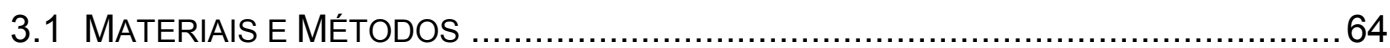

3.1.1 Filtragem do Ruído dos Artefatos de Movimento .....................64 64

3.1.2 Filtragem da Interferência da rede elétrica...............................66

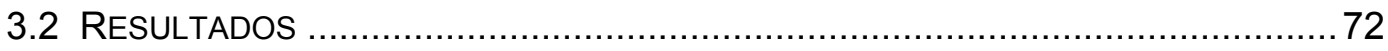

3.2.1 Filtragem do Ruído dos Artefatos de movimento ..................... 72

3.2.2 Filtragem da Interferência da rede elétrica..............................76 
RECONHECIMENTO DOS PADRÕES DO SME

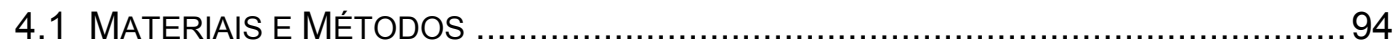

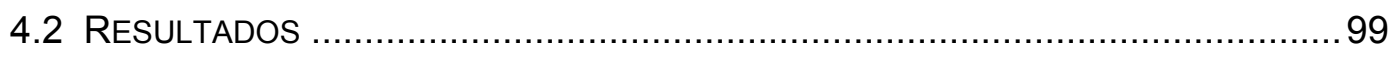

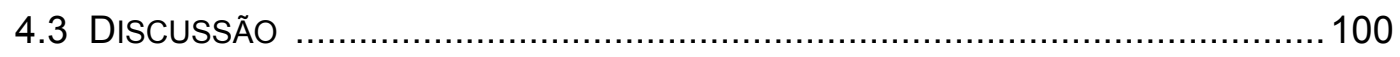

\begin{tabular}{ll} 
CONCLUSÕES & 101 \\
\hline
\end{tabular}

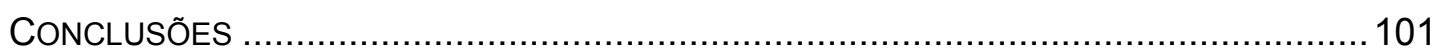

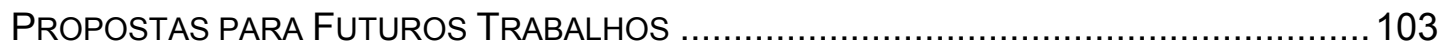

\begin{tabular}{ll} 
ANEXO & 104 \\
\hline
\end{tabular}

Resposta em FrequênCia para Filtragem ANALÓgica e Digital IIR

\begin{tabular}{ll} 
REFERÊNCIAS & 107 \\
\hline
\end{tabular}

APÊNDiCE - Algumas Aplicações com Canceladores de Ruído ADAPTATIVO 


\section{LiSTA DE FigURAS}

Fig. 1 - Neurônios (a) Motor e (b) Sensorial. (BELTRAMINI, 1999) ............ 9

Fig. 2 - Variação da tensão na membrana celular nervosa durante o Potencial de Ação. (adaptado de KOVÁKS, 1997)

Fig. 3 - Esquema de uma terminação neural invaginada numa fibra muscular. (adaptado de BELTRAMINI, 1999).

Fig. 4 - Estrutura do Músculo Esquelético (BELTRAMINI, 1999).

Fig. 5 - Constituição das Fibras Musculares Esqueléticas:
a) Fibra Muscular b) Miofibrilas
c) Filamentos de Actina e Miosina

(Beltramini,1999).

Fig. 6 - Unidade Motora (BELTRAMINI, 1999).

Fig. 7 - Esquema da geração de um MUAP. (adaptado de BASMAJIAN \& DeLUCA,1985)

Fig. 8 - Representação esquemática da geração do Sinal Mioelétrico de um músculo, a partir da somatória dos trens de MUAPs das $n$ unidades motoras deste músculo (adaptado de BASMAJIAN \& DeLUCA, 1985)

Fig. 9 - Sinal Mioelétrico do grupo extensor do antebraço durante extensão do punho.

Fig. 10 - Espectro de Densidade de Potência do sinal da Fig. 9............... 22

Fig. 11 - Eletrodos Passivos 25

Fig. 12 - Representação de um Amplificador Diferencial captando o sinal Mioelétrico. O SME é representado por " $m_{i}$ " e o ruído por " $n$ " (adaptado de DELSYS INC., 1996).

Fig. 13 - Eletrodo Ativo de Superfície Diferencial 26

Fig. 14 - Principais músculos superficiais do antebraço. Grupo Extensor:

a), b), c); Grupo Flexor: d), e), f), g).

a) Extensor dos dedos e extensor do mínimo, b) Extensores radiais longo e curto do carpo, c) Extensor ulnar do Carpo,

d) Flexor Superficial dos dedos, e) Flexor radial do Carpo,

f) Flexor ulnar do carpo, g) Palmar longo e curto.

(adaptado de KENDALL \& McCREARY, 1986).

Fig. 15 - Músculos que podem ser utilizados para fornecer o sinal da intenção do passo na Estimulação Elétrica Neuro-Muscular em pacientes lesados medulares a) Trapézio, b) Deltóide, c) Bíceps Braquial d) Peitoral Maior (adaptado de KENDALL \& McCREARY,1986). 
Fig. 16 - Tipos de Janela. a) Janela Retangular, b) Barlett, c) Hanning,

d) Hamming, e) Blackman, f) Kaiser

(adaptado de PARKS \& BURRUS, 1987).

Fig. 17 - Diagrama de blocos de um filtro adaptativo. $x(k)$ entrada e $\mathrm{y}(\mathrm{k})$ saída do filtro.

Fig. 18 - Filtro proposto por Wiener como cancelador de ruído.

$s(k)$ é o sinal que se deseja obter, $n(k)$ é o ruído inserido no sinal, $r(k)$ é o sinal de referência

e $\tilde{n}(k)$ é o ruído estimado pelo filtro de Wiener.

Fig. 19 - Superfície da performance do erro

(IFEACHOR \& JERVIS, 1993).

Fig. 20 - Diagrama de blocos de um cancelador de ruído adaptativo (adaptado de IFEACHOR \& JERVIS, 1993).

Fig. 21 - Convergência dos coeficientes $W(k)$ para $W_{\text {ótimo }}$

(IFEACHOR \& JERVIS, 1993).

Fig. 22 - Fluxograma do algoritmo LMS

(adaptado de IFEACHOR \& JERVIS, 1993).

Fig. 23 - Diagrama de blocos de um cancelador de ruído adaptativo multireferencial (adaptado de WIDROW et al., 1975)

Fig. 24 - Diagrama de blocos de um cancelador de ruído adaptativo utilizado como filtro Notch proposto por WIDROW et al. (1975).

(modificado de WIDROW et al.,1975) 55

Fig. 25 - Wavelets da famíla Daubechies. (MISITI et al., 1996) 58

Fig. 26 - llustração de como são calculados os coeficientes da transformada wavelet.

a) Correlação do primeiro período do sinal com uma wavelet,

b) Deslocamento da wavelet para obter os valores de correlação no tempo, c) Troca da escala da wavelet.

(adaptado de MISITI et al., 1996).

Fig. 27 - Gráfico de intensidade da correlação do sinal, $C$, com as diferentes escalas de wavelet (adaptado de MISITI et al., 1996).

Fig. 28 - Árvore de decomposição tradicional da transformada wavelet com três níveis de decomposição.

(MISITI et al., 1996)

Fig. 29 - Árvore de decomposição mostrando todos os nós terminais possíveis até o $3^{\circ}$ nível de decomposição.

(MISITI et al., 1996)

Fig. 30 - Decomposição do sinal, s, nas componentes terminais da árvore da fig. 28.

Fig. 31 - Árvore de decomposição utilizada para cancelar os artefatos de movimento. 
Fig. 32 - Sinal mioelétrico obtido com o ruído da rede elétrica. 68

Fig. 33 - Árvore de decomposição utilizada na decomposição do sinal por meio da transformada wavelet para atenuar a interferência de rede elétrica.

Fig. 34 - Intensidade de energia dos nós terminais de uma árvore com 4 níveis de decomposição. O eixo das abcissas representa o intervalo de captação do sinal. Análise realizada no sinal apresentado na figura 32 .

Fig. 35 - Intensidade de energia dos nós terminais da árvore de decomposição ilustrada na figura 33. O eixo das abcissas representa o intervalo de captação do sinal. Análise realizada no sinal apresentado na figura 32.

Fig. 36 - Sinal mioelétrico contaminado com ruído de artefato de movimento.

Fig. 37 - Sinal obtido do termo $a_{5}$ da decomposição através da transformada wavelet. Pelas baixas frequências que compõem este sinal pode-se dizer que ele representa a variação da tensão média do sinal ilustrado na figura 36

Fig. 38 - Sinal reconstruído com os termos $a_{5}$ e $d_{5}$ da decomposição utilizando a transformada wavelet. Este sinal apresenta componentes frequenciais de 0 a $31.25 \mathrm{~Hz}$

Fig. 39 - SME com ruído de artefato de movimento atenuado, reconstruído com os coeficientes da transformada wavelet $d_{1}, d_{2}, d_{3}, d_{4}$ e $d_{5}$.

Fig. 40 - Saída do filtro FIR passa alta de ordem 100 (janela de Kaiser) com frequência de corte de $20 \mathrm{~Hz}$. Na entrada do filtro foi aplicado o sinal apresentado na figura 36.

Fig. 41 - Saída do filtro IIR passa alta de $6^{\mathrm{a}}$ ordem (Chebyshev tipo II) com frequência de corte de $20 \mathrm{~Hz}$, para o sinal de entrada apresentado na figura 36 .

Fig. 42 - SME do grupo extensor do punho obtido durante extensão, $x(k)$.

Fig. 43 - SME da figura 42 com um ruído da rede adicionado, $x(k)=s(k)+n(k)$, obtendo uma SNR de $-18 \mathrm{~dB}$.

Fig. 44 - Em azul: o ruído da rede elétrica inserido no SME, $n(k)$, e em preto o sinal de referência, $r(k)$, gerado com $60 \mathrm{~Hz}$ e $120 \mathrm{~Hz}$ com valores de fase e amplitude aleatórios.

Fig. 45 - Em preto: o início do sinal estimado pelo algoritmo LMS, $\tilde{n}(k)$, se aproximando do ruído, $n(k)$, representado em azul.

Fig. 46 - Em azul: sinal mioelétrico, $s(k)$. Em preto: saída do cancelador de ruído adaptativo com algoritmo LMS, $y(k)$. 
Fig. 47 - Em azul: sinal mioelétrico, $s(k)$. Em preto: saída do cancelador de ruído adaptativo utilizando o algoritmo LMS, $y(k)$, durante os 200 ms iniciais de contração.

Fig. 48 - Em preto: Início do sinal estimado pelo filtro com algoritmo RLS, $\tilde{n}(k)$, se aproximando do ruído, $n(k)$, apresentado em azul.

Fig. 49 - Em azul: sinal mioelétrico, $s(k)$. Em preto: saída do cancelador de ruído adaptativo com algoritmo RLS, $y(k)$.

Fig. 50 - Em azul: SME, $s(k)$. Em preto: saída do cancelador de ruído adaptativo utilizando o algoritmo RLS, $y(k)$, durante o inicio da contração.

Fig. 51 - DFT do SME contaminado com ruído da rede elétrica apresentado na fig. 32.

Fig. 52 - Resposta do cancelador de ruído adaptativo com os parâmetros indicados na tabela 3. O sinal aplicado no filtro é o sinal apresentado na figura 32 .

Fig. 53 - DFT do SME contaminado com a interferência da rede (sinal tracejado) e a resposta da filtragem adaptativa (sinal contínuo) próximos à região da frequência de ressonância.

Fig. 54 - Resposta frequencial ao impulso, do filtro FIR notch de $664^{\mathrm{a}}$ ordem com janela de Kaiser.

Fig. 55 - Resposta do filtro FIR notch de $664^{\mathrm{a}}$ ordem com janela de Kaiser para o sinal de entrada descrito na figura 32.

Fig. 56 - DFT do SME contaminado com a interferência da rede (sinal tracejado) e a saída do filtro FIR (sinal contínuo)

próximos à frequência de ressonância.

Fig. 57 - Resposta frequencial ao impulso. Filtro de $2^{a}$ ordem IIR Chebishev tipo II.

Fig. 58 - Resposta do filtro notch de $2{ }^{\text {a }}$ ordem IIR chebishev tipo II para o sinal de entrada descrito na figura 32.

Fig. 59 - DFT do SME contaminado com a interferência da rede (sinal tracejado) e a saída do filtro IIR (sinal contínuo) próximos à frequência de ressonância.

Fig. 60 - Sinal reconstruído com as componentes $(4,0),(5,3),(6,5)$, $(6,13),(5,7),(4,2),(2,1)$ e $(1,1)$ do sinal decomposto pela transformada wavelet, com a árvore de decomposição ilustrada na fig. 33.

Fig. 61 - DFT do SME contaminado com a interferência da rede (sinal tracejado) e a DFT do sinal reconstruído com as componentes $(4,0),(5,3),(6,5),(6,13),(5,7),(4,2),(2,1)$ e $(1,1)$ do sinal decomposto pela transformada wavelet, com a árvore de decomposição ilustrada na fig. 33. 
Fig. 62 - SME referente aos 200 ms iniciais da flexão do antebraço $(\mu \mathrm{V}$ por $\mathrm{ms})$.

Fig. 63 - SME referente aos 200 ms iniciais da extensão do antebraço $(\mu \mathrm{V}$ por $\mathrm{ms})$.

Fig. 64 - Exemplo de SME captado pelo eletrodo situado no grupo flexor durante a flexão do punho.

a) Todo o sinal captado durante $2 \mathrm{~s}$, mostrando a janela de $200 \mathrm{~ms}$;

b) $200 \mathrm{~ms}$ iniciais após o início da contração, já normalizado.

Fig. 65 - Exemplo de SME captado pelo eletrodo situado no grupo extensor durante a extensão do punho... a) Todo o sinal captado durante $2 \mathrm{~s}$, mostrando a janela de $200 \mathrm{~ms}$; b) $200 \mathrm{~ms}$ iniciais após o início da contração, já normalizado.

Fig. 66 - Diagrama da rede neural utilizada com três unidades na camada intermediária.

Fig. 67 - Resultados dos testes da rede para as quatro arquiteturas utilizadas.

\section{ANEXO}

Fig . A1 -Espectro de amplitude de um filtro com resposta de Butterworth. (adaptado de PARKS \& BURRUS, 1987) 104

Fig . A2 -Espectro de amplitude da resposta dos filtros de Chebyshev. a) Tipo I e b) Tipo II. (adaptado de PARKS \& BURRUS, 1987) 105

Fig . A3 -Espectro de amplitude da resposta do filtro elíptico. (adaptado de PARKS \& BURRUS, 1987) 


\section{LISTA DE TABELAS}

Tab. 1 - Classificação e características das unidades motoras em músculos esqueléticos (adaptado de ROBSON, 1989)

Tab. 2 - Melhor relação sinal ruído alcançada nas saídas dos filtros adaptativos, a SNR de entrada foi de $1.99 \mathrm{~dB},-18 \mathrm{~dB}$ e $-38 \mathrm{~dB}$.

Tab. 3 - Parâmetros utilizados nos filtros, para atingir as SNRs descritas na tabela 2 76

Tab. 4 - Relações Sinal Ruído das saídas dos filtros adaptativos com características iguais 


\section{AbreviaÇões e Siglas}

Além das abreviações e siglas, são apresentadas também algumas expressões técnicas que normalmente são mencionadas em inglês.

A/D: Conversor Analógico Digital

Backpropagation: do inglês, Retropropagação

DC: Direct Current. Corrente Contínua

CMRR: Comom Mode Rejection Ratio. Razão de Rejeição em Modo Comum

D/A: Conversor Digital Analógico

DFT: Discrete Fourier Transformer - Transformada Discreta de Fourier.

EENM: Estimulação Elétrica Neuromuscular

EOG: Eletrooculograma

EMG: Eletromiografia

FF: Fast Fatigable - Tipo de fibra muscular rápida e facilmente fatigável

FR: Fast Resistence - Tipo de fibra muscular rápida e resistente à fadiga.

FIR: Finite Inpulse Respost . Resposta Finita ao Impluso

Hz: Hertz, unidade de frequência.

IIR: Infinite Inpulse Respost . Resposta Infinita ao Impulso
LMS: Least Mean Square. Média dos mínimos quadrados.

LS: Least Square. Mínimos Quadrados

MUAP: Motor Unit Action Potential. Potencial de ação da unidade motora

MUAPT: Motor Unit Action Potential Train. Trem de Potenciais de ação da unidade motora

MUP: Motor Unit Potential. Potencial da unidade motora

Notch : Fenda. Termo utilizado para filtros que rejeitam certas frequências

Offset : sintaxe relacionada com um nível de tensão indesejado que um circuito adiciona a um sinal

Overflow : Sintaxe designada para falta de memória durante a execução de uma processamento digital

RLS: Recursive Least Square. Mínimos Quadrados Recursivo

RMS: Root Mean Square. Raiz da média quadrática.

S: Slow. Tipo de fibra muscular lenta

SME: Sinal Mioelétrico

SNR: Signal Noise Ratio. Relação Sinal-Ruído 


\section{RESUMO}

Ortolan, R. L. (2002) "Estudo e Avaliação de Técnicas de Processamento do Sinal Mioelétrico para o Controle de Sistemas de Reabilitação". São Carlos, 2002. 113p. Dissertação (Mestrado) - Departamento de Engenharia Elétrica da Escola de Engenharia de São Carlos, Universidade de São Paulo.

Este trabalho tem a finalidade de analisar algumas técnicas de processamento do sinal mioelétrico, de forma a possibilitar uma posterior implementação de um circuito, que reconheça este sinal e apresente como saída um sinal de controle a ser utilizado em sistemas de reabilitação. Foram simuladas e avaliadas três técnicas de filtragem para o sinal mioelétrico, a fim de atenuar a interferência dos principais ruídos que corrompem este sinal. As técnicas avaliadas foram: filtragem digital clássica; cancelamento de ruído adaptativo e reconstrução do sinal por meio das componentes obtidas pela transformada wavelet. Também foi implementado e analisado um sistema simplificado de reconhecimento dos padrões para este sinal, realizado por meio de uma rede neural artificial, em que foi aplicado em sua entrada o próprio sinal mioelétrico e não suas características obtidas por processamentos matemáticos. Diante dos resultados obtidos os canceladores de ruído adaptativos apresentaram melhores resultados com relação às outras técnicas de filtragem. Apesar de não ter sido adequada para a filtragem, a transformada wavelet mostrou-se uma poderosa ferramenta de análise de sinais, em virtude da sua característica multiresolução. A técnica utilizada para reconhecer os padrões do sinal mostrou bons resultados com os sinais analisados.

Palavras-chave: Sinais Mioelétricos, Processamento Digital de Sinais, Filtragem Adaptativa, Reconhecimento de Padrões, Transformada Wavelet, Engenharia de Reabilitação. 


\section{Abstract}

Ortolan, R. L. (2002) "Study and Evaluation of Techniques for Myoelectric Signal Processing to Control Rehabilitation Systems". São Carlos, 2002. 113p. Dissertação (Mestrado) - Departamento de Engenharia Elétrica da Escola de Engenharia de São Carlos, Universidade de São Paulo.

This work has the purpose to analyze some techniques for myoelectric signal processing, towards a subsequent implementation of a circuit which can recognize this signal and present as output a control signal to be used in rehabilitation systems. Simulation and evaluation of three filtering techniques for the myoelectric signal were done in order to attenuate the main interferences of noises which corrupt this signal. The evaluated techniques were: classic digital filtering; adaptive noise cancelling and the signal reconstruction through the obtained components by the wavelet transform. A simplified system of pattern recognition for this signal also was implemented and analyzed, accomplished through an artificial neural network. The myoelectric signal itself was applied to the input instead of its characteristics obtained by mathematical processing. According to the results obtained the adaptive noise cancelling presented better results in comparison to the other filtering techniques. Despite not being adequate for filtering, the wavelet transform proved to be a powerful tool for signal analysis, by virtue of its multiresolution characteristics. The technique used to recognize the signal patterns has shown good results with the analyzed signals.

Keywords: Myoelectric Signals, Digital Signal Processing, Adaptive Filtering, Pattern Recognition, Wavelet Transform, Rehabilitation Engineering. 


\section{PREFÁCIO}

“...Embriagai-vos sem tréguas! De vinho, de poesia ou de virtude, como achardes melhor."

Charles Baudelaire.

\section{Introdução}

O maior problema que portadores de algum tipo de deficiência enfrentam é a sua integração com a sociedade. Atividades simples, como abrir uma porta, escrever, levantar e andar, tomar banho ou mesmo tomar uma xícara de café, na realidade podem se tornar complexas quando estes indivíduos devem realizá-las.

Com a intenção de reabilitar estes indivíduos, muitos trabalhos já foram realizados, como por exemplo: próteses funcionais de mão para amputados (SCOTT \& PARKER, 1988; KYBERD et al., 1995); estimulação elétrica nos membros de pacientes lesados medulares, tornando possível que estes indivíduos possam ficar de pé e andar (CLIQUET, 1989; CLIQUET, 1991); implementação de um sistema de estimulação táctil para cegos (ANTONINO \& CLIQUET, 1992); oclusor para pacientes colostomizados (PAULA et al., 1994); desenvolvimento de ambientes de comunicação para pacientes com traumatismo crânio encefálico (LaCOURSE \& HLUDIK, 1990; CLIQUET, 1997; ORTOLAN et al., 2001); próteses de perna, implantes de cóclea e retina (DIAS, 1999), e muitos outros.

A utilização de equipamentos elétricos para reabilitação normalmente necessita de um sinal de controle, que fornece informação de como este equipamento deve funcionar. Quando este controle é realizado pelo paciente pode ser feito de diversas maneiras, dentre elas: por meio de chaves liga/desliga, da voz (CLIQUET et al., 1992) ou do sinal elétrico proveniente 
de uma contração muscular (ORTOLAN et al., 2000; PAVANI et al., 2001; FRANCA et al., 2002).

Em certos sistemas de reabilitação, o uso do sinal mioelétrico (sinal proveniente de uma contração muscular) apresenta algumas vantagens em relação a outros tipos de sinal de controle. No caso de uma prótese funcional, esta pode ser acionada mais facilmente pelo usuário quando controlada pelos músculos preservados do membro acima da amputação. $A$ marcha induzida em lesados medulares, com a estimulação elétrica, também é controlada pelo paciente de forma mais simples quando comandada pelos músculos localizados acima da lesão, ou seja, utilizando o sinal mioelétrico do braço ou ombro do paciente, quando movimentar a muleta ou andador para dar o passo. Outro caso em que se pode utilizar o sinal mioelétrico é em pacientes com traumatismo crânio encefálico. Estes indivíduos muitas vezes só conseguem mexer os olhos, desta forma é possível obter os sinais dos músculos oculares a fim de fornecer informações para um sistema de comunicação entre o paciente e outras pessoas.

Este trabalho tem a finalidade de avaliar o desempenho de algumas técnicas de processamento do sinal mioelétrico, para posteriormente implementar um circuito que reconheça este sinal e controle um dos sistemas descritos no parágrafo anterior, da forma mais confiável possível.

A fim de que os pacientes possam se desconectar facilmente dos equipamentos controlados pela sua atividade muscular, para por exemplo, poder tomar banho ou dormir, foram utilizado eletrodos não invasivos (de superfície) para captar o sinal. Outra vantagem do uso destes tipos de eletrodos, com relação aos eletrodos invasivos, é que não apresentam os inconvenientes da necessidade de excelente esterilização, do perigo da quebra dos fios dentro do músculo e sobretudo do desconforto do paciente (BASMAJIAN \& DeLUCA, 1985).

Em virtude das baixas amplitudes do Sinal Mioelétrico (SME), quando este sinal é utilizado em análises clínicas, recomenda-se a captação em ambiente apropriado de forma a atenuar a interferência de possíveis ruídos, a fim de evitar o uso de filtros que poderiam comprometer o sinal (DELSYS 
INC., 1996). Porém, para que um equipamento, que utilize o SME como sinal de controle, tenha desempenho satisfatório em qualquer ambiente, deve ser imune aos mais diversos tipos de ruídos e interferências, fazendo-se necessário o uso de filtros que devem ser projetados cuidadosamente para não alterar as características do sinal.

Um ruído relevante é o ruído da rede elétrica $(60 \mathrm{~Hz})$, pois está presente nos mais variados ambientes, tem amplitude razoável se comparado às amplitudes do sinal mioelétrico (ZHANG et al., 1997), e tem frequência dentro da faixa de maior concentração de energia do SME (DELSYS INC., 1996).

Outro tipo de ruído pode ser induzido pelos artefatos de movimento. Pode-se observar facilmente que quando um músculo se contrai, a pele também se movimenta, desta forma os eletrodos de superfície podem ter um pequeno deslocamento em relação à pele durante uma contração, gerando assim um ruído de baixa frequência relacionado com a variação da tensão média do SME. Este tipo de ruído pode também contaminar o SME por meio do movimento dos cabos de captação.

Além da filtragem do sinal, outra forma capaz de aumentar a confiabilidade do sistema, é o uso de alguma técnica de reconhecimento dos padrões do sinal mioelétrico. Com o uso de tais técnicas, é possível diferenciar os sinais provenientes dos vários músculos próximos ao eletrodo de captação, além de inibir respostas inadequadas do sistema, resultante de ruídos presentes no sinal e da atividade dos músculos não relacionados com o movimento na vizinhança do eletrodo.

Inicialmente o sinal mioelétrico foi considerado como um processo puramente estocástico (KREIFELDT \& YAO, 1974; PARKER et al., 1977; DeLUCA, 1979), no entanto posteriormente foram encontradas características determinísticas dentro dos primeiros $200 \mathrm{~ms}$ de uma contração muscular (HUDGINS et al., 1991; HUDGINS et al., 1993; BASHA et al., 1994), possibilitando desta forma reconhecer os padrões do SME utilizando esta janela de $200 \mathrm{~ms}$. 
Neste trabalho são apresentadas e avaliadas técnicas de processamento de sinal, a fim de obter o SME com a melhor relação sinal ruído. As técnicas utilizadas foram: filtragem digital clássica (IIR e FIR); cancelamento de ruído adaptativo; e reconstrução do sinal utilizando as componentes obtidas pela transformada wavelet. É apresentada também uma topologia de reconhecimento de padrões utilizando redes neurais artificiais com treinamento por backpropagation. 


\section{Objetivos}

Os objetivos deste trabalho são o estudo, simulação e avaliação de algumas técnicas de filtragem do sinal mioelétrico e análise do desempenho de um sistema simples de reconhecimento dos padrões deste sinal.

Foram filtrados sinais mioelétricos contaminados com ruídos provenientes da rede elétrica e dos artefatos de movimento. As técnicas de filtragem analisadas foram:

- Filtragem Digital Clássica (FIR e IIR)

- Cancelamento de Ruído Adaptativo (Algoritmos LMS e RLS)

- Reconstrução do Sinal Utilizando Determinadas Componentes do Sinal Decomposto pela Transformada Wavelet

O reconhecimento dos padrões do sinal foi realizado por meio de uma topologia de rede neural artificial, utilizando o próprio sinal mioelétrico como entrada da rede, sem extrair suas caracteristicas. Foi utilizado o treinamento da rede por backpropagation.

A avaliação destas técnicas visa fornecer subsídios, para a posterior implementação de um circuito, que reconheça o sinal de uma atividade muscular e apresente um sinal de controle para os seguintes processo de reabilitação:

- Prótese Antropomórfica Multifunção de Membros Superiores.

- Estimulação Elétrica Neuromuscular para Lesados Medulares.

- Ambiente de Comunicação para pacientes com Traumatismo Crânio-Encefálico. 


\section{CAPÍtUl0 1}

"Feliz aquele que transfere o que sabe e aprende o que ensina."

Cora Coralina.

\section{O SinAL Mioelétrico}

O sinal mioelétrico é proveniente do potencial de ação que percorre a fibra muscular levando-a à contração. A primeira dedução lógica que um músculo gera correntes elétricas foi documentada pelo italiano Francesco Redi, em 1666. Ele suspeitou que o choque da enguia elétrica era de origem muscular (BIEDERMAN, 1898). As primeiras investigações a respeito da relação entre a eletricidade e a contração muscular foram realizadas por Luidgi Galvani, em 1791, que despolarizava pernas de sapos com o toque de varas metálicas, causando a contração muscular. Em homenagem à este experimento, esta data é considerada o aniversário da neurofisiologia e Galvani o 'pai' desta área. Alessandro Volta provou que a corrente elétrica, advinda de eletrodos, em contato com o fluido dos tecidos musculares, gera um estímulo que leva a contração muscular.

Em 1838, Carlos Mateucci, utilizando músculos de sapo com nervos intactos, mostrou que havia contração do músculo com a estimulação de um toque no nervo, e utilizando-se dos primeiros galvanômetros (primeira construção data de 1820), demonstrou a evidência da atividade elétrica durante a contração muscular.

Frenchman Dubois-Reymond se interessou pelo trabalho de Mateucci e, em 1849, realizou a primeira deteç̧ão do sinal mioelétrico obtido voluntariamente de músculos humanos. Dubois-Reymond detectou o sinal mioelétrico com um tipo de eletrodo de superfície, em que os dedos eram 
inseridos em uma solução salina, e realizando o movimento dos braços foi observada uma pequena deflexão na agulha de um galvanômetro. Retirando um pouco da pele dos dedos, DuBois percebeu que a deflexão da agulha aumentou de 2 ou 3 graus para 65 graus e este resultado se manteve constante para vários experimentos (DuBOIS-REYMOND, 1849).

Com o surgimento do tubo de raios catódicos, em 1897 por Braun, tornou-se possível estudar a morfologia do sinal mioelétrico. Hebert $\mathrm{S}$. Gasser e Joseph Erlanger foram os primeiros a estudar as características do sinal mioelétrico, obtido com um osciloscópio (GASSER \& ERLANGER, 1925) o que Ihes rendeu o prêmio Nobel em 1944.

A partir de então, a Eletromiografia (EMG), que é considerada o estudo das funções musculares através da captação do Sinal Mioelétrico (SME), começou a utilizar dispositivos para detecção, amplificação e apresentação do SME em forma gráfica. Denny Brown e Pennybacker, em 1939 no Reino Unido, utilizaram pela primeira vez um eletromiógrafo para uso clínico.

A partir do começo da segunda guerra mundial, foram desenvolvidos eletromiógrafos mais eficientes, principalmente em virtude das necessidades clínicas. No final da guerra os eletromiógrafos passaram a ser produzidos comercialmente.

No fim dos anos 60, iniciou-se o uso de computadores para processamento do sinal mioelétrico, e desde então pode-se obter informações mais consistentes do sinal.

Atualmente, além das análises clínicas, o SME pode ser utilizado para outros fins, como por exemplo, no controle de equipamentos utilizados em engenharia de reabilitação.

A seguir será apresentado o processo de contração muscular, incluindo a fisiologia das partes envolvidas e a geração dos potenciais de ação musculares, que somadas representam o SME. Serão mencionadas também as formas de captação e características deste sinal, além de detalhar as aplicações em que se pretende utilizar o SME como sinal de controle. 


\subsection{Processo de Contração Muscular.}

O processo de contração muscular envolve o potencial de ação conduzido pelo neurônio motor, a transmissão sináptica, os potenciais de ação musculares que somados representam o sinal mioelétrico e a contração das fibras musculares.

\subsubsection{O Neurônio.}

A célula nervosa ou neurônio, como outras células biológicas, é delimitada por uma membrana celular semipermeável, responsável pela capacidade desta célula de transmitir informações.

No neurônio, podem ser identificadas três porções com funções distintas: o corpo celular ou soma, os dendritos e o axônio.

O corpo celular é a porção que contém citoplasma, núcleo e organelas. Em um neurônio motor, que comanda diretamente a contração das fibras musculares, o soma está entre os dendritos e o axônio, já em certos neurônios sensórios localiza-se discretamente à margem do axônio (Fig. 1).

Os dendritos são processos celulares, tipicamente curtos e altamente ramificados de maneira a oferecer amplas áreas de contato para a recepção de informação. Estas estruturas são especializadas em receber informações e enviar estímulos para o corpo celular. Os impulsos nervosos são conduzidos do corpo celular para outros neurônios ou glândulas através do axônio. Em sua extremidade, o axônio ramifica-se formando os seus terminais, que contêm estruturas minúsculas chamadas botões sinápticos. Quando estas estruturas recebem um impulso nervoso liberam neurotransmissores, que são substâncias químicas que transmitem sinais de um neurônio para outro (GUYTON, 1988). 


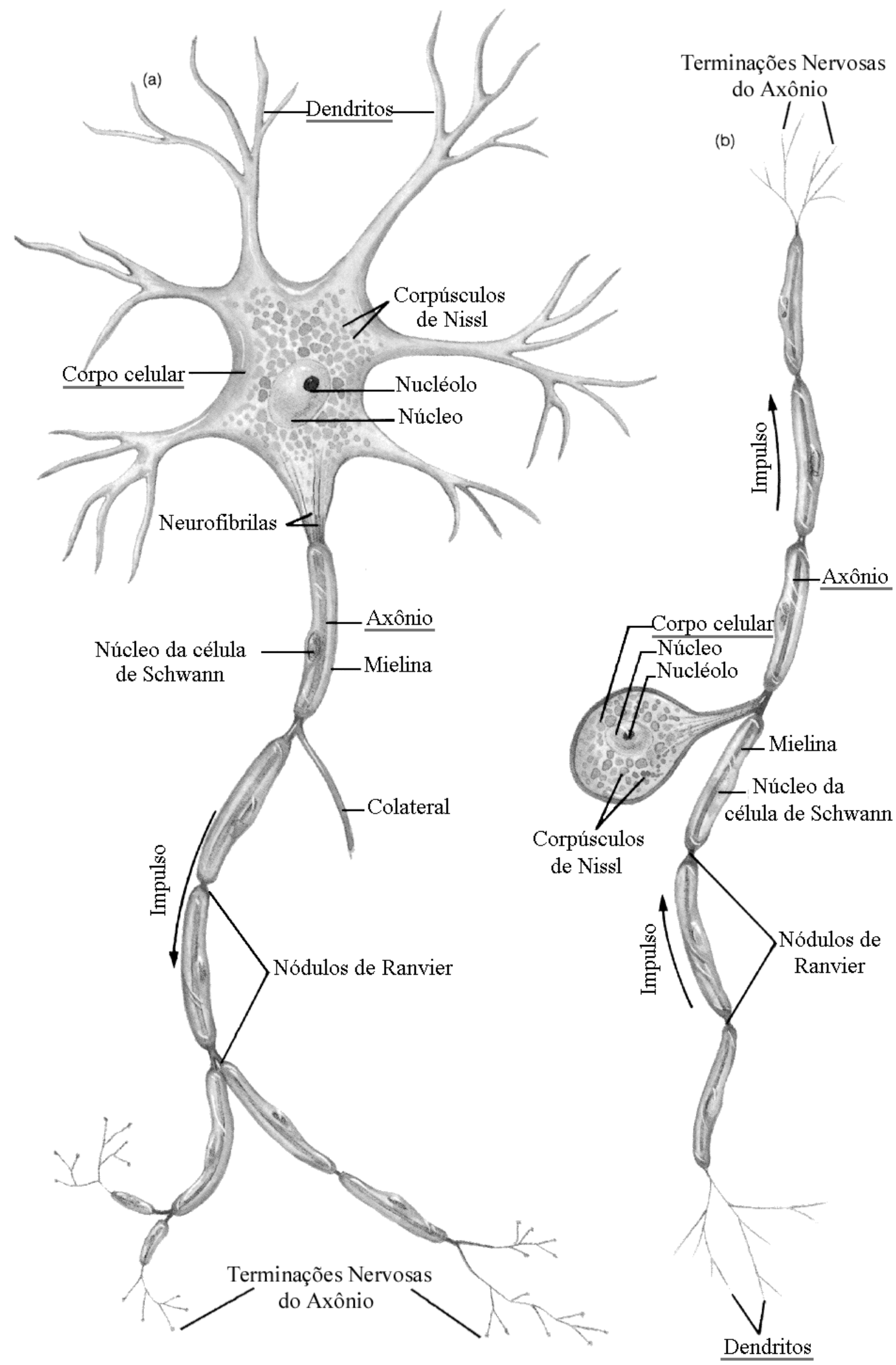

Fig. 1 - Neurônios (a) Motor e (b) Sensorial. (BELTRAMINI, 1999) 
A função básica do axônio é de transmitir informações na forma de pulsos regenerativos, isto é sem atenuação, para várias partes do sistema nervoso e do organismo. Os axônios podem ter até 1 metro de comprimento e em várias ocasiões juntam-se em troncos nervosos ou nervos, nos quais podem ser reunidos até dezenas de milhares de axônios. No Sistema Nervoso Periférico, axônios aferentes conduzem informações sensoriais para dentro do sistema nervoso e axônios eferentes enviam os comandos do Sistema Nervoso Central aos efetores do organismo.

Os axônios, da maioria dos neurônios dos vertebrados, estão envolvidos por capas isolantes de mielina, substância branca, rica em lipídios, produzida por células neurogliais de Schwann. Entre as células de Schwann existem estreitamentos, nódulos de Ranvier, pontos nos quais os axônios não estão isolados. As linhas de corrente associada aos sinais transmitidos pelo axônio, só podem ser fechadas pelos nódulos de Ranvier. Desta forma o pulso resultante salta de um nódulo para outro, com uma velocidade de propagação algumas dezenas de vezes superior a um axônio não mielinizado (KOVÁKS, 1997).

\subsubsection{O Potencial de Ação Neural}

Os potenciais de ação neurais são reações eletroquímicas responsáveis pela condução dos sinais nervosos nos neurônios. Hodgkin e Huxley em 1952 puderam determinar o mecanismo básico de produção e reprodução regenerativa do potencial de ação, ao descrever quantitativamente as propriedades físicas e eletroquímicas da membrana axonal, utilizando o axônio gigante do molusco Loligo (HODGKIN \& HUXLEY, 1952).

O potencial de ação pode ser descrito como variações muito rápidas dos potenciais externo e interno da membrana da célula nervosa. Tais potenciais se deslocam ao longo da fibra nervosa até atingirem o terminal do axônio. Cada potencial de ação começa por uma modificação abrupta de um 
potencial de repouso negativo para um potencial positivo, e em seguida termina com um rápido retorno para o potencial negativo. As sucessivas fases do potencial de ação são as seguintes (GUYTON, 1988):

Repouso: A membrana celular neural é relativamente impermeável aos íons Sódio $\left(\mathrm{Na}^{+}\right)$. Em contrapartida é bastante permeável aos íons Potássio $\left(\mathrm{K}^{+}\right)$. Dada a alta concentração de $\mathrm{K}^{+}$no interior da membrana, estes íons difundem-se para o exterior, provocando a passagem de cargas positivas para fora da fibra, mas deixando muitos íons protéicos em seu interior. Desta forma, em repouso a membrana gera um potencial de membrana negativo, da ordem de $-70 \mathrm{mV}$ no interior da fibra.

Despolarização: Algum estímulo de qualquer natureza (químico, elétrico, térmico ou mecânico) pode aumentar subitamente a permeabilidade da membrana aos íons $\mathrm{Na}^{+}$iniciando o potencial de ação. Estes íons movem-se rapidamente para o interior da célula, carregando cargas positivas, o que produz positividade nesta região dentro do neurônio.

Repolarização: Após total despolarização desta área da célula, a membrana torna-se novamente impermeável ao Sódio $\left(\mathrm{Na}^{+}\right)$, embora continue permeável ao potássio $\left(\mathrm{K}^{+}\right)$. Em virtude da alta concentração de íons positivos no interior da célula nervosa, grandes quantidades do íon potássio $\left(\mathrm{K}^{+}\right)$voltam a se difundir para o meio externo, tornando esta região no interior da célula nervosa novamente negativa. Nesta situação o neurônio torna-se novamente apto a transmitir um novo impulso nervoso.

Na figura 2 está representada a variação da tensão de uma membrana nervosa durante o potencial de ação, indicando suas três fases.

Caso o estímulo inicial não ultrapasse um certo limiar, não existe resposta ou existe apenas um potencial de ação local. Ultrapassando este limiar a membrana nervosa responde com um potencial de ação, que se difunde para as regiões próximas provocando ali outro potencial de ação e, assim, sucessivamente causando a propagação de uma onda não atenuada com uma velocidade de algumas dezenas de $\mathrm{cm} / \mathrm{s}$ até $150 \mathrm{~m} / \mathrm{s}$, dependendo 
das características do axônio. Após a ocorrência do potencial de ação, durante alguns milissegundos, a membrana fica incapaz de gerar um outro potencial de ação, independente da intensidade da despolarização imposta. Este intervalo de tempo é chamado de período refratário.

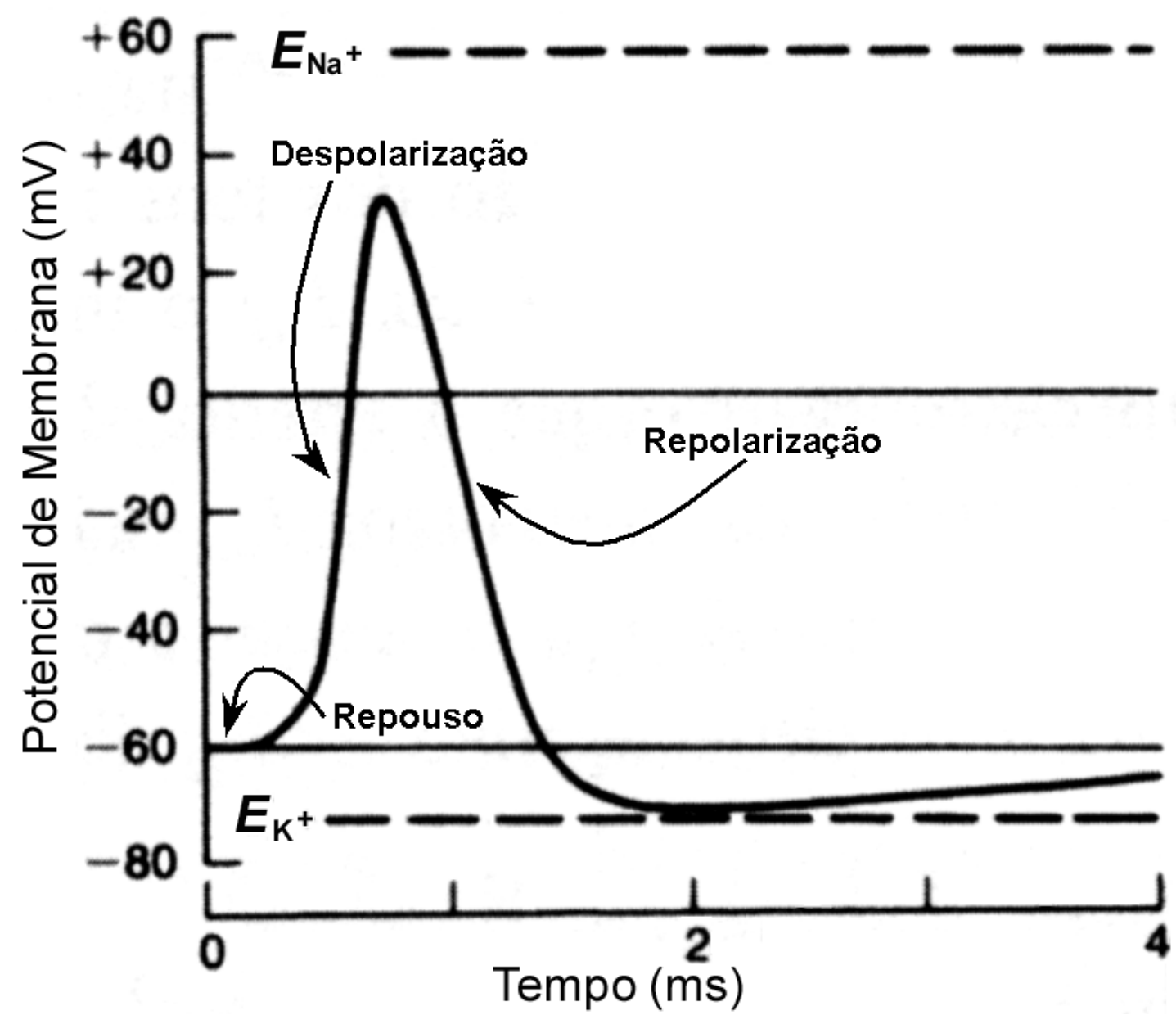

Fig. 2 - Variação da tensão na membrana celular nervosa durante o Potencial de Ação. (adaptado de KOVÁKS, 1997)

A transmissão do impulso nervoso, conforme descrita até então, está relacionada com os neurônios que não possuem bainha de mielina. Nos neurônios mielinizados o potencial de ação ocorre apenas nos nódulos de Ranvier, pontos em que a membrana plasmática faz contato direto com o fluido intersticial. Neste caso ocorre a chamada condução saltatória, que se caracteriza em um tipo de condução mais rápida e com menos gasto de energia. 


\subsubsection{Junção neuromuscular}

A junção neuromuscular, ou placa motora, é a região onde as fibras musculares são enervadas pelas terminações nervosas do axônio.

O terminal do axônio contém um grande número de vesículas sinápticas e mitocôndrias. As vesículas sinápticas armazenam a acetilcolina, neurotransmissor responsável pela excitação da membrana muscular. As mitocôndrias fornecem energia para a síntese da acetilcolina no terminal do axônio.

A invaginação na membrana muscular por uma terminação nervosa do axônio é chamada de goteira sináptica (Fig. 3).

As membranas da célula nervosa e da célula muscular são separadas por uma fenda sináptica com cerca de 20 a $30 \mathrm{~nm}$.

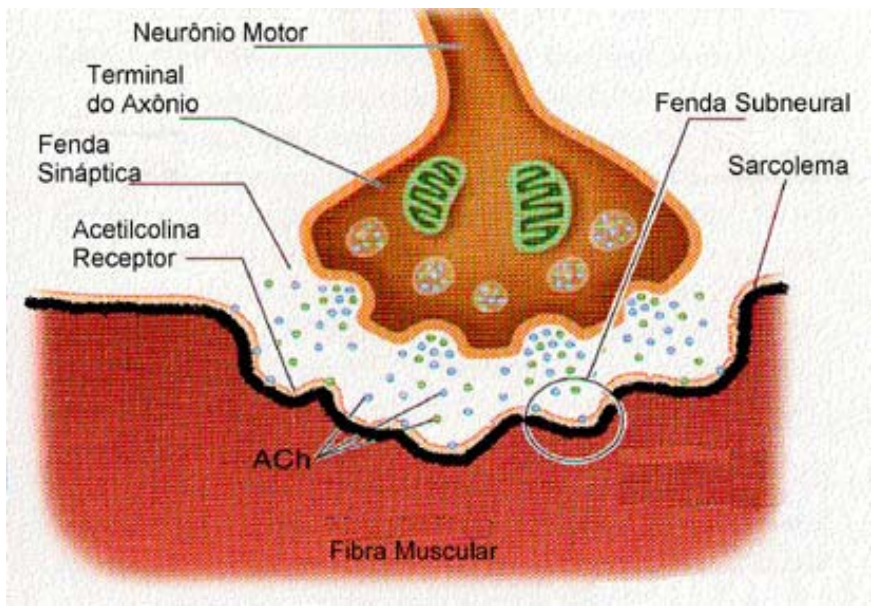

Fig. 3 - Esquema de uma terminação neural invaginada numa fibra muscular. (adaptado de BELTRAMINI, 1999).

No fundo da goteira sináptica, na membrana muscular, existem dobras menores, chamadas de pregas subneurais, que aumentam a área de superfície sobre a qual vai atuar o transmissor sináptico (GUYTON, 1988).

Quando um potencial de ação chega ao terminal do axônio, ocorre a liberação de acetilcolina na fenda sináptica e com isso os receptores de acetilcolina, nas pregas subneurais, tornam a membrana muscular mais permeável a íons de Sódio $\left(\mathrm{Na}^{+}\right)$. O influxo abrupto destes íons no músculo gera um potencial de ação muscular, que se propaga na membrana da fibra muscular da mesma forma como nas membranas neurais, porém nas duas direções do músculo. O potencial de ação despolariza a membrana da fibra muscular e também penetra profundamente no interior desta. Depois de aproximadamente $0,2 \mathrm{~ms}$ que a acetilcolina é liberada pelas vesículas sinápticas, é transformada em acido acético e colina, pela enzima acetilcolinesterase presente na fenda sináptica. Esta reação ocorre para que 
a membrana muscular, localizada na fenda sináptica, diminua a permeabilidade ao potássio de maneira que a placa motora fique preparada para um novo estímulo (GUYTON, 1988).

\subsubsection{Fisiologia do Músculo Esquelético}

O músculo esquelético é composto por vários fascículos musculares, e estes são formados por células chamadas de fibras musculares (Fig. 4). As fibras musculares esqueléticas têm a forma de um cilindro com diâmetros variando entre 10 e $80 \mu \mathrm{m}$. Cada fibra é constituída por centenas de miofibrilas, núcleos celulares e pelo Retículo Sarcoplasmático, envoltos em uma membrana plasmática, chamada de Sarcolema (BELTRAMINI, 1999).

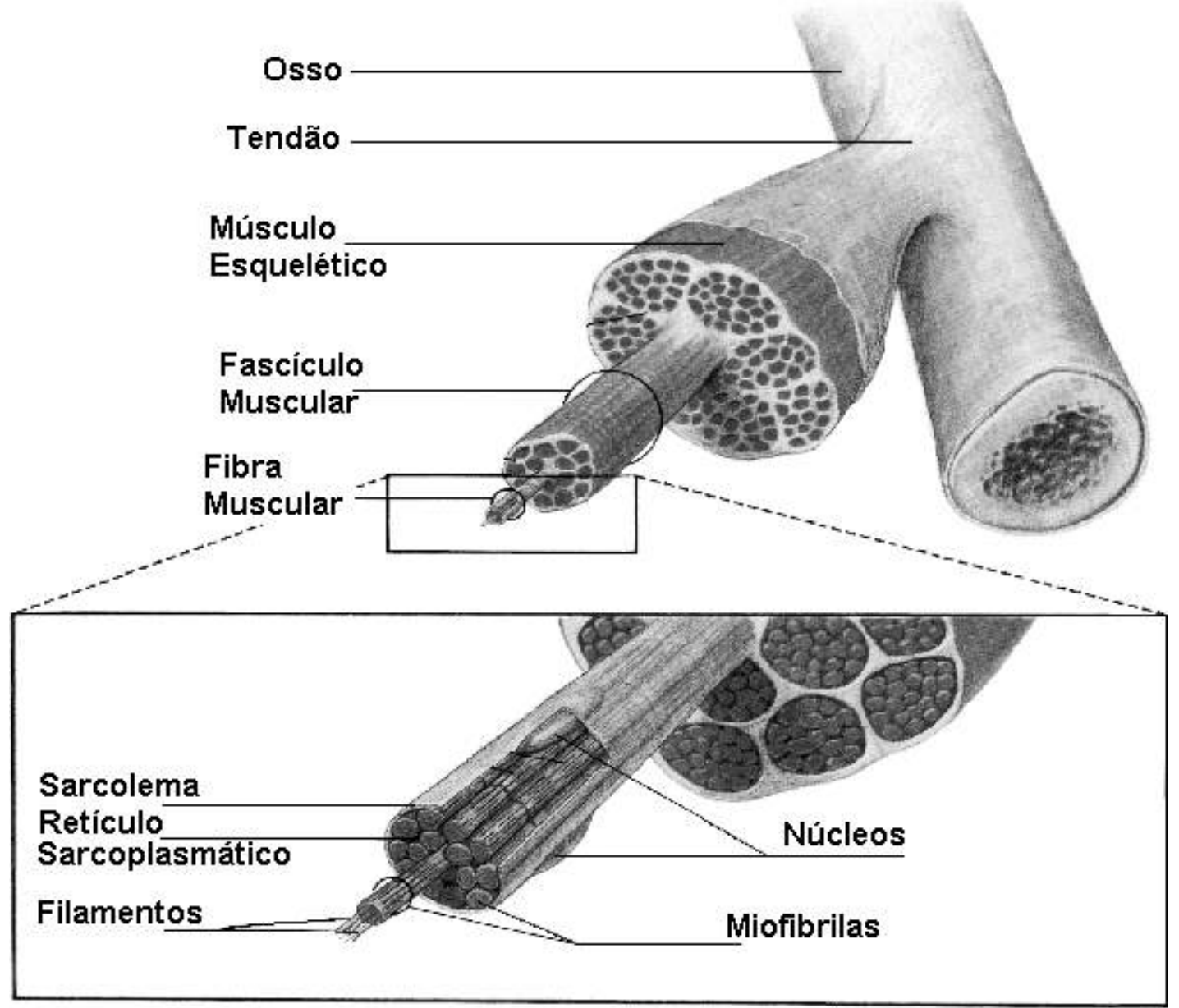

Fig. 4 - Estrutura do Músculo Esquelético (BELTRAMINI, 1999). 
O Retículo Sarcoplasmático armazena grande concentração de íons de Cálcio $\left(\mathrm{Ca}^{++}\right)$e tem como função liberar estes íons durante o processo de contração muscular.

As miofibrilas são compostas por miofilamento, que são constituídos pelas proteínas miosina (filamentos grossos) e actina (filamentos mais finos) (Fig. 5). Os filamentos de actina e de miosina são arranjados ao longo da fibra muscular e se sobrepõem conforme indicado na figura 5(c). A disposição destes filamentos na fibra faz com que o músculo esquelético apresente estrias, por este motivo este músculo também é chamado de estriado. Quando um potencial de ação muscular percorre uma fibra, ocorrem alterações na permeabilidade da membrana do Retículo Sarcoplasmático e grande quantidade de cálcio difunde-se para o citoplasma. No citoplasma, o cálcio forma um complexo com as proteínas miosina e actina, levando as a deslizar uma em direção à outra, constituindo o processo contrátil das miofibrilas, caracterizando a contração muscular. Uma vez cessado o estímulo restabelece-se o sistema de transporte ativo do retículo sarcoplasmático e o excesso de $\mathrm{Ca}^{++}$retorna para o interior do retículo, cessando assim a contração.

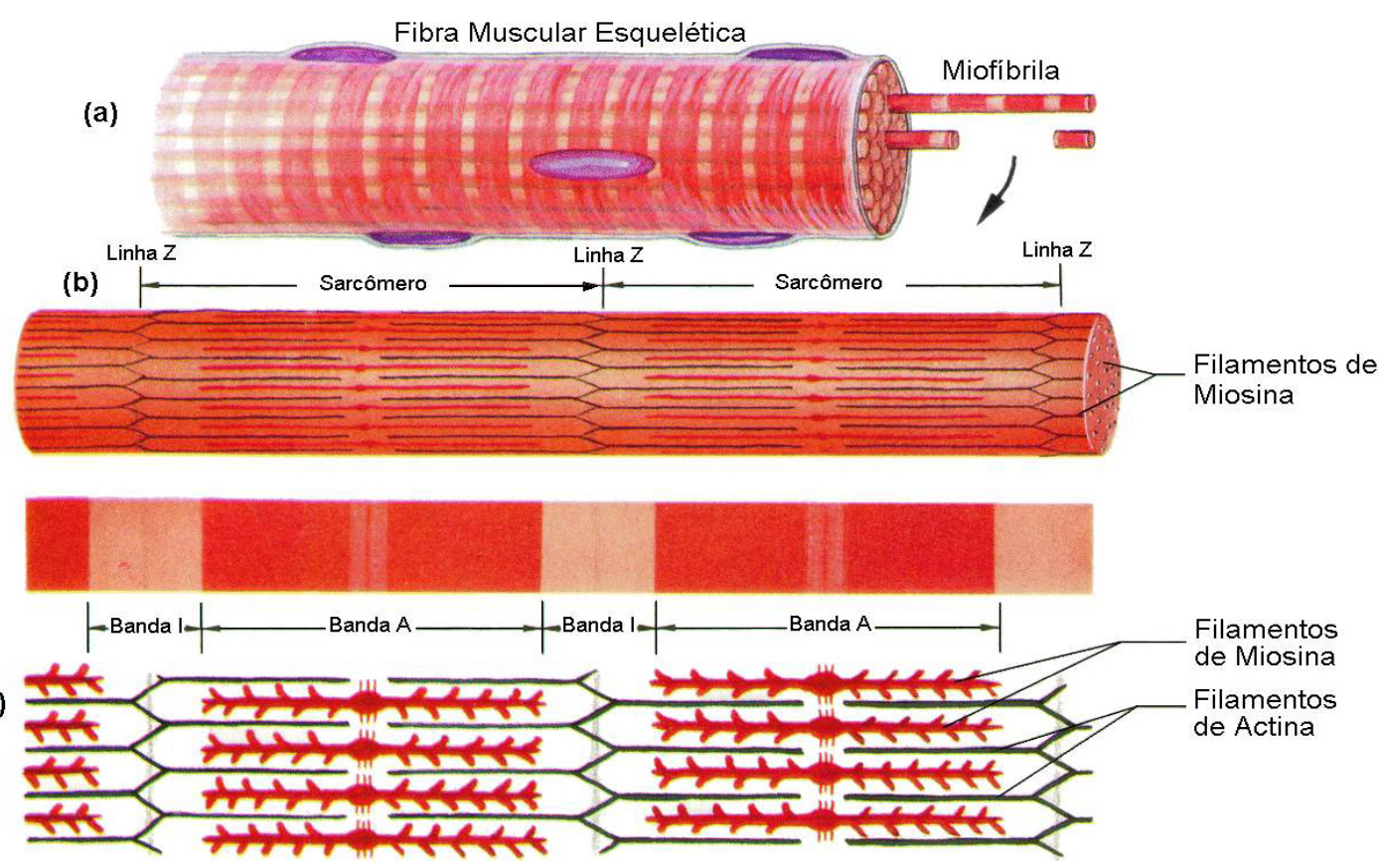

Fig. 5 - Constituição das Fibras Musculares Esqueléticas:
(a) Fibra Muscular
(b) Miofibrila

(c) Filamentos de Actina e Miosina (BELTRAMINI, 1999) 


\subsubsection{Unidade Motora}

A unidade motora é o termo utilizado para descrever a menor unidade muscular controlável. Uma unidade motora é constituída por um neurônio motor, suas junções neuromusculares e as fibras musculares enervadas por este neurônio (Fig. 6).

Uma fibra nervosa pode enervar desde uma até centenas de fibras musculares, este número é chamada de taxa de enervação.

A fibra muscular não é capaz de graduar sua contração, então as variações na força de contração do músculo são devidas às variações no

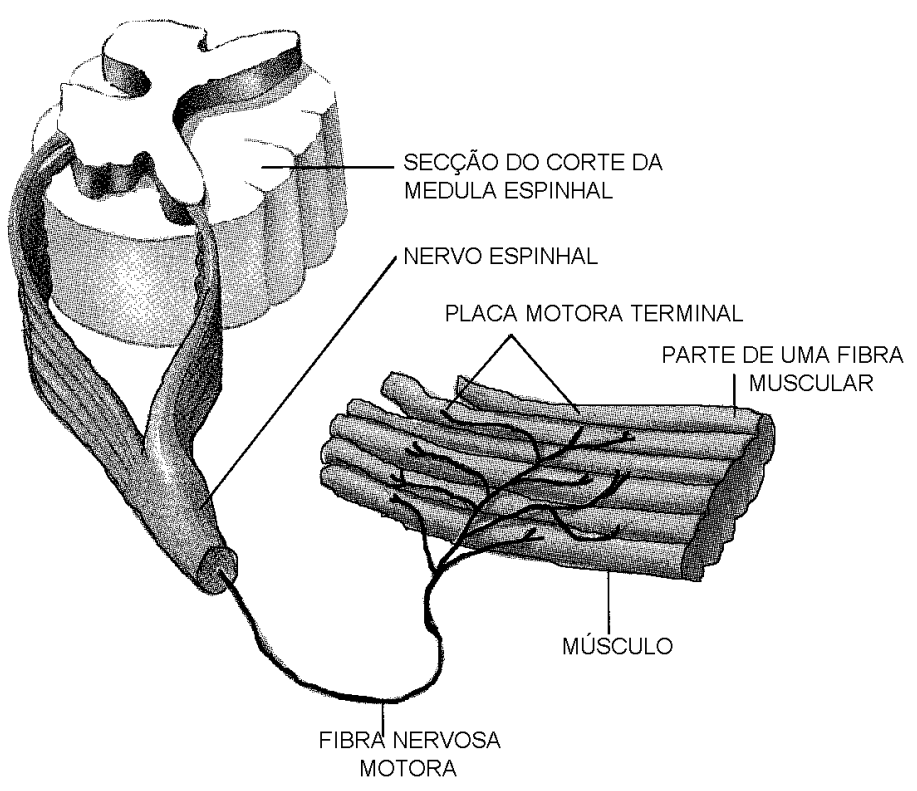

Fig. 6 - Unidade Motora (BELTRAMINI, 1999). número de fibras musculares mobilizadas (BELTRAMINI, 1999). Por exemplo, em músculos extra-oculares de humanos, que não requerem altas forças mas um posicionamento exato, a taxa de enervação é cerca de 10; nos músculos da mão é cerca de 100 e nos músculos muito grandes, como o gastrocnêmio (músculo da perna), que requerem maiores níveis de força, a taxa de enervação é cerca de 2000. No entanto uma menor taxa de enervação indica uma maior capacidade de graduação fina da força total do músculo (GHEZ, 1991).

A taxa de enervação representa a força que um determinado músculo pode executar, no entanto, o controle da força é realizado pelo número de unidades motoras recrutadas, em uma dada contração. Inicialmente são utilizadas poucas unidades motoras e na medida que o músculo é mais solicitado mais unidades motoras são usadas.

Além do número de unidades motoras recrutadas, a força que um músculo executa também é regulada pela frequência de estimulação de uma 
unidade motora. A partir de uma certa frequência, os estímulos irão se sobrepor resultando numa contração suave e gradual do músculo. Este fenômeno é conhecido como tetanização. As frequências de estimulação, para que a tetanização ocorra, vão de $20 \mathrm{~Hz}$ para as fibras musculares lentas a $100 \mathrm{~Hz}$ para as fibras rápidas. Portanto, o controle da força muscular é realizado por meio de uma somatória temporal e espacial dos potenciais de ação das unidades motoras. A somatória temporal está relacionada com a frequência de estimulação das unidades motoras e a somatória espacial com o número de unidades motoras recrutadas.

As unidades motoras são classificadas fisiologicamente de acordo com o tempo que as fibras musculares levam para atingir o pico de força durante uma contração e o grau de fadiga delas. As unidades motoras se dividem em FF (Fast Fatigable), S (Slow) e FR (Fast Resistent). As unidades FF têm fibras que se contraem e relaxam rapidamente, mas fadigam rapidamente quando estimuladas repetitivamente. Estas unidades geram a maior força durante a tensão ou contração tetânica. As unidades $S$ apresentam fibras com tempo de contração muito mais longo e altamente resistente à fadiga, no entanto, só podem gerar de 1 a $10 \%$ da força das unidades FF. As unidades FR têm os dois tipos de fibras musculares, tendo assim propriedades intermediárias (GHEZ, 1991).

As unidades $S$, que são as mais numerosas e requerem um maior suporte metabólico, são localizadas mais profundamente no músculo. As fibras musculares destas unidades motoras são chamadas de fibras tipo I ou fibras vermelhas, graças ao maior suprimento de sangue. As fibras musculares rápidas, das unidades FF, são chamadas de tipo II ou fibras brancas, por utilizar a glicólise para sua demanda de energia. Por este motivo as unidades FF estão sempre mais próximas da superfície dos músculos, onde a vascularização é menor.

As propriedades das fibras nervosas também estão intimamente ligadas ao tipo de unidade motora. O diâmetro, e consequentemente a velocidade de condução do axônio é maior nas unidades FF, do que nas unidades $S$, em que os neurônios somente disparam em frequências baixas, 
pois cada potencial de ação é seguido por um longo período de hiperpolarização pós-potencial (período refratário), o que previne a ocorrência de outro impulso imediatamente. (GHEZ, 1991).

A Tabela 1 apresenta características funcionais das unidades motoras.

Tab. 1 - Classificação e características das unidades motoras em músculos esqueléticos (adaptado de ROBSON, 1989)

\begin{tabular}{|l|c|c|c|}
\hline Tipo de Unidade Motora & FF & FR & S \\
\hline Tipo de Fibra Muscular & II b & II a & I \\
\hline Velocidade de Contração & rápida & rápida & lenta \\
\hline Tempo de Tensão da Contração & pequeno & pequeno & grande \\
\hline Resistência à Fadiga & baixa & alta & muito alta \\
\hline Tensão Tetânica & alta & intermediária & baixa \\
\hline Taxa de Enervação & grande & intermediária & pequena \\
\hline Frequência do Uso & baixa & intermediária & alta \\
\hline $\begin{array}{l}\text { Ordem de Recrutamento } \\
\text { (em movimentos lentos) }\end{array}$ & última & intermediária & primeira \\
\hline $\begin{array}{l}\text { Tamanho do Corpo Celular } \\
\text { da Unidade }\end{array}$ & grande & intermediário & pequeno \\
\hline
\end{tabular}

\subsubsection{O Potencial de Ação da Unidade Motora (MUAP)}

Quando um neurônio motor envia um potencial de ação, todas as fibras musculares da sua unidade motora são estimuladas. No entanto, não são estimuladas simultaneamente, ocorrendo pequenos atrasos entre as contrações. Há dois motivos para estes atrasos: um deles ocorre por causa dos diferentes tempos de propagação das várias ramificações dos axônios no neurônio motor; outra situação, que defasa os potenciais de ação musculares, está relacionada à natureza aleatória das descargas de acetilcolina nas junções neuromusculares.

O resultado da soma algébrica dos potenciais de ação nas $n$ fibras de uma unidade motora é chamado de potencial de ação da unidade motora, 
cuja sigla em inglês é MUAP (Motor Unit Action Potential). Na figura 7 é apresentada uma representação esquemática da geração do MUAP, o qual é indicado por $\mathrm{h}(\mathrm{t})$.
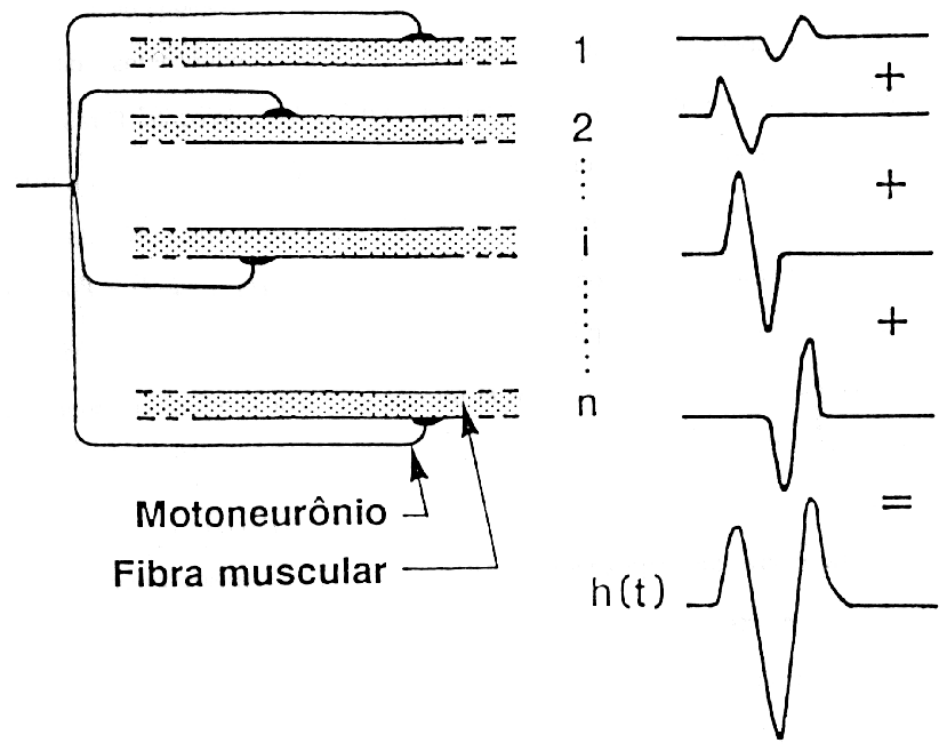

Fig. 7 - Esquema da geração de um MUAP.

(adaptado de BASMAJIAN \& DeLUCA,1985)

A duração de um MUAP é de aproximadamente 2 a $10 \mathrm{~ms}$ com amplitudes na faixa de $100 \mu \mathrm{V}$ a $2 \mathrm{mV}$ e banda de frequência de $5 \mathrm{~Hz}$ a $10 \mathrm{kHz}$. O MUAP é usado clinicamente para detecção de miopatias, lesões neurogênicas e outras desordens musculares. (ALMEIDA, 1997).

Pelo fato do MUAP ter um período relativamente pequeno (2 a $10 \mathrm{~ms}$ ), as unidades motoras devem ser ativadas repetitivamente para que se possa sustentar uma contração muscular por períodos maiores. Esta sequência de MUAPs é denominada trem de potenciais de ação da unidade motora, cuja sigla em inglês é MUAPT (Motor Unit Action Potential Train).

Os MUAPTs de cada unidade motora são diferentes devido às variações nas sequências de acionamento de cada unidade motora e às diferentes características dos MUAPs de cada unidade.

Como os músculos contêm fibras musculares de várias unidades motoras, a captação de um MUAPT isolado só pode ser obtida se forem recrutadas apenas as fibras de uma única unidade motora na vizinhança do eletrodo. Esta situação só ocorre em contrações musculares muito fracas. 


\subsection{Formas de Captação e Características do SME}

Os MUAPs, ao percorrer as fibras musculares geram um campo eletromagnético nas redondezas das fibras. Um eletrodo, localizado dentro deste campo, é capaz de detectar o potencial elétrico referente a uma contração muscular, que é chamado de Sinal Mioelétrico (SME). Neste item serão apresentadas as características do sinal mioelétrico e os tipos de eletrodos que podem ser utilizados para captar este sinal.

\subsubsection{Características do SME de Superfície}

O sinal mioelétrico, de cada músculo, é composto pela soma dos vários potenciais de ação musculares, resultando nos diversos MUAPs de cada unidade motora, que apresentam características diferentes entre si (Fig. 8).

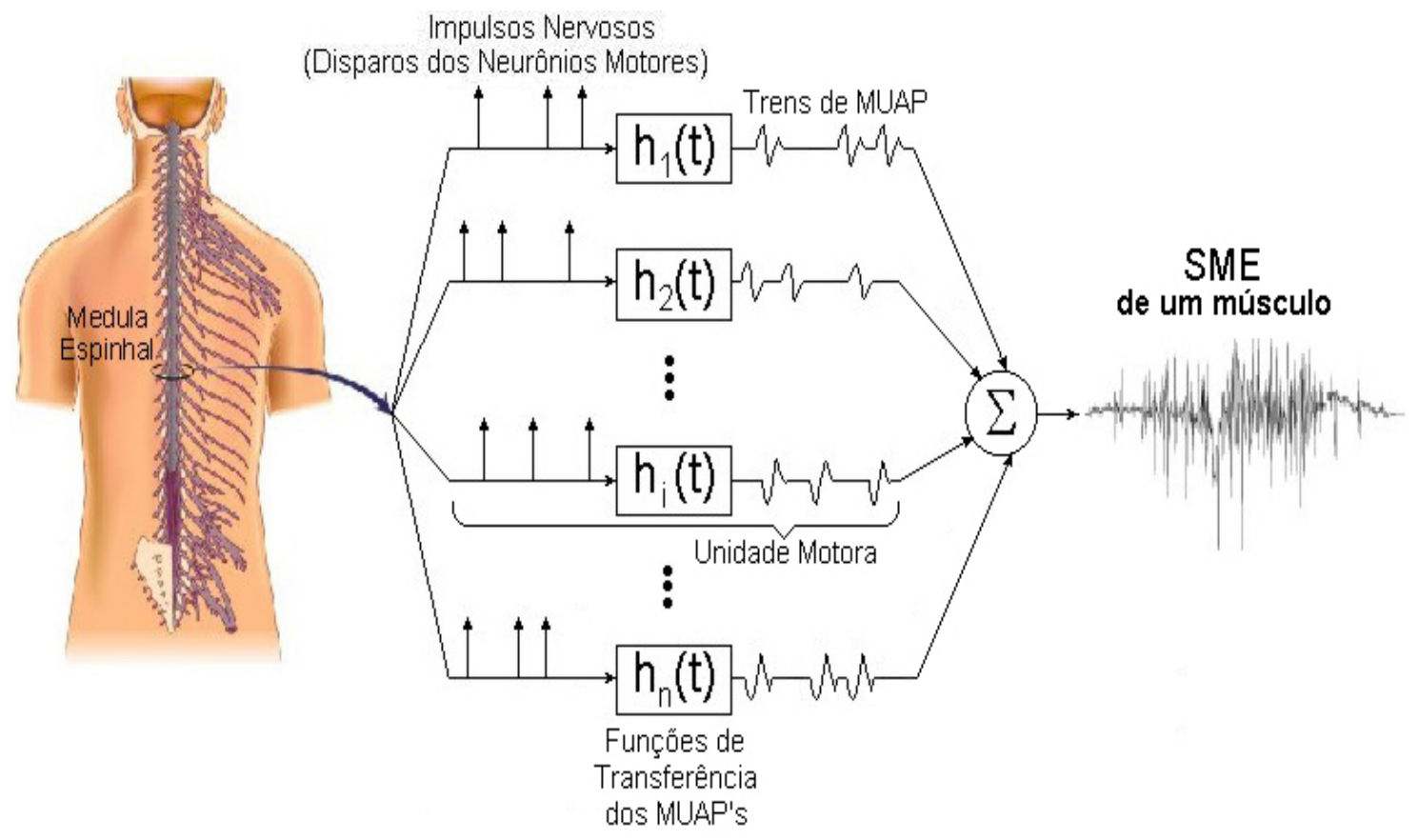

Fig. 8 - Representação esquemática da geração do Sinal Mioelétrico de um músculo, a partir da somatória dos trens de MUAPs das $\boldsymbol{n}$ unidades motoras deste músculo (adaptado de BASMAJIAN \& DeLUCA, 1985) 
Contrações musculares que requerem altas forças são realizadas por grupos musculares (conjuntos de músculos que podem realizar um mesmo movimento), como por exemplo, o quadríceps femoral, trapézio (superior, médio e inferior), deltóide (anterior, médio e posterior) e triceps braquial. Portanto o sinal mioelétrico, quando captado com eletrodos de superfície, pode conter sinais de vários músculos.

Em virtude da diferença entre os MUAPs, da irregularidade na taxa de disparo dos neurônios motores e também pelo fato de que uma contração pode ter mais de um músculo envolvido, o sinal mioelétrico foi descrito como um processo estocástico (KREIFELDT \& YAO, 1974; DeLUCA, 1979). PARKER et al. (1977) aproximaram a função de densidade de probabilidade do sinal por uma função gaussiana, implicando que a amplitude instantânea do sinal é uma variável gaussiana de média zero. No entanto HUDGINS et al. (1991 e 1993) encontraram características determinísticas no SME durante os $200 \mathrm{~ms}$ iniciais de uma contração muscular.

O SME obtido com eletrodos de superfície é afetado pelas propriedades de filtro das camadas epiteliais e da interface eletrodo-pele, de forma que apresenta componentes frequenciais desde DC até cerca de $500 \mathrm{~Hz}$, manifestando maior concentração do sinal dentro da faixa de 50 a $150 \mathrm{~Hz}$ (DELSYS INC., 1996). As amplitudes máximas deste sinal variam entre $50 \mu \mathrm{V}$ e $5 \mathrm{mV}$ (ALMEIDA, 1997). Estes valores variam de acordo com o tipo de músculo analisado, o nível de contração muscular, e também o tipo e a localização dos eletrodos utilizados.

$\mathrm{Na}$ figura 9 é apresentado um sinal mioelétrico do grupo extensor do punho (localizado na parte posterior do antebraço), captado durante a extensão do punho, com eletrodos ativos de superfície. Na figura 10 é ilustrada a densidade do espectro de potência do sinal apresentado na figura 9 . 


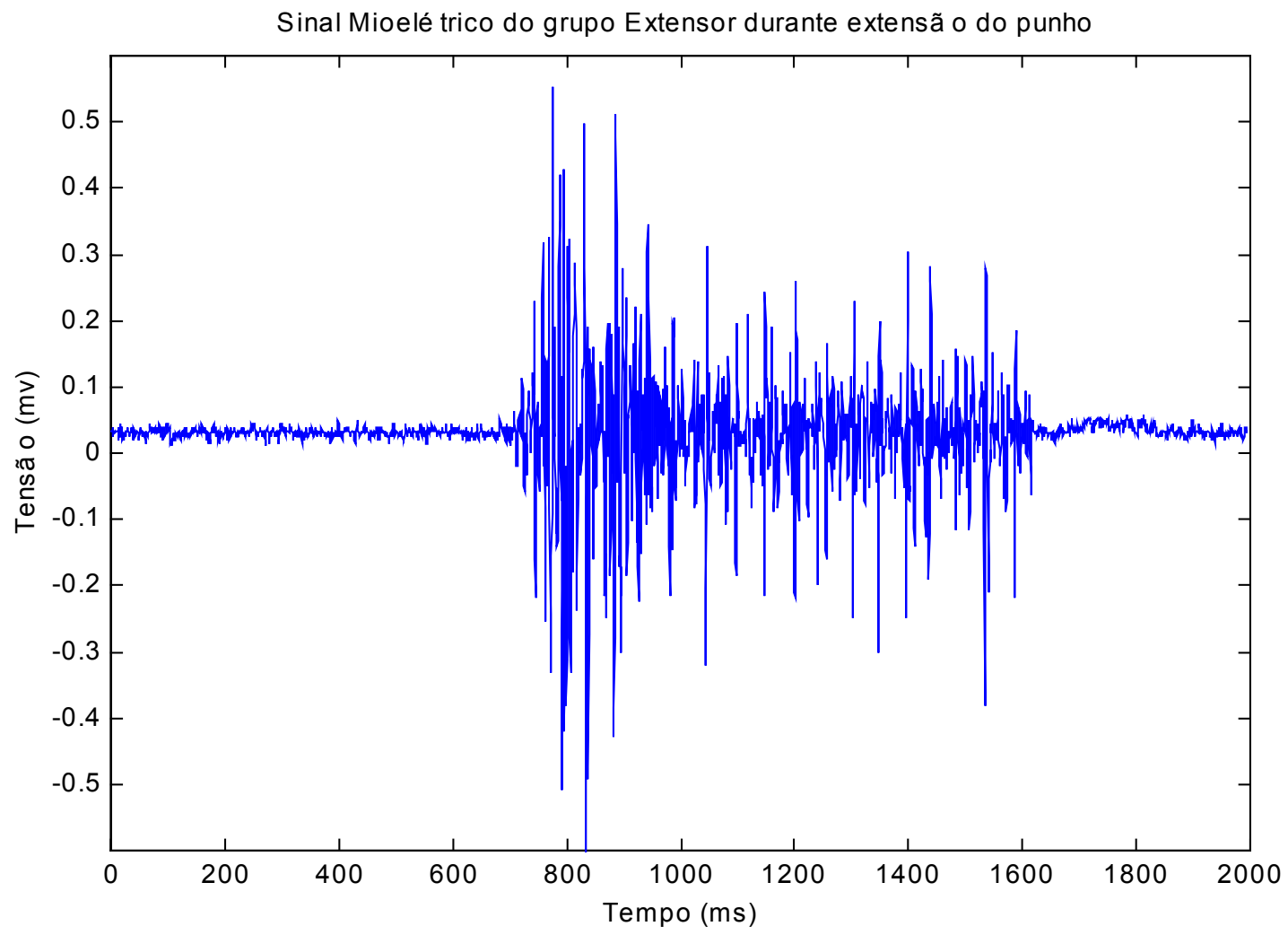

Fig. 9 - Sinal Mioelétrico do grupo extensor do antebraço durante extensão do punho.

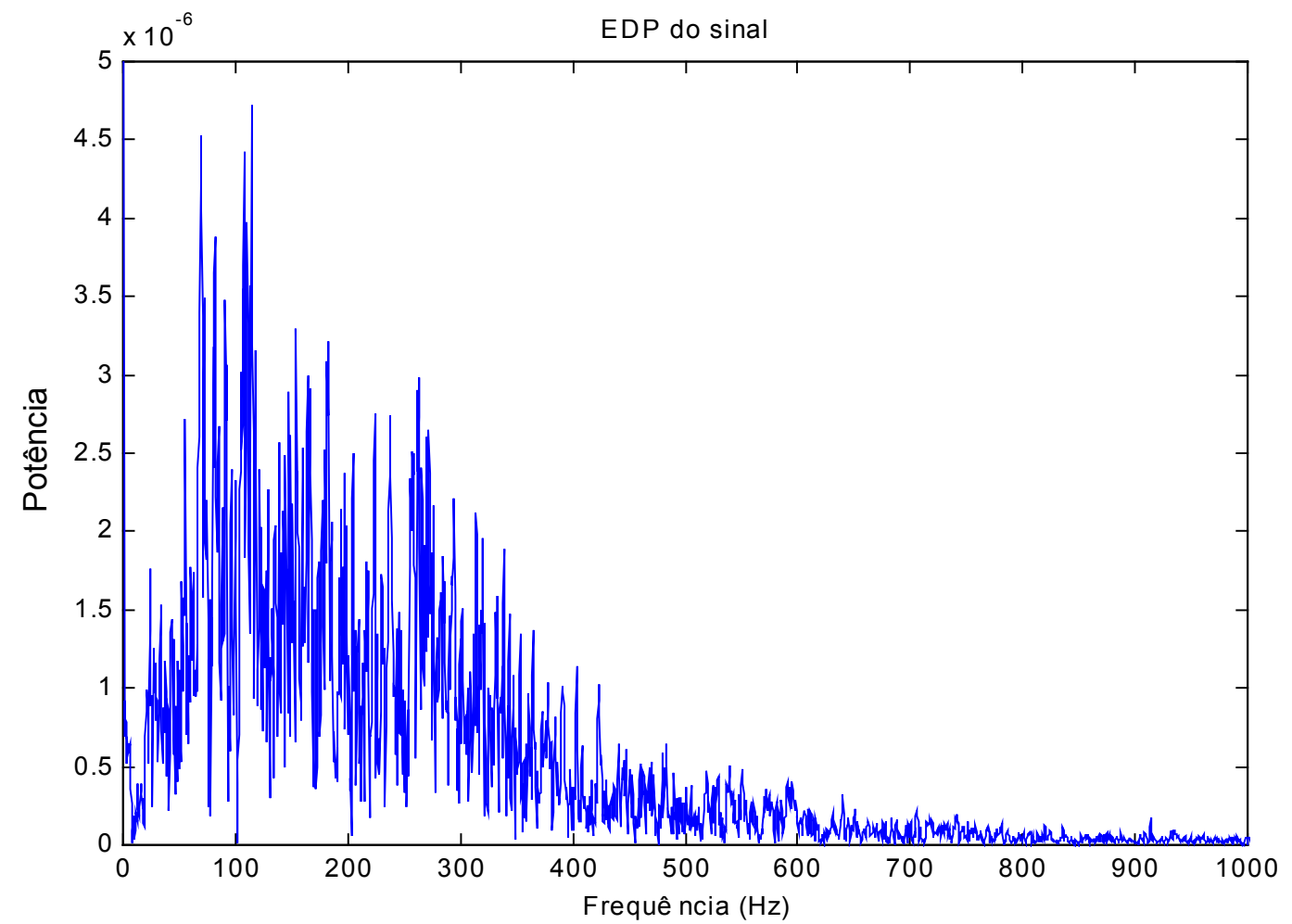

Fig. 10 - Espectro de Densidade de Potência do sinal da Fig. 9. 


\subsubsection{Eletrodos utilizados para captar o SME}

O SME pode ser obtido por meio de configurações monopolares e bipolares. A configuração monopolar obtém diferenças de potenciais entre dois pontos, sendo um deles o ponto de referência. Na configuração bipolar são obtidos dois sinais em relação a uma referência, e posteriormente são subtraídos, neste caso são necessários três pontos de detecção. Para as duas configurações normalmente utilizam-se eletrodos confeccionados com prata revestida com cloreto de prata $(\mathrm{Ag}-\mathrm{AgCl})$, pois é um metal nobre não polarizável, evitando assim a indução de um nível DC nos eletrodos de detecção. Os eletrodos para captação do SME podem ser invasivos ou não invasivos.

\section{Eletrodos Invasivos}

Os eletrodos invasivos são os de fio ou de agulha. Pelo fato destes eletrodos estarem em contato com o fluído corpóreo, que possui baixa resistência, não necessitam de gel condutor. Estes eletrodos, comparados com eletrodos não invasivos, captam maiores amplitudes e espectro de potência mais amplo, com frequências até $10 \mathrm{kHz}$ (OLSON, 1998).

Eletrodos invasivos são utilizados principalmente em análises clínicas, pois são capazes de detectar até mesmo o potencial de ação de uma única unidade motora e explorar a atividade isolada de músculos profundos. Tais eletrodos embora permitam a aquisição de sinais que mostrem o comportamento da unidade motora em detalhes, possuem vários inconvenientes como a necessidade de excelente esterilização, o perigo da quebra dos fios dentro do músculo, e sobretudo o desconforto do paciente (BASMAJIAN \& DeLUCA, 1985).

Os eletrodos de fio normalmente são utilizados em longos períodos de aquisição do sinal e para estudos de músculos profundos. Eletrodos de agulha são indicados para análise das características dos MUAPs.

Por questões de precisão nos resultados e higiene, os eletrodos invasivos devem ser limpos com álcool $70 \%$ a fim de remover partículas de pele, sangue coagulado e tecido muscular. Também pode-se utilizar ultra- 
som na limpeza destes eletrodos. Além da simples limpeza é necessária a esterilização dos eletrodos por meio de algum destes métodos: água fervente, vapor, autoclave ou calor seco. É importante garantir que as temperaturas utilizadas não danifiquem a isolação dos eletrodos. Não é recomendado o uso de banhos químicos, pois podem alterar as características elétricas dos eletrodos (BASMAJIAN \& DeLUCA, 1985).

\section{Eletrodos Não Invasivos}

A aquisição não invasiva do SME, utilizando eletrodos de superfície, é um método conveniente apesar de produzir uma informação grosseira sobre o músculo em investigação, pois capta a atividade de todo um músculo ou grupo muscular. Eletrodos de superfície são capazes de captar sinais até $500 \mathrm{~Hz}$ com amplitudes variando entre $50 \mu \mathrm{V}$ e $5 \mathrm{mV}$ dependendo do músculo analisado e da configuração do eletrodo utilizado. A densidade espectral de potência do SME é estimada para várias aplicações clínicas, como tremores patológicos e análise de fadiga muscular (ALMEIDA, 1997)

Eletrodos de superfície podem ser ativos ou passivos. O eletrodo passivo consiste de um disco de $\mathrm{Ag}-\mathrm{AgCl}$, que deve ser posicionado acima da pele (Fig. 11). Em geral estes eletrodos são utilizados em conjunto com um gel ou pasta condutora contendo íons cloro, a fim de diminuir a impedância de contato entre o eletrodo e a pele. Para melhores resultados, pode-se remover a camada superficial da pele com o uso de um gel abrasivo, e normalmente é necessário realizar a raspagem dos pelos (tricotomia) na área onde o eletrodo será posicionado. Eletrodos passivos podem ser reutilizáveis ou descartáveis, sendo que os descartáveis normalmente vêm com gel condutor e adesivo, para manter-se em contato com a pele. Eletrodos não descartáveis são fixados com cintas ou fitas adesivas.

Os eletrodos não invasivos reutilizáveis também devem ser higienizados utilizando um pedaço de gaze embebido em água destilada, pois o gel, ou pasta condutora, reage com a superfície de detecção de forma a danificar os eletrodos. (BASMAJIAN \& DeLUCA, 1985). 

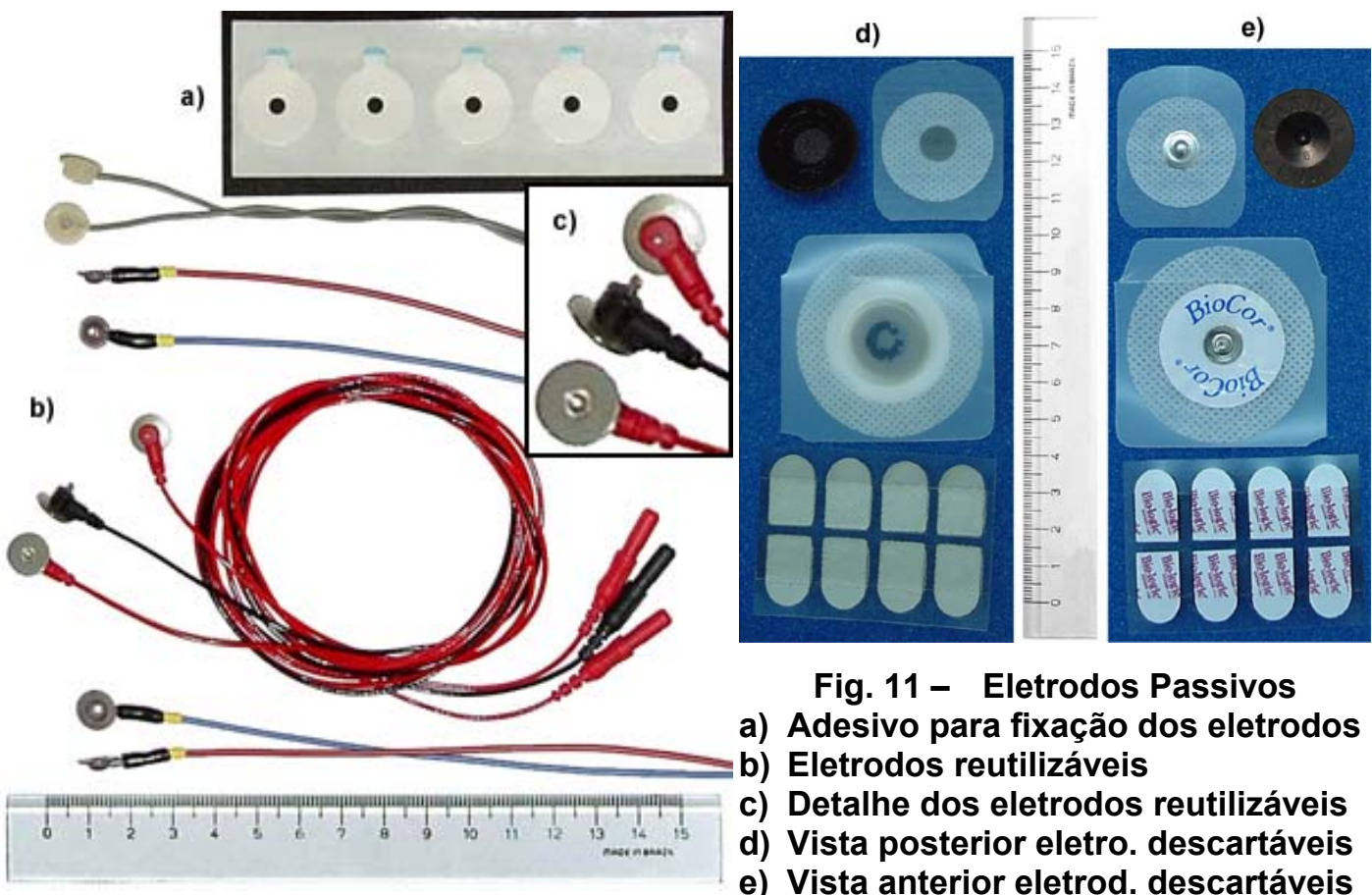

Fig. 11 - Eletrodos Passivos

a) Adesivo para fixação dos eletrodos

b) Eletrodos reutilizáveis

c) Detalhe dos eletrodos reutilizáveis

d) Vista posterior eletro. descartáveis

e) Vista anterior eletrod. descartáveis

Eletrodos ativos possuem um circuito de amplificação encapsulado no próprio eletrodo. Normalmente estes eletrodos são bipolares, ou seja, o amplificador utilizado é diferencial. Tais eletrodos também são chamados de eletrodos secos, pois normalmente não necessitam o uso de gel condutor, pasta abrasiva ou a retirada dos pelos (DELSYS INC., 1996).

$\mathrm{Na}$ figura 12 é representado um amplificador diferencial captando o sinal mioelétrico $\left(m_{\mathrm{i}}\right)$ com ruído $(n)$. O amplificador diferencial é utilizado para que o ruído $(n)$, que é induzido nas duas entradas, seja subtraído e portanto minimizado na saída.

Para que este tipo de amplificador desempenhe sua função da melhor maneira deve ter alta impedância de entrada e alto CMRR (Sigla inglesa para "Razão de Rejeição em Modo Comum").

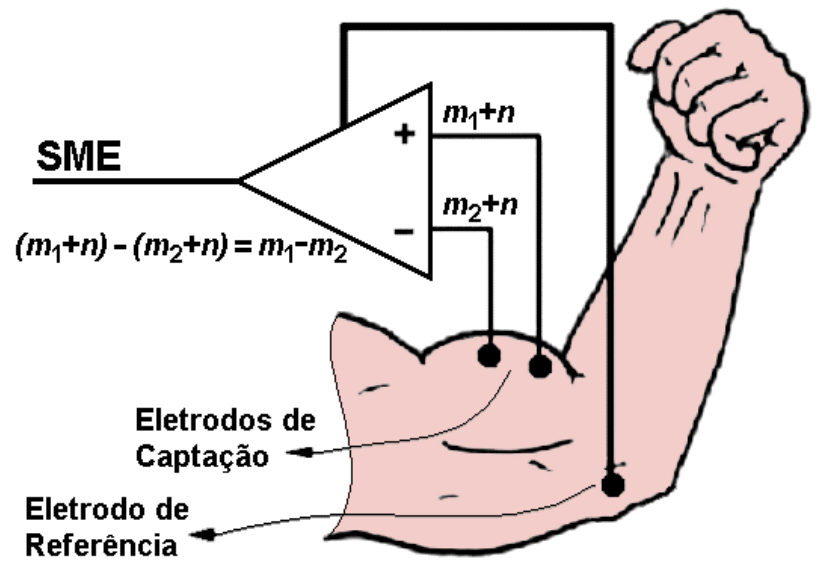

Fig. 12 - Representação de um Amplificador Diferencial captando o sinal Mioelétrico. O SME é representado por " $m_{i}$ " e o ruído por " $n$ " (adaptado de DELSYS INC., 1996) 
Pelo fato dos eletrodos ativos serem compostos por um amplificador diferencial necessitam de um eletrodo de referência, que deve ter uma área de aproximadamente $4 \mathrm{~cm}^{2}$ e estar localizado em uma região sem músculos para não interferir na medida (DELSYS INC., 1996).

Nesta forma de detecção do sinal mioelétrico, os eletrodos de captação podem ser compostos por 2 discos de $\mathrm{Ag}-\mathrm{AgCl}$ com $2 \mathrm{~mm}$ de diâmetro, ou duas barras de $\mathrm{Ag}-\mathrm{AgCl}$ com $1 \mathrm{~mm}$ de largura por $10 \mathrm{~mm}$ de comprimento, dispostas paralelamente e distantes $1 \mathrm{~cm}$ entre si, de acordo com a configuração sugerida por BASMAJIAN \& DeLUCA (1985). Na figura 13 é apresentado um modelo de eletrodo ativo diferencial.

A melhor localização do eletrodo é entre a junção neuromuscular e o tendão de inserção do músculo, e as barras de prata do eletrodo devem estar perpendiculares às fibras musculares.

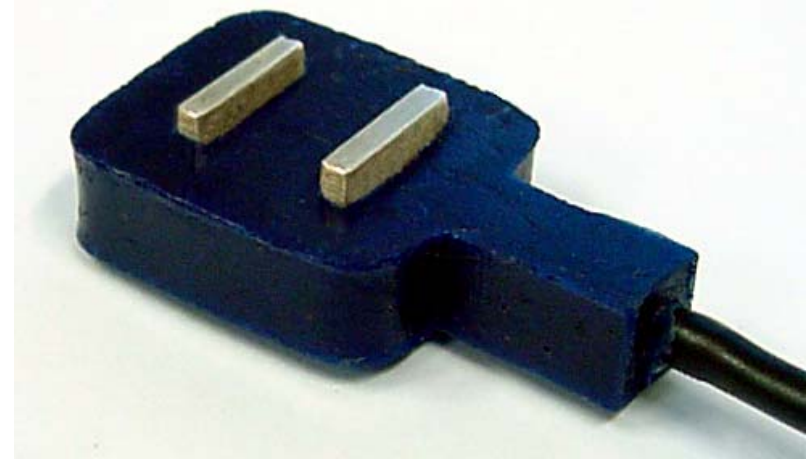

Fig. 13 - Eletrodo Ativo de Superfície Diferencial

Para os eletrodos não invasivos ativos é recomendado que os contatos metálicos sejam regularmente limpos, com álcool $70 \%$, para remover qualquer oxidação que pode acumular na superfície de detecção (BASMAJIAN \& DeLUCA, 1985).

As desvantagens de eletrodos de superfície são duas: a limitação no uso para músculos profundos e a impossibilidade de utilizá-los para detectar seletivamente sinais de músculos pequenos, pois os músculos adjacentes interferem no sinal captado. Porém, estes eletrodos são os mais recomendados para captar sinais de músculos superficiais, interfacear um indivíduo com dispositivos eletromecânicos e estudar a força e tempo de contração muscular (BASMAJIAN \& DeLUCA, 1985).

O SME, quando utilizado como sinal de controle, pode ser proveniente da atividade de um músculo ou de um grupo muscular localizados superficialmente, sendo assim o uso de eletrodos de superfície torna-se 
viável para a implementação de projetos de reabilitação, tendo em mente também o conforto do paciente e a possibilidade deste se desconectar facilmente do equipamento. 


\subsection{Algumas aplicações do Sinal Mioelétrico}

O estudo e a captação do Sinal Mioelétrico são definidos como EMG (eletromiografia). A EMG teve início com finalidade estritamente clínica, e se desenvolveu fortemente como ferramenta diagnóstica durante a segunda guerra mundial. Hoje em dia o SME tem sido usado por profissionais nas áreas de Anatomia, Reabilitação, Fisioterapia, Esportes, Educação Fisíca, Medicina, Odontologia, Fonoaudiologia, etc. (CLARYS \& LEWILLIE, 1992).

Dentre as aplicações clínicas, a EMG estuda as lesões da unidade motora para diferentes patologias miogênicas e neurogênicas; desenvolve o estudo de fraqueza, fadiga e paralisia muscular; lesões supra-nucleares e estudo dos reflexos; estudo da velocidade de condução nervosa, etc.

O SME pode ainda ser utilizado em vários estudos como da função muscular normal, fadiga muscular e ergonômicos relacionados com atividades musculares. Também pode ser usado na detecção de esforço muscular durante atividades físicas, além de estudos e acompanhamento do desenvolvimento muscular em fisioterapias.

Com relação à forma de captação, a EMG de fibra única é utilizada para detecções de disfunções neuromusculares como a miastenia grave. A aquisição dos MUAPs é utilizada clinicamente para detectar miopatias, lesões neurogenicas e outras desordens neuromusculares, já o espectro de densidade de potência do SME de superfície é estimado para várias aplicações como tremores patológicos e análise da fadiga neuromuscular (ALMEIDA, 1997).

Além de estudos de movimento e fisiologia muscular, atualmente 0 SME também pode ser utilizado em acionamento de próteses, em sistemas de estimulação elétrica neuromuscular e outros processos de reabilitação. A seguir são apresentadas três aplicações, que utilizam o SME como sinal de controle em sistemas de reabilitação. As técnicas de processamento do SME analisadas neste trabalho estão enfocadas nestas três aplicações apresentadas. 


\subsubsection{O uso do SME em próteses de mão}

Pelo fato de vários músculos que executam os movimentos da mão estarem localizados no antebraço, o uso do SME destes músculos preservados é uma boa opção de controle de uma prótese de mão. É interessante salientar, que com o uso dos sinais destes músculos, o comando de um movimento da prótese pode ser realizado por meio dos mesmos músculos que realizariam um movimento similar na mão natural, de forma que o indivíduo pode se acostumar mais facilmente com o uso da prótese.

Os principais músculos superficiais localizados no antebraço são: Grupo Extensor: a) Extensor dos dedos, b) Extensores radiais do carpo, c) Extensor ulnar do carpo; Grupo Flexor: d) Flexor superficial dos dedos, e) Flexor radial do carpo, f) Flexor ulnar do carpo, g) Palmar longo (KENDALL \& McCREARY, 1986).

Na figura 14 são ilustrados estes músculos.

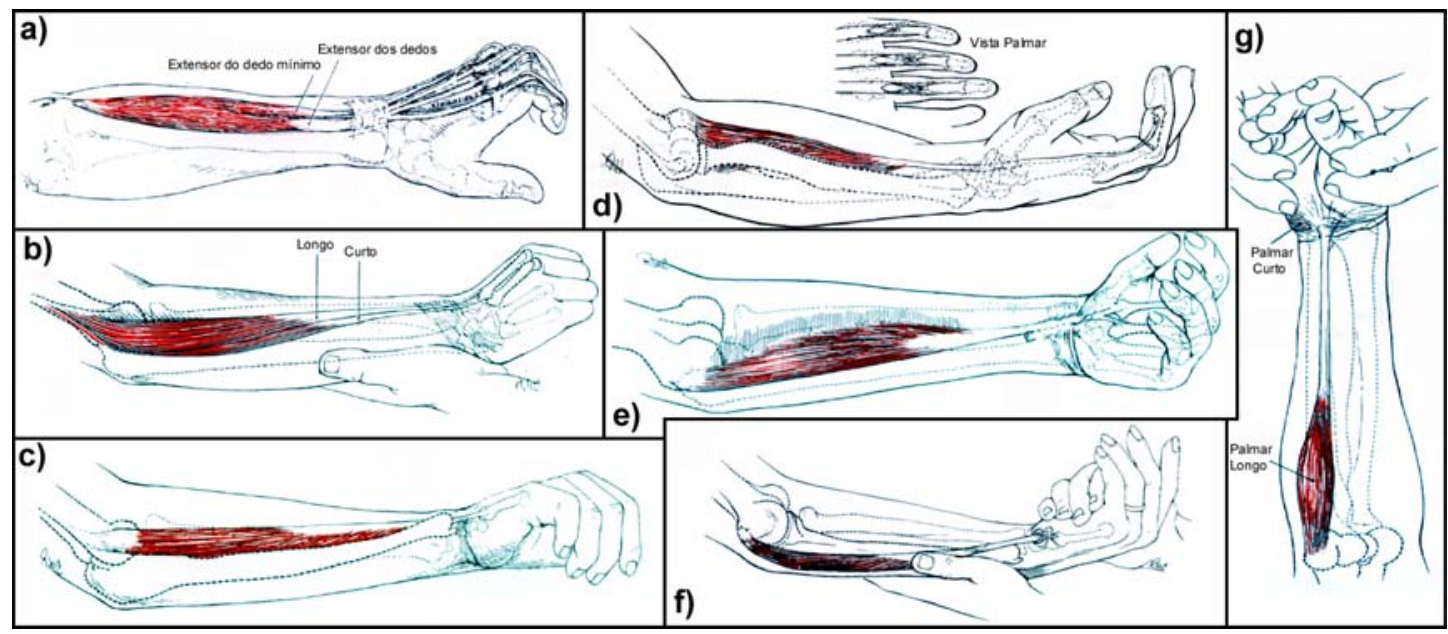

Fig. 14 - Principais músculos superficiais do antebraço. Grupo Extensor: a), b), c); Grupo Flexor: d), e), f), g). a) Extensor dos dedos e extensor do mínimo, b) Extensores radiais longo e curto do carpo, c) Extensor ulnar do Carpo, d) Flexor Superficial dos dedos, e) Flexor radial do Carpo, f) Flexor ulnar do carpo, g) Palmar longo e curto. (adaptado de KENDALL \& McCREARY, 1986)

Diversos trabalhos tratam do projeto e construção de próteses mioelétricas para membros superiores (PARKER et al.1977; CHAPPELL \& 
KYBERD, 1991; PORFÍRIO et al., 1992; HUDGINS et al. 1994; KYBERD et al., 1995; CUNHA et al., 2000).

O controle da prótese pode ser realizado de várias maneiras. Uma delas relaciona o número de contrações com o movimento, ou seja, uma contração corresponderia ao movimento ' $A$ ', duas contrações ao movimento ' $B$ ' e assim por diante. Outra forma de controle é realizada por um conjunto de eletrodos captando sinais de vários músculos, assim dependendo do músculo contraído pelo paciente tem-se como resultado um determinado movimento da prótese. Pode-se também controlar a prótese mediante o reconhecimento de padrões dos sinais mioelétricos, relacionando estes padrões com os movimentos que a prótese deve realizar. Neste caso podese otimizar o número de eletrodos.

Para que a prótese seja o mais antropomórfica possível, deve realizar um grande número de movimentos, e quanto mais movimentos, maior deve ser o número de eletrodos ou mais eficiente o reconhecimento dos padrões dos sinais mioelétricos.

Pelo fato de eletrodos de superfície captarem sinais referentes às atividades dos vários grupos musculares localizados nas proximidades dos eletrodos, e considerando que diferentes movimentos de um membro são realizados pelo recrutamento diferenciado dos grupos musculares (KENDALL \& McCREARY, 1986), então certos movimentos podem ser reconhecidos utilizando um número reduzido de eletrodos, como por exemplo, um eletrodo no grupo extensor e outro no grupo flexor do antebraço (HUDGINS et al., 1993). No entanto com o uso de mais eletrodos o sistema pode tornar-se mais confiável (KURUGANTI et al., 1995).

O reconhecimento de padrões do SME é eficiente tanto para determinar o tipo de movimento que a prótese deve executar de acordo com as características do sinal, assim como, para evitar que sinais de outros músculos que não estão relacionados com a intenção de movimento da prótese possam ativá-la.

Para realizar este reconhecimento torna-se necessária a implementação de um sistema de reconhecimento dos padrões do SME 
referente ao início da contração muscular, que apresenta um intervalo determinístico nos 200 ms iniciais.

Posteriormente ao reconhecimento do sinal, que só apresenta características determinísticas no início da contração, pode ser feita uma análise da quantidade de energia contida no SME de forma a extrair parâmetros para controlar a força de preensão executada pela prótese. Ou seja, quanto mais intensa for a contração muscular, maior será a amplitude do SME, e maior será a quantidade de energia presente no sinal, consequentemente a prótese deverá segurar o objeto com maior força. A intensidade do SME pode ser calculada por meio do valor RMS (Root Mean Square) ou da integral do sinal retificado. É interessante salientar que a integral do sinal retificado é mais fácil de ser obtida, mas o valor RMS apresenta uma melhor relação com a energia contida no sinal (ORTOLAN et al., 2000).

\subsubsection{Aplicação do SME em sistemas de Estimulação Elétrica Neuro-Muscular (EENM)}

O SME pode ser utilizado em sistemas de Estimulação Elétrica NeuroMuscular (EENM), com a intenção de restabelecer movimentos em lesados medulares. O sistema de EENM pode utilizar o SME de duas formas: como um sinal de realimentação da malha de controle (GRAUPE \& KORDYLEWSKI, 1997) e como um sinal de intuito do passo (QUEVEDO \& CLIQUET, 1992 e 1993).

\section{$\underline{\text { SME como sinal de realimentação no processo de EENM }}$}

Pelo fato do SME estar relacionado com a atividade de um músculo, pode ser usado como sinal de realimentação em um processo de estimulação muscular, indicando a intensidade da contração. Mas a grande vantagem de se utilizar o SME, é que a banda de maior energia do sinal se 
desloca para frequências mais baixas na medida que o músculo começa a entrar em processo de fadiga (BASMAJIAN \& DeLUCA, 1985). Desta forma, monitorando o SME é possível prever uma fadiga muscular no paciente e com o uso desta informação adicional, torna-se possível implementar um sistema mais robusto com relação à fadiga do músculo estimulado (PAVANI et al., 2001).

O inconveniente é que o SME apresenta baixas amplitudes em vista das centenas de volts aplicadas no membro pela EENM. Porém, a EENM não apresenta sinal de estimulação durante todo o tempo, por causa da habituação nervosa, de forma que são aplicados alguns pulsos de centenas de volts em um pequeno período e depois existe um intervalo sem estímulo. Portanto uma forma de obter o SME sem a interferência do sinal da EENM é acoplar os dois equipamentos de forma que o SME seja obtido durante o intervalo em que não existe estimulação (CHESLER \& DURFEE, 1997).

\section{$\underline{\text { SME como sinal de intenção do passo na marcha }}$}

O SME, quando utilizado como sinal de intenção do passo, é obtido por meio de algum membro acima do nível da lesão, ou seja, mediante controle voluntário do paciente. Este sinal pode ser obtido dos músculos: Bíceps Braquial, Deltóide, Peitoral Maior ou Trapézio dependendo do nível da lesão medular e do tipo do aparelho ortopédico utilizado (bengala/muleta/andador). Na figura 15 são ilustrados os músculos descritos.

Não é conveniente reconhecer a intenção do passo apenas comparando o sinal com um limiar, pois alguns movimentos do tronco ou de outros músculos, que não possuem qualquer relação com a intenção de executar o passo, podem proporcionar amplitudes suficientes no SME captado, de forma que se atinja o limiar e ocorra a geração do estímulo (QUEVEDO \& CLIQUET, 1991). É interessante então realizar a implementação de alguma técnica de reconhecimento de padrões para que o paciente receba o estímulo apenas no momento desejado. 


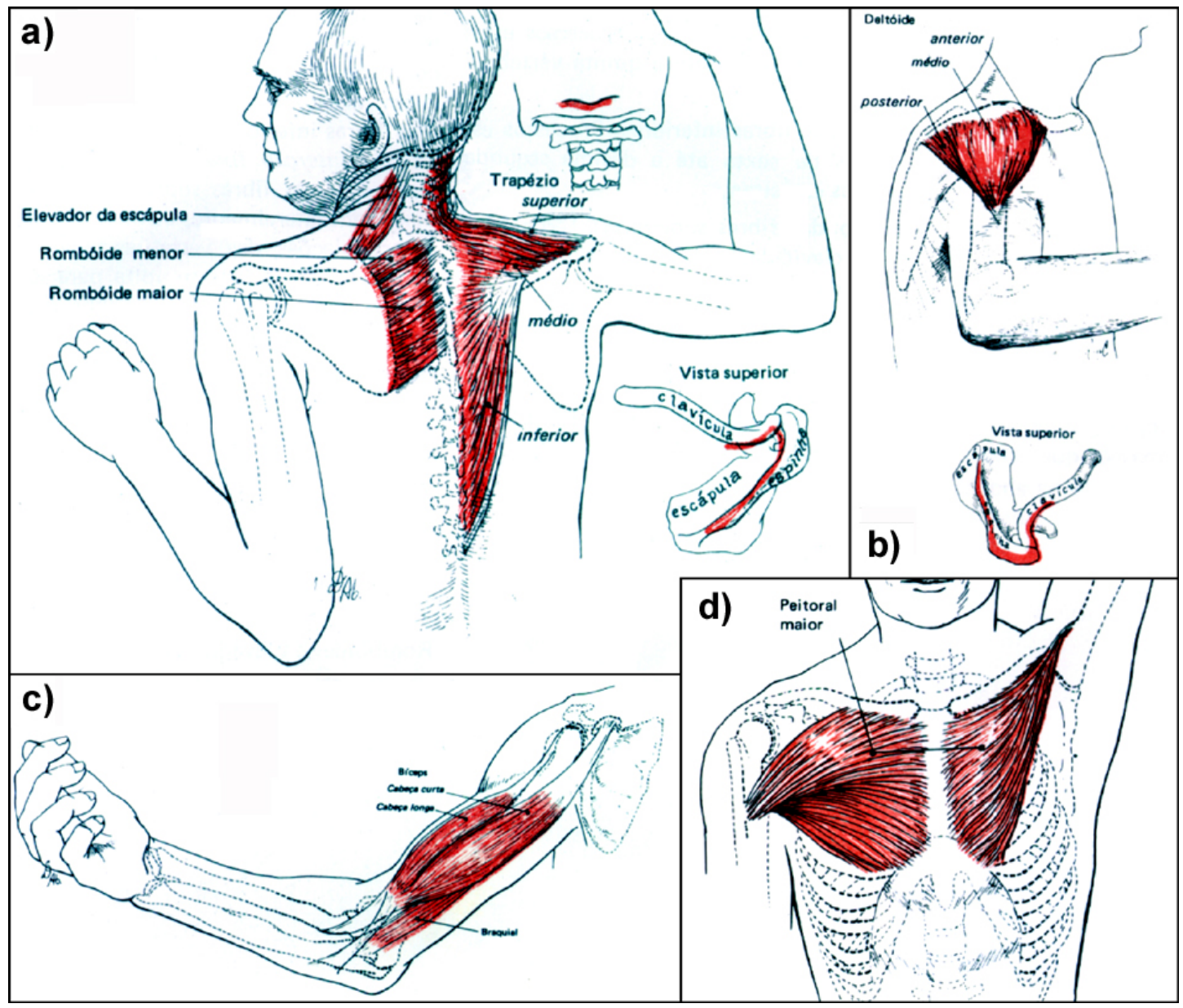

Fig. 15 - Músculos que podem ser utilizados para fornecer o sinal da intenção do passo na Estimulação Elétrica Neuro-Muscular em pacientes lesados medulares a) Trapézio, b) Deltóide, c) Bíceps Braquial d) Peitoral Maior (adaptado de KENDALL \& McCREARY,1986)

\subsubsection{Controle de ambiente de comunicação para pacientes com Traumatismo Crânio Encefálico}

Em muitos casos, indivíduos com traumatismo crânio-encefálico têm a perda da mobilidade e sensibilidade de todo corpo, além da ausência de comunicação. Com o intuito de promover um elo de comunicação para estas pessoas são desenvolvidos ambientes artificiais de comunicação.

Alguns trabalhos já foram realizados com o intuito de implementar um sistema de comunicação para estes pacientes. CHEN et al. (1999) 
desenvolveram um par de óculos que emite um feixe infravermelho em um painel fotossensível, disposto com as letras do alfabeto e um sensor de toque que é acionado com a língua do paciente, para selecionar as letras.

EVANS et al. (2000) implementou um sistema parecido onde é preso à testa do paciente um emissor infravermelho e por meio de fotoreceptores o paciente consegue movimentar o cursor na tela de um computador conforme movimenta sua cabeça.

O grande problema é que a maioria dos pacientes com traumatismo crânio-encefálico não consegue mexer a cabeça e nem a língua, restando ativo apenas o sistema ocular. Tendo isso em vista foram propostos alguns trabalhos que utilizam sensores que "rastreiam" o movimento dos olhos e a piscada (LaCOURSE \& HLUDIK, 1990; CLIQUET, 1997; ORTOLAN et al., 2001).

Monitorando o movimento dos olhos é possível que o paciente percorra com o cursor uma tela de computador, e escolha alguma opção disponível. O paciente deve ainda fechar os olhos durante um certo período, para que o sistema reconheça a piscada assim como o 'clic' do mouse.

O movimento dos olhos é realizado por três pares de músculos extraoculares dispostos ao redor do globo ocular de forma que um par seja responsável pelo movimento horizontal do olho, outro pelo movimento vertical e o terceiro par pelo movimento obliquo (GUYTON, 1988). Portanto é possível obter o potencial dos músculos extra-oculares de acordo com a posição dos olhos, utilizando eletrodos de superfície.

Para este caso são utilizados cinco eletrodos dispostos da seguinte forma: um par colocado externamente aos olhos para captar os movimentos na direção horizontal, outro par acima/abaixo de um dos olhos para captar o movimento vertical e um outro eletrodo é usado como referência, posicionado em uma região óssea (LaCOURSE \& HLUDIK, 1990).

O sistema pode ficar ligado $24 \mathrm{~h}$ com os sensores conectados, e quando o indivíduo deseja fechar os olhos pode selecionar um modo de descanso. Outra possibilidade é do paciente selecionar letras e escrever alguma frase. 


\section{CAPÍTULO 2 \\ "Nunca ande pelo caminho traçado, pois ele conduz somente até onde os outros foram." \\ Alexander Graham Bell.}

\section{TÉCNICAS DE FILTRAGEM}

O propósito de qualquer filtro é separar elementos diferentes. A filtragem de sinais elétricos está relacionada com a passagem do sinal em bandas de frequências específicas e rejeição dos sinais situados fora destas bandas. Portanto para realizar a filtragem de um sinal de forma adequada é importante conhecer as características dos sinais que se deseja obter e rejeitar. Como o SME já foi caracterizado no capítulo anterior serão apresentadas aqui as características dos principais ruídos em EMG.

Um sinal pode ser filtrado de forma analógica ou digital. Graças às vantagens que o processo digital apresenta, serão comentadas neste capítulo as seguintes técnicas deste tipo de processamento: filtragem clássica, filtragem adaptativa e reconstrução do sinal utilizando componentes da transformada wavelet. 


\subsection{Caracterização dos Ruídos em EMG}

Os principais ruídos, que podem interferir na aquisição do sinal mioelétrico, são provenientes da indução eletromagnética da rede elétrica e dos artefatos de movimento.

\subsubsection{Interferência da rede elétrica $(60 \mathrm{~Hz})$}

A interferência da rede elétrica é a mais danosa ao sinal mioelétrico, pois está presente no cotidiano da maioria da população, além de ter amplitude razoável se comparado às baixas amplitudes do SME (ZHANG et al., 1997). Outro fator importante, é que a frequência da rede elétrica e suas primeiras harmônicas $(60 \mathrm{~Hz}, 120 \mathrm{~Hz}, 180 \mathrm{~Hz}, 240 \mathrm{~Hz})$ estão dentro da faixa de maior concentração de energia do sinal mioelétrico.

Existem várias técnicas que procuram atenuar a interferência de $60 \mathrm{~Hz}$ dos sinais biomédicos, como por exemplo, trançar os fios (diminuindo a área entre eles susceptível a interferências magnéticas), usar um amplificador diferencial, coletar os dados em ambiente apropriado e adotar uma parte do corpo do paciente como terra (HUHTA \& WEBSTER, 1973). Porém, apesar de utilizar tais técnicas, ainda podemos estar expostos à interferência de 60 $\mathrm{Hz}$, em maior ou menor intensidade, dependendo do local da coleta dos dados e de outras características como a umidade da pele, oxidação dos eletrodos, etc. No intuito de implementar um sistema com maior robustez, que capte o sinal mioelétrico, sem a interferência da rede elétrica, independente do local da coleta e de outras características da aquisição, é interessante que seja desenvolvido um filtro para atenuar o ruído de $60 \mathrm{~Hz}$ proveniente deste tipo de interferência.

Pelo fato da frequência de $60 \mathrm{~Hz}$ estar dentro da banda de maior concentração de energia do sinal, o filtro desenvolvido para cancelar o ruído 
da rede deve ter uma banda de corte estreita, de forma a atenuar o ruído mas não prejudicar o SME.

\subsubsection{Artefatos de Movimento}

Outra fonte de ruído é proveniente dos artefatos de movimento, que está relacionada com o movimento dos cabos e dos eletrodos de captação do sinal.

Quando um músculo se contrai a pele também se movimenta, desta forma os eletrodos de superfície podem ter um pequeno deslocamento em relação à pele durante uma contração. Este deslocamento dos eletrodos, e também o movimento dos cabos durante uma captação, podem gerar um ruído de baixa frequência, relacionado com a variação da tensão média do SME, que interfere na aquisição do sinal pois altera as suas características.

Como a interferência dos artefatos de movimento é de baixa frequência, um filtro passa alta é capaz de atenuar a ação deste ruído. De acordo com a empresa DelSys (DELSYS INC., 1996) é recomendo o uso de filtros passa alta, com frequência de corte igual a $20 \mathrm{~Hz}$ para evitar a aquisição do sinal da taxa de disparo das unidades motoras, que são particularmente instáveis em virtude das suas características semialeatórias. Desta forma, se alguma frequência próxima a $20 \mathrm{~Hz}$ for suficiente para atenuar a interferência dos artefatos de movimento, pode ser utilizada, pois também cancela os sinais provenientes das taxas de disparo das unidades motoras. 


\subsection{Filtragem Analógica versus Digital}

A filtragem de sinais pode ser realizada por meio de processamento analógico ou digital.

Em relação aos elementos que compõem um filtro analógico, estes podem ser passivos ou ativos. Filtros passivos são utilizados desde os primórdios da tecnologia de filtros e são compostos basicamente por resistores, capacitores e indutores. Com o surgimento dos amplificadores operacionais torna-se possível a implementação de filtros ativos. Estes filtros têm a vantagem de não necessitarem de indutores (visto que temos poucos valores de indutores disponíveis no mercado), e graças à propriedade de isolação dos amplificadores operacionais, é possível obter filtros de ordem elevada colocando vários estágios em cascata.

Atualmente a tendência é realizar a maioria do processamento de forma digital, pois com esta técnica as modificações podem ser feitas em software, além de ser possível trabalhar com o sinal de forma não linear e também executar funções iguais ou similares aos processos analógicos.

A grande diferença entre estas técnicas é que analogicamente o sinal é processado de forma contínua e digitalmente o sinal é amostrado, ou seja, a informação do sinal é obtida em intervalos de tempos iguais, sendo este intervalo chamado de período de amostragem. Apenas para quantificar, o período de amostragem pode chegar à escala de nanossegundos. Para que o sinal seja amostrado de forma adequada, por um conversor analógico/digital (A/D), deve ter amplitude suficiente e frequência máxima de duas vezes a frequência de amostragem. Portanto na maioria dos casos em que é utilizado o processamento digital é necessário um pré-processamento analógico, de forma a condicionar o sinal aos valores adequados na entrada do conversor A/D. 


\subsection{Filtragem Digital Clássica}

A filtragem digital clássica pode ser realizada de duas maneiras, com filtros de resposta ao impulso infinita (cuja sigla em inglês é IIR) ou filtros de resposta ao impulso finita (com a sigla FIR em inglês).

A função de transferência de um processo digital é definida por $H(z)$, onde $z$ é uma variável complexa $\left(z=r \cdot e^{w \cdot j}\right)$, com argumento $r$ e ângulo $w, j$ é referente à base imaginária e $z^{-k}$ é um operador de atraso de $k$ amostras.

\subsubsection{Filtros IIR}

Os Filtros IIR são baseados nos filtros contínuos no tempo, ou analógicos. Portanto, para projetar um filtro IIR deve-se definir o tipo de resposta que o filtro deve apresentar, como por exemplo, Butterworth, Chebyshev ou Elíptico (vide Anexo), depois encontra-se a função de transferência contínua deste filtro, $H(s)$, e então converte-se esta função em uma função de transferência discreta, $H(z)$, que tem o seguinte formato:

$$
H(z)=\frac{\sum_{k=0}^{M} b_{k} \cdot z^{-k}}{\sum_{k=0}^{N} a_{k} \cdot z^{-k}}
$$

Sendo $N$ o número de pólos da função e consequentemente a ordem do filtro, $M$ o número de zeros da função e $b_{k}$ e $a_{k}$ são os valores que serão encontrados, ou seja, os coeficientes do filtro.

Para encontrar a função de transferência discreta a partir da contínua pode-se utilizar a transformação bilinear, aproximação das derivadas ou invariância ao impulso (PARKS \& BURRUS, 1987; DeFATTA et al., 1988; OPPENHEIM \& SCHAFER, 1989). 
Pelo fato da função de transferência deste tipo de filtro considerar os valores da saída (coeficientes $a_{k}$ ), configurando-se como um processo realimentado, este filtro também é chamado de filtro recursivo.

\subsubsection{Filtros FIR}

Os Filtros FIR têm a grande vantagem de apresentarem resposta linear com relação à fase do sinal quando o sistema é causal (sistema que não depende de futuros valores da entrada).

Considerando $M-1$ a ordem de um filtro FIR, a sua saída é calculada utilizando somente o valor da entrada no instante $k$ e nas $M-1$ amostras anteriores. Desta forma este filtro não é realimentado, como os filtros IIR, e por isso também é chamado de filtro não recursivo ou filtro de média móvel. A equação 2 apresenta a equação de diferenças de um filtro FIR.

$$
y(k)=b_{0} \cdot x(k)+b_{1} \cdot x(k-1)+\ldots+b_{M-1} \cdot x(k-M+1)=\sum_{i=0}^{M-1} b_{i} \cdot x(k-i)
$$

Sendo $y$ a saída e $x$ a entrada do filtro, $k$ as amostras a cada instante e $b_{i}$ os coeficientes do filtro.

Passando esta equação para o domínio da frequência é possível então encontrar a Função de Transferência do filtro FIR, conforme a equação 3.

$$
H(z)=\sum_{k=0}^{M-1} b_{k} \cdot z^{-k}
$$

Onde $z^{-k}$ é o atraso de $k$ amostras.

Pelo fato da Função de Transferência deste filtro não apresentar denominador e a sua saída ser calculada por um número finito de amostras da entrada, este filtro sempre apresenta uma resposta estável.

A desvantagem do filtro FIR é que deve ter alta ordem para ter uma resposta equivalente a um filtro IIR. 
Como os coeficientes $b_{k}$ do filtro FIR são definidos dentro do intervalo $0 \leq k \leq M-1$, então fora desta faixa os valores de $b_{k}$ são nulos. Pelo fato da resposta em frequência do filtro FIR ser composta por uma série de Fourier, os valores nulos indicam um truncamento na série. Este truncamento não afeta a resposta em amplitude do filtro, porém insere oscilações nas bandas de passagem e atenuação, este efeito é chamado de fenômeno de Gibbs (DeFATTA et al., 1988). Estas indesejadas oscilações podem ser reduzidas multiplicando os coeficientes da resposta ao impulso do filtro por uma função apropriada de janela, que atenua as descontinuidades geradas pelo truncamento. $\mathrm{Na}$ figura 16 são apresentadas as janelas normalmente utilizadas em filtros FIR. A janela retangular é o simples truncamento da série de Fourier do filtro. A janela de Kaiser varia suas características de acordo com o parâmetro $\beta$, sendo que para $\beta=0$ esta janela é igual a janela retangular (PARKS \& BURRUS, 1987; OPPENHEIM \& SCHAFER, 1989).
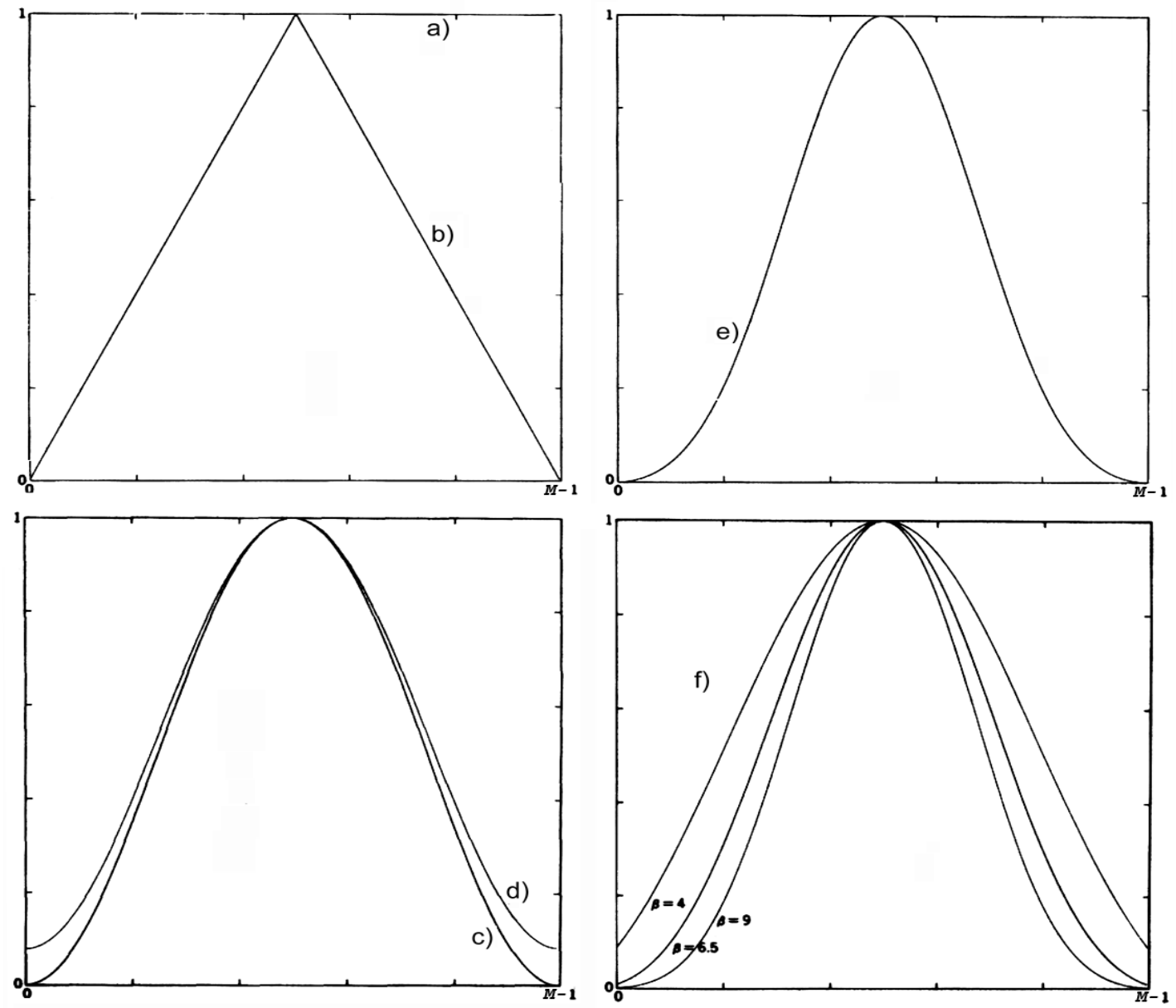

Fig. 16 - Tipos de Janela. a) Janela Retangular, b) Barlett, c) Hanning, d) Hamming, e) Blackman, f) Kaiser (adaptado de PARKS \& BURRUS, 1987). 


\subsection{Filtros Adaptativos}

Filtros adaptativos são filtros que ajustam seus próprios parâmetros conforme as características de um sinal que se deseja obter.

Os filtros adaptativos são compostos basicamente de um filtro digital e um algoritmo adaptativo que controla os coeficientes do filtro. Para determinar estes coeficientes o algoritmo adaptativo se baseia no sinal de saída. Na figura 17 é ilustrado o diagrama de blocos de um filtro adaptativo.

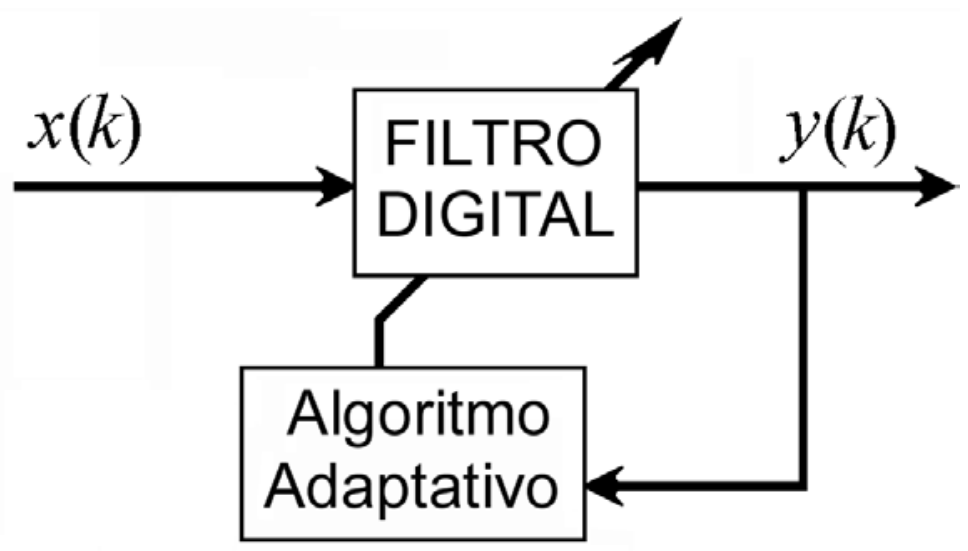

Fig. 17 - Diagrama de blocos de um filtro adaptativo. $x(k)$ entrada $e$ $y(k)$ saída do filtro.

Filtros adaptativos normalmente usam filtros FIR, portanto a saída pode ser calculada de acordo com a equação 3.

$$
y(k)=\sum_{i=0}^{M-1} w_{i}(k) \cdot x(k-i)
$$

Onde $M-1$ é a ordem do filtro e $w_{i}(k)$ são os $M$ coeficientes do filtro que podem se alterar a cada instante $k$.

É interessante observar que a única diferença entre a equação 2 e 3 é que os coeficientes do filtro podem variar a cada instante de amostragem. 


\subsection{Filtro de Wiener (Cancelador de Ruído Estacionário)}

O desenvolvimento de filtros ótimos foi originado pelo pioneiro trabalho de Wiener e foi estendido e aprimorado por Kalman, Bucy e outros (WIENER,1949; BODE \& SHANNON, 1950; KALMAN, 1960; KALMAN \& BUCY 1961; KAILATH, 1974).

O Filtro de Wiener é baseado em um filtro FIR no qual os coeficientes do filtro são calculados de forma a encontrar valores ótimos. O sistema proposto por Wiener, é chamado de cancelador de ruído, pois capta uma amostra do ruído, $r(k)$, ajusta esta amostra por meio do filtro de Wiener, de forma a ficar o mais parecido possível com o ruído, $n(k)$, que contamina um sinal, $s(k)$. O ruído estimado, $\tilde{n}(k)$, é então subtraído do sinal contaminado, $x(k),(I F E A C H O R \&$ JERVIS, 1993). O esquema do filtro é apresentado na figura 18.

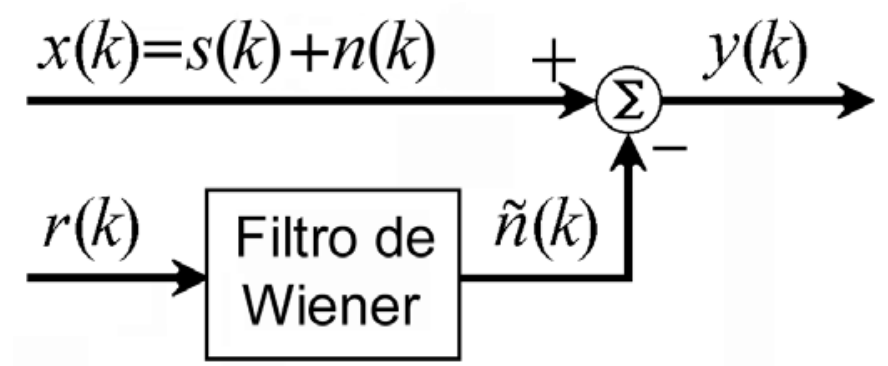

Fig. 18 - Filtro proposto por Wiener como cancelador de ruído. $s(k)$ é o sinal que se deseja obter, $n(k)$ é o ruído inserido no sinal, $r(k)$ é o sinal de referência e $\tilde{n}(k)$ é o ruído estimado pelo filtro de Wiener.

Como o sistema é baseado num filtro FIR, o ruído estimado, $\tilde{n}(k)$, é obtido através da seguinte equação:

$$
\tilde{n}(k)=\sum_{i=0}^{M-1} w_{i} \cdot r(k-i)
$$

Sendo $w_{i}$ os coeficientes do filtro de Wiener.

Pelo diagrama da figura 18 pode-se obter a seguinte equação para saída do filtro.

$$
y(k)=x(k)-\tilde{n}(k)=x(k)-\sum_{i=0}^{M-1} w_{i} \cdot r(k-i)=x(k)-\left[W^{T} \cdot R(k)\right]
$$


Sendo $W$ o vetor dos coeficientes do filtro e $R(k)$ o vetor de referência do ruído no instante $k$ e nas $M-1$ amostras anteriores:

$$
W=\left[\begin{array}{c}
w_{0} \\
w_{1} \\
\vdots \\
w_{M-1}
\end{array}\right]
$$

$$
R(k)=\left[\begin{array}{c}
r(k) \\
r(k-1) \\
\vdots \\
r(k-(M-1))
\end{array}\right]
$$

Pode-se observar que o erro entre a saída do filtro de Wiener, $\tilde{n}(k)$, e a entrada, $x(k)$, é representado pela saída $y(k)$.

Elevando o erro ao quadrado tem-se:

$$
e(k)^{2}=y(k)^{2}=x(k)^{2}-2 x(k) \cdot\left[R(k)^{T} \cdot W\right]+W^{T} \cdot R(k) \cdot R(k)^{T} \cdot W
$$

Avaliando o valor esperado do erro quadrático obtém-se:

$$
E\left[e(k)^{2}\right]=E\left[x(k)^{2}\right]-2 E\left[x(k) \cdot\left(R(k)^{T} \cdot W\right)\right]+E\left[W^{T} \cdot R(k) \cdot R(k)^{T} \cdot W\right]
$$

Sendo:

$$
P=E[x(k) \cdot R(k)] \quad, \quad R^{*}=E\left[R(k) \cdot R(k)^{T}\right]
$$

Onde:

$P$ a correlação cruzada entre a entrada, $x(k)$, e a referência, $R(k)$.

$R^{*}$ é a autocorrelação do ruído de referência, $R(k)$.

Substituindo os valores de $P$ e $R^{*}$ da equação (10) na equação (9):

$$
\left.E\left[e(k)^{2}\right]=\sigma^{2}-2 P^{T} \cdot W+W^{T} \cdot R^{*} \cdot W\right]=J
$$

Onde: $J$ é a esperança do erro quadrático médio $\sigma^{2}$ é a variância do sinal de entrada $E\left[x(k)^{2}\right]$ 
A fim de encontrar o menor erro, e(k), ou seja, para que o sinal de saída, $y(k)$, apresente o menor ruído, $n(k)$, é procurada a menor esperança do erro quadrático, $J$, da equação 11.

Esboçando $J$ em função dos coeficientes do filtro obtém-se a superfície parabolóide descrita na figura 19.

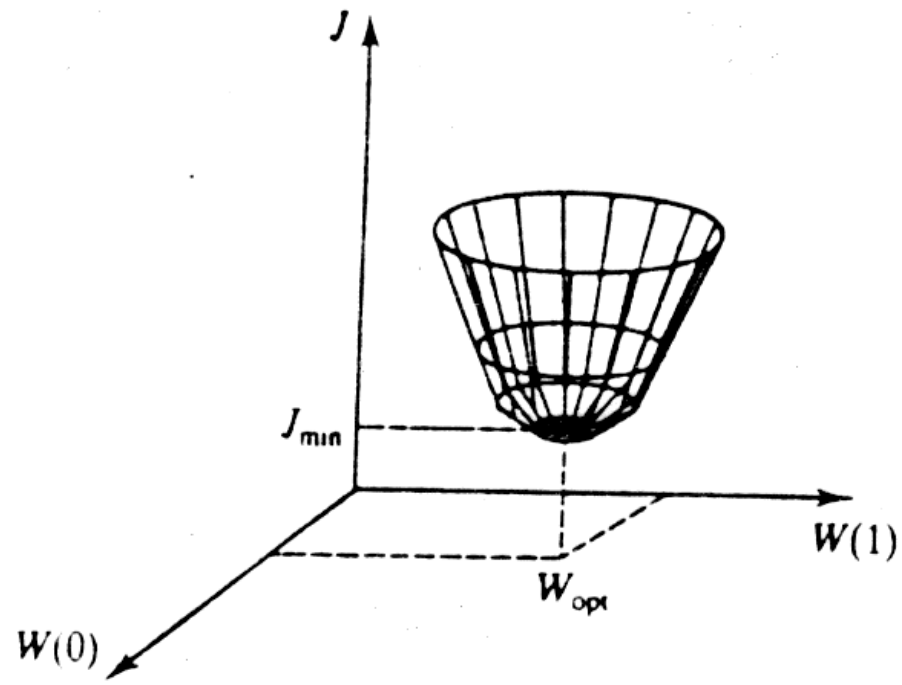

Fig. 19 - Superfície da performance do erro (IFEACHOR \& JERVIS, 1993).

A menor esperança do erro quadrático, $J$, da equação 11 situa-se no ponto de mínimo no gráfico da figura 19. Para encontrar este ponto é calculada a derivada da função 11 e igualada a zero. Com isso pode-se encontrar o $W_{\text {ótimo }}$ do filtro, que será o vetor de coeficientes do filtro $(W)$ que resultará no erro de menor quantidade de energia.

$$
\begin{aligned}
& \nabla=\frac{d J}{d W}=-2 P+2 R * W=0 \\
& W_{\text {ótimo }}=R^{*-1} \cdot P
\end{aligned}
$$

No entanto o filtro de Wiener tem várias limitações práticas:

É necessário o conhecimento da matriz de autocorrelação $R^{*}$ e o vetor de correlação cruzada $P$, e ambos podem não ser conhecidos a priori.

A operação de inversão de matriz é considerada uma operação complicada.

Se o erro ou o sinal não for estacionário então $R^{*}$ e $P$ não serão valores fixos, portanto $W_{\text {ótimo }}$ deve ser calculado continuamente. 


\subsection{Cancelamento de Ruído Adaptativo}

O cancelamento de ruído adaptativo é realizado de forma semelhante ao cancelamento proposto por Wiener, porém os valores dos coeficientes são ajustados a cada instante de amostragem (como os filtros adaptativos), de forma a obter valores ótimos mesmo para sinais não estacionários. Assim, esta configuração precisa de amostras da saída e do sinal de referência, que deve ser correlacionado com o sinal a ser estimado pelo filtro. Nos casos em que o sinal a ser estimado é bem conhecido, não é necessário obter o sinal de referência externamente, pois este pode ser gerado ou modelado pelo sistema.

O primeiro trabalho que se tem conhecimento em cancelamento de ruído adaptativo foi desenvolvido por Howelss e Applebaum na General Electric Company entre os anos de 1957 e 1960 (HOWELLS, 1965). Eles desenvolveram e construíram um sistema de cancelamento de lóbulo lateral em antena, que usava como referência o sinal de uma antena auxiliar.

Em 1959, Widrow e Hoff desenvolveram na Universidade de Stanford, o algoritmo adaptativo da média dos mínimos quadrados (cuja sigla em inglês é LMS) e um sistema de reconhecimento de padrões baseado em técnicas adaptativas (WIDROW \& HOFF, 1960).

$\mathrm{Na}$ figura 20 é apresentado o diagrama de blocos do cancelador de ruído adaptativo.

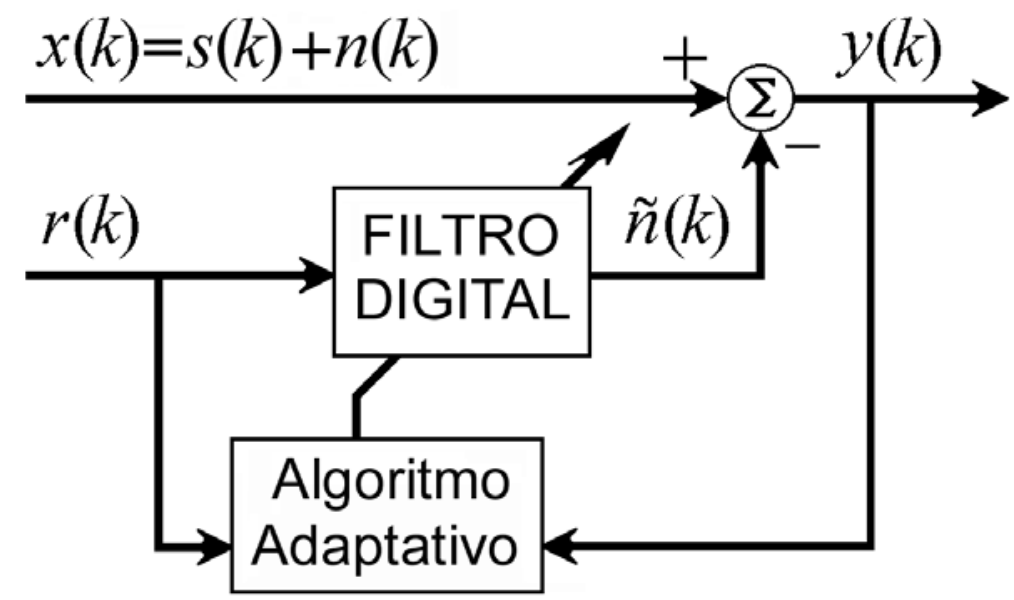

Fig. 20 - Diagrama de blocos de um cancelador de ruído adaptativo (adaptado de IFEACHOR \& JERVIS, 1993) 
Portanto quanto melhor for a estimativa do ruído, mais parecido com o sinal $s(k)$ será a saída.

Os algoritmos adaptativos mais utilizados são o LMS e RLS. O algoritmo de adaptação LMS (Least Mean Square) é a Média dos Mínimos Quadrados. Este algoritmo não sofre instabilidade numérica e é relativamente simples de ser implementado, sendo por isso amplamente utilizado. O algoritmo RLS (Recursive Least Square), que significa Mínimos Quadrados Recursivos, tem uma melhor convergência, mas pode sofrer de instabilidade numérica (IFEACHOR \& JERVIS, 1993)

O cancelamento de ruído adaptativo é utilizado quando é necessário que as características do filtro sejam variáveis, ou quando o espectro do ruído está dentro do espectro do sinal (ou vice-versa) e também quando a banda ocupada pelo ruído é desconhecida ou variante no tempo.

\subsubsection{O algoritmo LMS}

O algoritmo LMS é baseado num algoritmo de convergência no qual os coeficientes do filtro são atualizados a cada amostra de acordo com a seguinte equação.

$$
W(k+1)=W(k)-\mu \nabla(k)
$$

Sendo: $W(k)$ - vetor dos $M$ coeficientes do filtro no instante $k$

$\nabla$ - gradiente de correção dos coeficientes do filtro segundo a proposta de Wiener para encontrar os valores ótimos.

$\mu$ - coeficiente de amortecimento (controla estabilidade e taxa de convergência do filtro)

Para que $w$ convirja para $w_{\text {ótimo }} \mu$ deve estar dentro da seguinte faixa:

$$
0<\mu<\frac{1}{\lambda_{\operatorname{Max}}}
$$

Sendo $\lambda_{\operatorname{Max}}$ o máximo autovalor da matriz de autocorrelação $R^{*}$. 
Quanto mais próximo de 0 for $\circ \mu$, a saída, $y(k)$, levará mais tempo para convergir para o valor desejado, $s(k)$, e caso $\mu$ seja igual a zero, a saída será igual a entrada, $x(k)$. Para valores de $\mu$ próximos de $1 / \lambda_{\text {Max }}$, o sinal na saída do filtro irá convergir mais rápido para o sinal desejado, $s(k)$, mas se $\mu$ for muito próximos ou igual a $1 / \lambda_{\operatorname{Max}}$ a saída, $y(k)$, irá divergir, ou seja, o filtro perderá a estabilidade.

Da equação 12 pode-se obter o valor do gradiente, $\nabla(k)$ :

$$
\nabla(k)=-2 \cdot P(k)+2 \cdot R^{*}(k) \cdot W(k)
$$

Substituindo os valores de $P$ e $R^{*}$ da equação 10 obtém-se:

$$
\begin{aligned}
& \nabla(k)=-2 R(k) \cdot x(k)+2 R(k) \cdot R(k)^{T} \cdot W(k) \\
& \nabla(k)=-2 R(k) \cdot\left[x(k)-R(k)^{T} \cdot W(k)\right]
\end{aligned}
$$

Da equação 6 pode-se obter que:

$$
y(k)=x(k)-R(k)^{T} \cdot W(k)
$$

Portanto:

$$
\nabla(k)=-2 R(k) \cdot y(k)
$$

Assim a equação 13 pode ser descrita conforme a seguir:

$$
W(k+1)=W(k)+2 \mu y(k) \cdot R(k)
$$

O filtro de Wiener adaptativo, baseado no algoritmo LMS é descrito basicamente pelas equações 18 e 20. Inicialmente adota-se um valor arbitrário para o $W(0)$ e encontra-se a saída do filtro neste instante, $y(0)$, através da equação 18. Depois é encontrado o valor de $W$ no instante seguinte através da equação 20. Com o valor seguinte de $W$ é calculado então o valor seguinte da saída do filtro, $y(k+1)$, e assim sucessivamente até que $W$ atinja o valor de $W_{\text {ótimo }}$, conforme ilustrado na figura 21. 


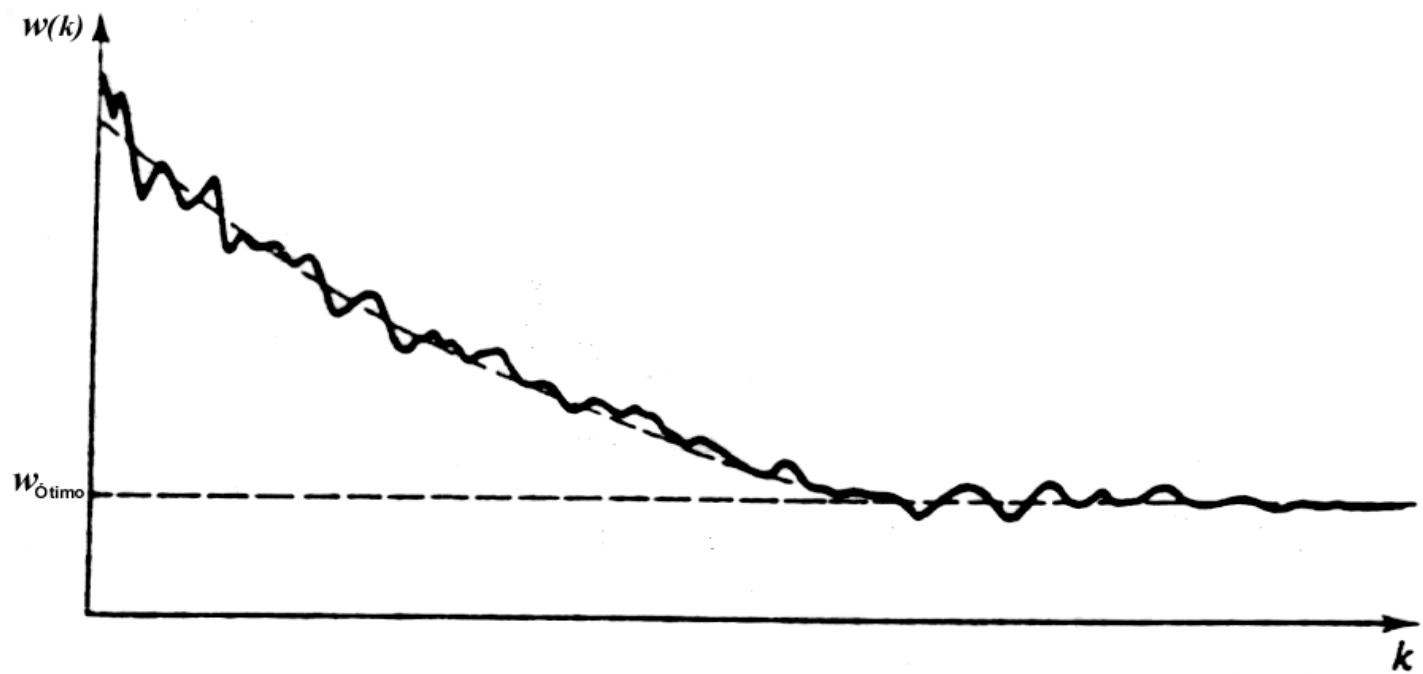

Fig. 21 - Convergência dos coeficientes $W(k)$ para $W_{\text {ótimo }}$ (IFEACHOR \& JERVIS, 1993).

Na figura 21 pode-se observar que os coeficientes do filtro, $W(k)$, nunca

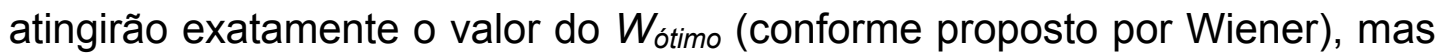
ficarão oscilando em torno deste valor dentro de um erro aceitável. Este tipo de resposta é típico de circuitos realimentados.

$\mathrm{Na}$ figura 22 é apresentado o fluxograma do algoritmo LMS, no qual, conforme comentado anteriormente, é inicializado $W(0)$ e $R(0)$. Sendo $R(k)$ composto pelo $r(k)$ atual e pelos $M-1 r(k)$ anteriores ( $M$ é a ordem do filtro).

Normalmente inicia-se $W(0)$ com zeros. É então encontrado o ruído estimado, $\tilde{n}(k)$ e a saída do filtro, $y(k)$. A partir destes valores é então encontrado o valor de $W$ no instante seguinte e assim sucessivamente.

$W(k)=\left[\begin{array}{c}w_{0}(k) \\ w_{1}(k) \\ \vdots \\ w_{M-1}(k)\end{array}\right] R(k)=\left[\begin{array}{c}r(k) \\ r(k-1) \\ \vdots \\ r(k-M+1)\end{array}\right]$

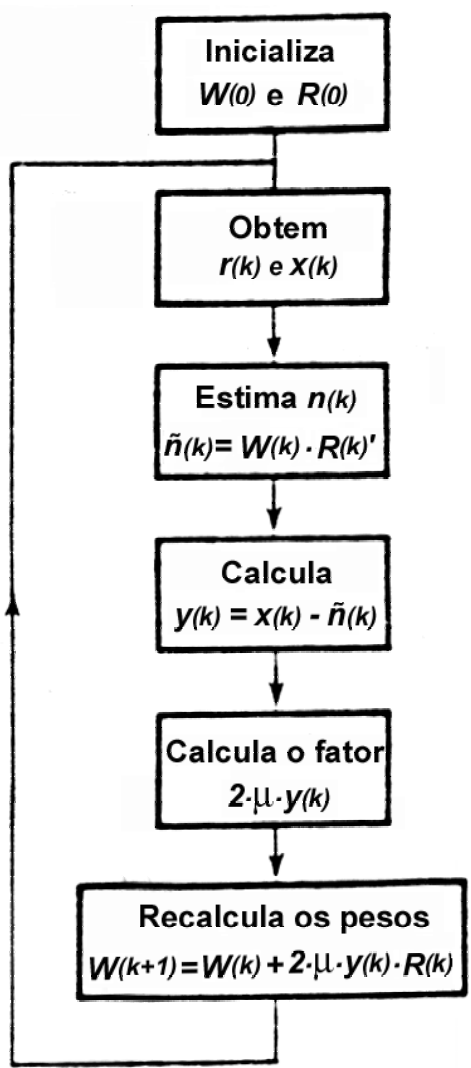

Fig. 22 - Fluxograma do algoritmo LMS (adaptado de IFEACHOR \& JERVIS, 1993) 


\subsubsection{O algoritmo RLS}

O algoritmo RLS (mínimos quadrados recursivo) é baseado no método dos mínimos quadrados (Least Square - LS), porém como este não é adequado para ser utilizado em tempo real, por causa da inversão de matriz $\left[R^{\star}\right]^{-1}$ calculada todo instante, então é sugerido um método recursivo para estimar o valor dos coeficientes do filtro sem necessitar a inversão de matriz a todo momento.

Um algoritmo RLS adequado deve obter coeficientes exponenciais, de forma a remover gradualmente os efeitos de dados antigos e permitir 0 rastreamento de variações lentas nas características do sinal (IFEACHOR \& JERVIS, 1993).

A atualização dos coeficientes do filtro é dada por:

$$
W(k+1)=W(k)+G(k) y(k)
$$

Onde:

$$
G(k)=\frac{P(k-1) \cdot R(k)}{\alpha(k)}
$$

e

$$
\alpha(k)=\gamma+R(k)^{T} \cdot P(k-1) \cdot R(k)
$$

$\gamma$ é o fator de esquecimento do filtro, ou seja, $\gamma$ fará com que o algoritmo torne as amostras antigas irrelevantes, $\gamma$ normalmente está entre 1 e 0,98 . Caso $\gamma$ seja igual a 1 então o algoritmo levará em conta todos os valores obtidos, ou seja, tem-se um filtro LS. $\gamma$ também pode ser definido como memória do filtro e para o caso de $\gamma=1$ o filtro terá memória infinita.

$P(k)$ é a maneira recursiva de computar a matriz inversa $\left[R^{*}\right]^{-1}$. A atualização de $P(k)$ é dada por:

$$
P(k)=\frac{1}{\gamma}\left[P(k-1)-G(k) \cdot R(k)^{T} \cdot P(k-1)\right]
$$


E a saída do filtro será:

$$
y(k)=x(k)-R(k)^{T} \cdot W(k-1)
$$

No entanto este algoritmo apresenta algumas limitações. Uma delas é que se o sinal de referência for zero por um longo período, a matriz $P(k)$ irá atingir valores muito grandes podendo ocorrer erro de 'overflow' no filtro, pois $P(k)$ é definido por $P(k-1)$ dividido por $\gamma$, que é menor que 1. Outra condição que gera instabilidade do filtro é se a matriz $P(k)$ tiver valores negativos, pode-se observar que não é possível assegurar que $P(k)$ seja positiva através da equação 24 .

O problema da instabilidade numérica pode ser resolvido pela fatoração da matriz $P$. Dois algoritmos são propostos para tal: o algoritmo do quadrado da raiz e da fatoração UD (IFEACHOR \& JERVIS, 1993). O algoritmo da fatoração UD é mais eficiente, pois requer menos memória por não realizar a operação de raiz quadrada.

\section{Algoritmo do quadrado da raiz:}

Este algoritmo trabalha com uma matriz chamada $S(k)$, a qual tem o valor da raiz quadrada de $P(k)$. Portanto $P(k)$ e encontrada a partir de $S(k)^{2}$, desta forma garantindo que $P(k)$ seja positiva

$$
S(k)=\frac{1}{\gamma^{2}} S(k-1) \cdot H(k-1)
$$

Onde $H(k)$ é uma matriz triangular superior. $P(k)$ é encontrado de acordo com a equação 27.

$$
P(k)=S(k) S(k)^{T}
$$




\section{Algoritmo da Fatoração UD:}

Este algoritmo trabalha com duas matrizes, $U(k)$ e $D(k)$, as quais são atualizadas a cada amostra e alteram então os valores da matriz $P(k)$. Os valores de $P(k)$ são dados por:

$$
P(k)=U(k) D(k) U(k)^{T}
$$

Onde: $U(k)$ é uma matriz triangular superior unitária.

$D(k)$ é uma matriz diagonal

\subsubsection{Efeito da Presença de Componentes do Sinal Desejado no Sinal de Referência}

Pode acontecer, em alguns casos, do sinal de referência, $r(k)$, conter uma certa quantidade do sinal desejado, $s(k)$. Desta forma o sinal de referência estará correlacionado com o sinal desejado, e este sofrerá um certo cancelamento na saída do filtro. A questão é se este cancelamento é suficiente para inutilizar o cancelador de ruído adaptativo.

De certa forma é intuitivo que acarretará uma baixa distorção no sinal de saída do filtro, se na entrada, $x(k)$, tivermos uma alta relação sinal ruído, e se na entrada de referência, $r(k)$, tivermos uma baixa relação sinal ruído. Ou seja, quanto maior for o sinal desejado na entrada do filtro e maior o ruído na entrada de referência, o sinal na saída do filtro será mais próximo do sinal desejado.

Segundo WIDROW et al. (1975) a distorção no sinal de saída do filtro pode ser dada pela seguinte equação:

$$
D=\frac{\rho_{\text {referência }}}{\rho_{\text {entrada }}}
$$

Onde: $D$ : Distorção do sinal de saída do filtro.

$\rho_{\text {referência: }}$ Relação sinal/ruído da referência do filtro, $r(k)$.

$\rho_{\text {entrada }}$ : Relação sinal/ruído do sinal de entrada do filtro, $x(k)$. 
Para exemplificar, assumindo um sinal de referência que contém o ruído e o sinal desejado (sendo o ruído 10 vezes maior que o sinal desejado), e um sinal de entrada no qual o sinal desejado tem o dobro da energia do ruído, então:

$$
\rho_{\text {referência }}=1 / 10 \quad \rho_{\text {entrada }}=2
$$

A distorção da saída será:

$$
D=\frac{1 / 10}{2}=5 \%
$$

Isso mostra que a existência do sinal desejado na entrada de referência (apesar de ser um caso a ser evitado) não torna o cancelamento de ruído inutilizável.

\subsubsection{Cancelamento de Ruído Adaptativo Utilizando Multireferências}

Em vários casos apenas uma entrada de referência, $r(k)$, não é suficiente. Para estes casos utiliza-se o cancelamento de ruído multireferencial conforme ilustrado na figura 23.

Um exemplo do uso do cancelador de ruído multireferencial é para atenuar a interferência do ruído da rede elétrica, pois esta pode conter além da frequência de $60 \mathrm{~Hz}$ também suas harmônicas $(120 \mathrm{~Hz}, 180 \mathrm{~Hz}$, $240 \mathrm{~Hz}, \ldots)$, que podem ter variações diferentes nas amplitudes de acordo com as variações da interferência. Como estas frequências são bem determinadas não é necessário o uso do sensor de ruído, pois este sinal pode ser gerado matematicamente. 


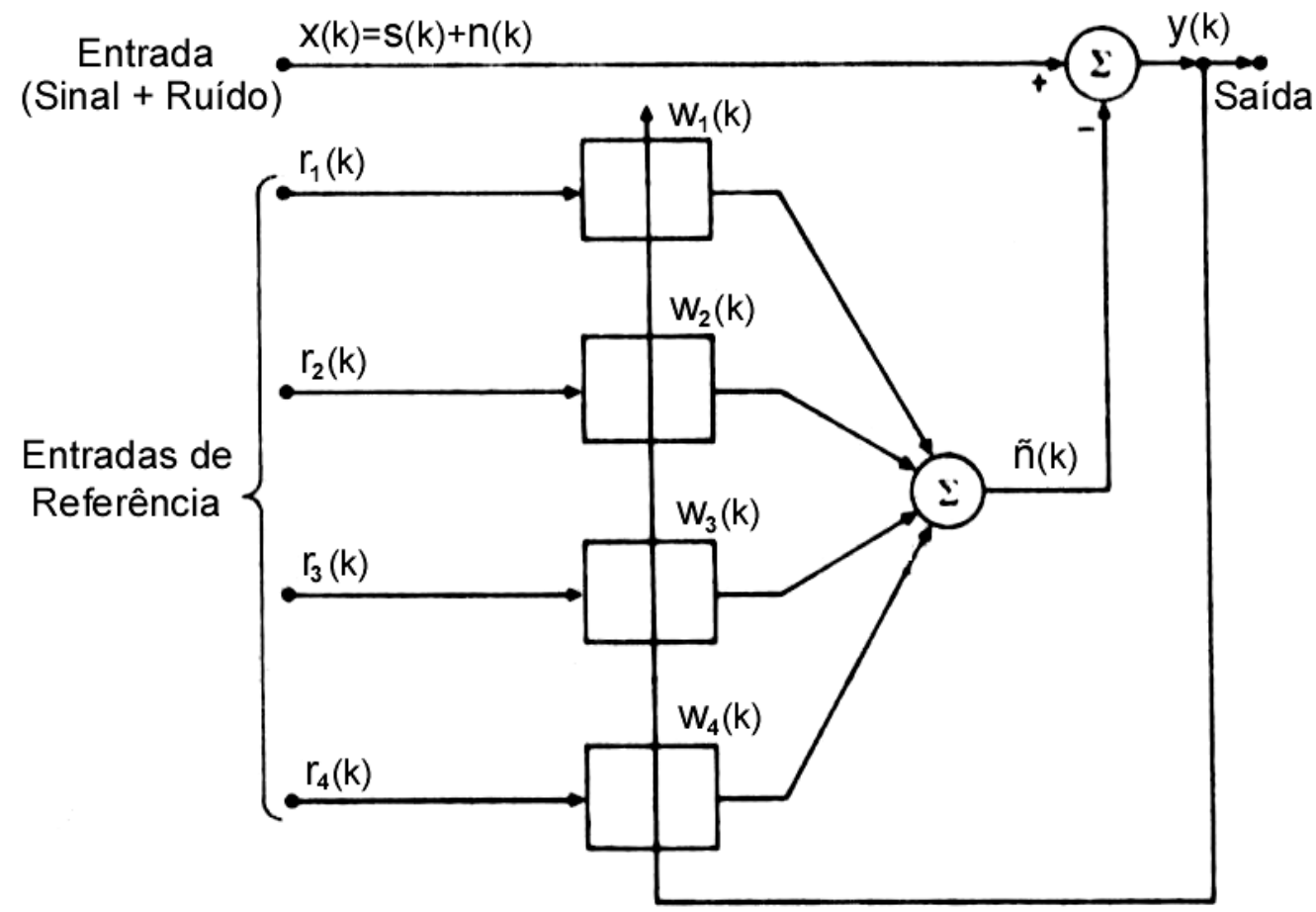

Fig. 23 - Diagrama de blocos de um cancelador de ruído adaptativo multireferencial (adaptado de WIDROW et al., 1975)

\subsubsection{Filtro Notch com o Cancelamento de Ruído Adaptativo}

Filtros notch são filtros que cortam uma faixa de frequência com largura de banda pré-determinada. Para casos em que um sinal é corrompido com um ruído senoidal, a atenuação deste ruído pode ser realizada com o uso de um filtro notch com frequência de ressonância igual a frequência do ruído.

O cancelador de ruído adaptativo pode ser configurado como filtro notch. A principal vantagem de se utilizar um filtro notch adaptativo é que este filtro pode variar a frequência de ressonância caso a frequência do ruído seja alterada. Além disso, a largura de banda pode ser facilmente controlada.

Para realizar a implementação de um filtro notch adaptativo deve-se aplicar um sinal senoidal de frequência bem determinada, $\omega_{0}$, como sinal de referência. Esta frequência é então a frequência de ressonância. Para a 
implementação de um filtro notch com mais de uma frequência de corte basta inserir sinais de referências com as frequências de ressonância desejadas, assim como comentado no item anterior, relacionado com multireferências.

Apesar da implementação do filtro notch, conforme citado, funcionar bem, WIDROW et al. (1975) propuseram um filtro notch adaptativo em que um dos sinais de referência, $r(k)$, é uma onda cossenoidal de amplitude $A$, frequência $\omega_{0}$ e fase $\phi$, e além deste sinal existe um outro, $r_{2}(k)$, defasado $90^{\circ}$ de $r(k)$. Com a utilização de um sinal senoidal e um cossenoidal, adotando frequências iguais e variações diferentes nas amplitudes, é possível reconstruir rapidamente qualquer sinal de mesma frequência com outros valores de fase e amplitude. Desta forma a estimação do ruído se torna mais rápida.

O filtro proposto por Widrow utiliza o algoritmo LMS, como algoritmo de adaptação. A seguir é apresentado o diagrama de blocos do filtro notch adaptativo proposto por Widrow (Fig. 24).

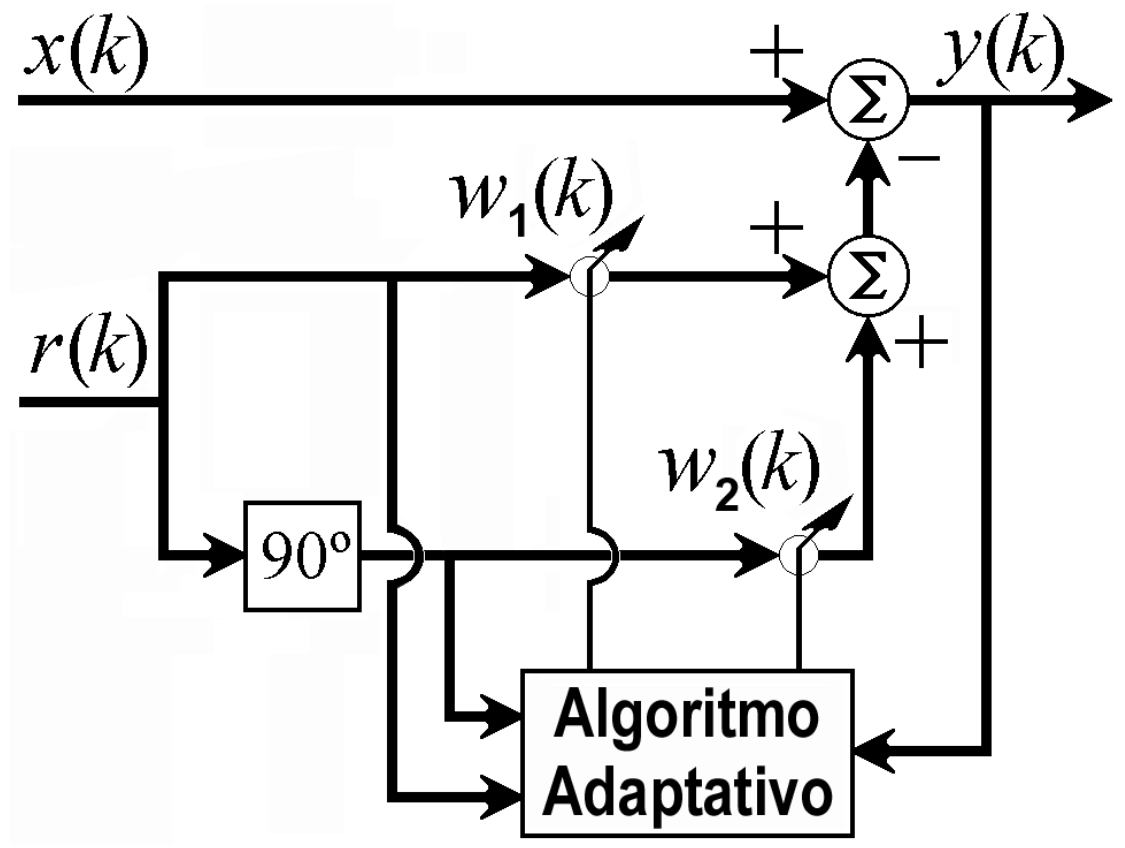

Fig. 24 - Diagrama de blocos de um cancelador de ruído adaptativo utilizado como filtro Notch proposto por WIDROW et al. (1975).

(modificado de WIDROW et al.,1975) 
Considerando $r(k)=A \cdot \cos \left(\omega_{0} \cdot k+\phi\right)$, a largura de banda do filtro notch adaptativo é dada por:

$$
B W=\mu \cdot A^{2} \cdot \Omega / \pi
$$

Sendo: $\mu$ : Coeficiente de amortecimento do algoritmo LMS

$A$ : Amplitude do sinal de referência

$\Omega$ : Frequência de amostragem (rad/seg) 


\subsection{Reconstrução do Sinal Utilizando as Componentes da Transformada Wavelet}

A transformada wavelet apresenta a intensidade das componentes frequenciais que compõem um sinal, assim como a transformada de Fourier, porém com a transformada wavelet a resposta de cada componente é apresentada no domínio do tempo.

Conhecendo as características do sinal que se deseja obter é possível realizar uma análise em cada componente frequencial e determinar quais componentes contêm as informações desejadas. Utilizando apenas as componentes com estas informações pode-se reconstruir um sinal, cancelando o efeito de componentes frequenciais indesejadas.

\subsubsection{Wavelets}

Wavelet é o nome dado a algumas funções que satisfazem certas propriedades, como por exemplo, duração limitada e média zero. As wavelets podem ser suaves ou não, simétricas ou não, além de poderem apresentar expressões matemáticas simples ou complexas (MORETTIN, 1999).

Existem várias famílias de wavelets, alguns exemplos são: Harr, Daubechies, Coiflets, Biortogonal, Symlets, Morlet, Meyer e Chapéu Mexicano. (MISITI et al., 1996). As famílias de wavelets são geradas a partir de uma wavelet mãe, que é comprimida $\mathrm{N}$ vezes gerando as $\mathrm{N}$ ondas que compõe esta família. Para realizar a transformada wavelet normalmente usam-se famílias de wavelets que definem bases ortogonais, pois desta forma é possível realizar a transformada inversa.

As wavelets definidas pela função de Haar são as mais simples e antigas. A wavelet mãe da família Haar é definida com valor 1 entre 0 e $1 / 2$, e -1 entre $1 / 2$ e 1 . A wavelet de Morlet é chamada também de gaussiana 
modulada. O chapéu mexicano é obtido através da segunda derivada da densidade gaussiana. As Coiflets e Daubechies não são simétricas e as Symmlets são as funções mais simétricas. Na figura 25 é apresentada a família Daubechies

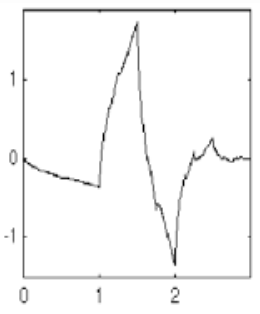

$\mathrm{db} 2$

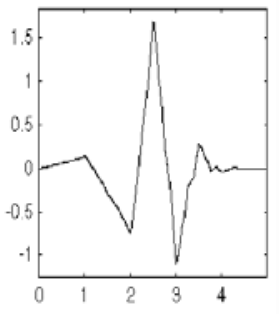

db3

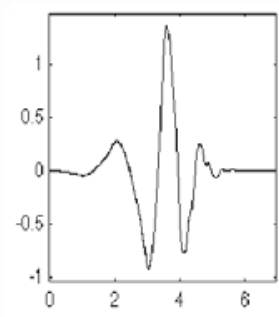

$\mathrm{db} 4$

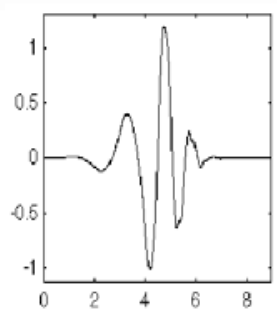

$\mathrm{db} 5$

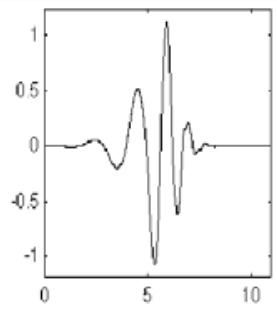

$\mathrm{db} 6$

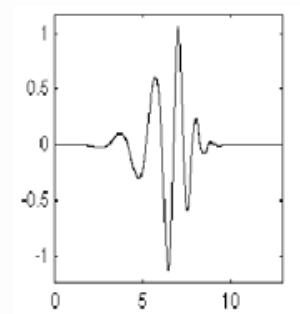

$\mathrm{db} 7$

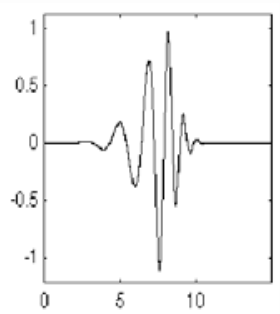

$\mathrm{db} 8$

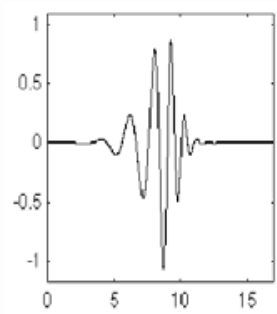

db9

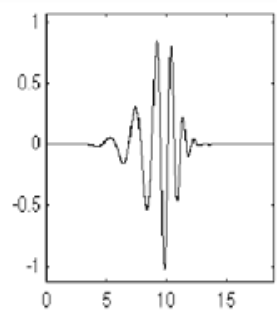

$\mathrm{db} 10$

Fig. 25 - Wavelets da famíla Daubechies. (MISITI et al., 1996)

\subsubsection{Transformada Wavelet}

A análise de um sinal, utilizando transformada Fourier, consiste na aproximação deste sinal em funções senos e cossenos, por meio de combinação linear. A transformada wavelet realiza o mesmo processo, porém o sinal é aproximado por funções wavelet.

A transformada wavelet é obtida da seguinte forma: primeiro é calculado o valor de $C$ que representa quanto um intervalo do sinal está correlacionado com uma wavelet (item a) da figura 26). Este procedimento é realizado nos intervalos seguintes até o termino do sinal, conforme indicado no item b) da figura 26. Encontra-se depois a correlação do sinal para escalas maiores de wavelet conforme ilustrado no item c) da figura 26 


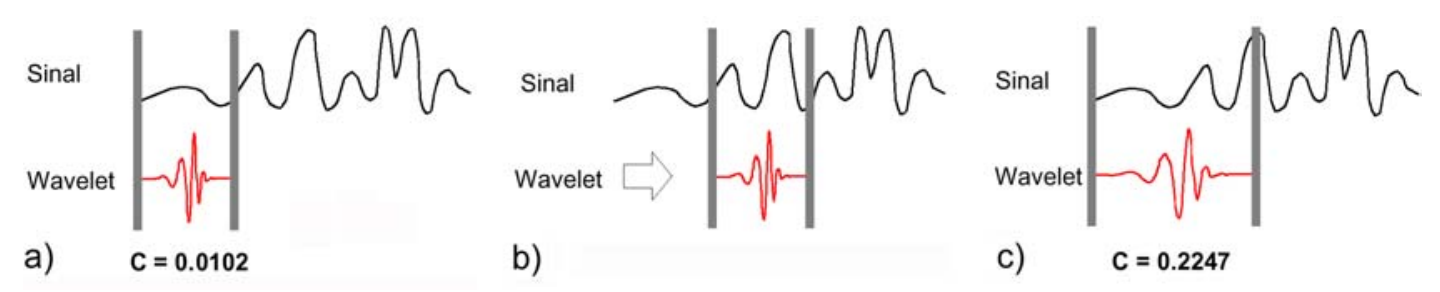

Fig. 26 - llustração de como são calculados os coeficientes da transformada wavelet.

a) Correlação do primeiro período do sinal com uma wavelet,

b) Deslocamento da wavelet para obter os valores de correlação no tempo,

c) Troca da escala da wavelet. (adaptado de MISITI et al., 1996).

Utilizando os valores de correlação do sinal $(C)$ a cada instante com as diferentes escalas de wavelet, pode-se montar o gráfico representado na figura 27. Note que é possível obter informação do sinal no domínio do tempo.

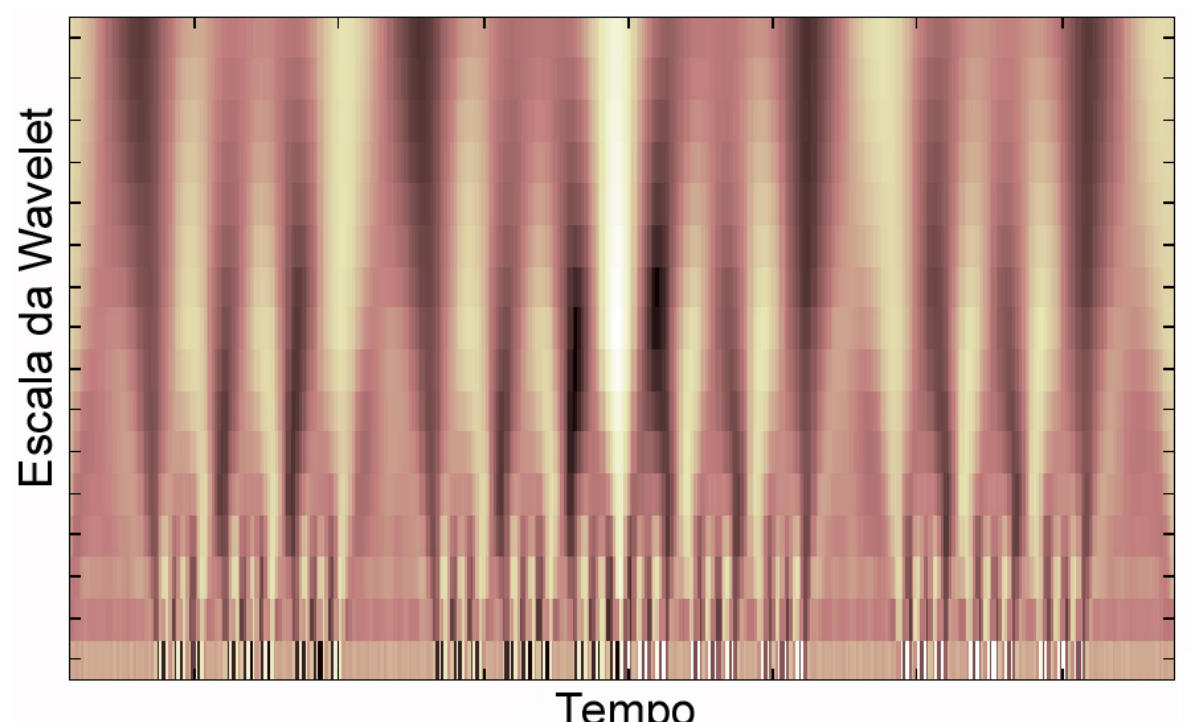

Tempo
Valores altos de C

Valores baixos de $\mathrm{C}$

Fig. 27 - Gráfico de intensidade da correlação do sinal, $C$, com as diferentes escalas de wavelet (adaptado de MISITI et al., 1996).

No entanto, digitalmente não é possível realizar estas correlações para um número infinito de escalas. MALLAT (1989) desenvolveu então um método eficiente para encontrar a transformada wavelet discreta. $O$ algoritmo de Mallat consiste em um banco de filtros FIR, no qual o sinal é dividido sucessivamente em sinais de alta e baixa frequência. A árvore de decomposição tradicional da transformada wavelet é ilustrada na figura 28. 
$\mathrm{Na}$ figura 28 as componentes de baixas frequências são representadas por $A_{n}$ e as de alta frequência por $D_{n}$. A árvore de decomposição tradicional faz divisões sucessivas sempre na componente de baixa frequência.

É interessante comentar que a reconstrução do sinal é realizada por meio dos coeficientes terminais de uma árvore de decomposição.

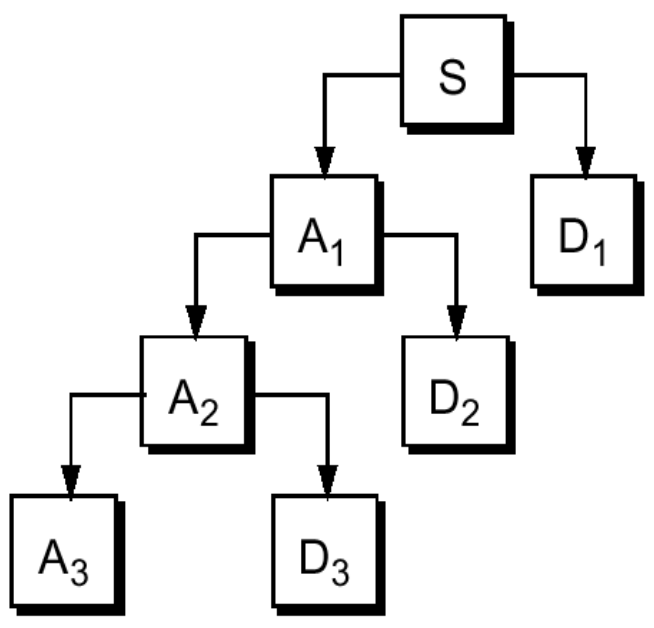

Fig. 28 - Árvore de decomposição tradicional da transformada wavelet com três níveis de decomposição. (MISITI et al., 1996)

Para casos em que a árvore tradicional não apresenta resultados satisfatórios pode-se utilizar outros tipos de árvores de decomposição, conforme o exemplo ilustrado na figura 29.

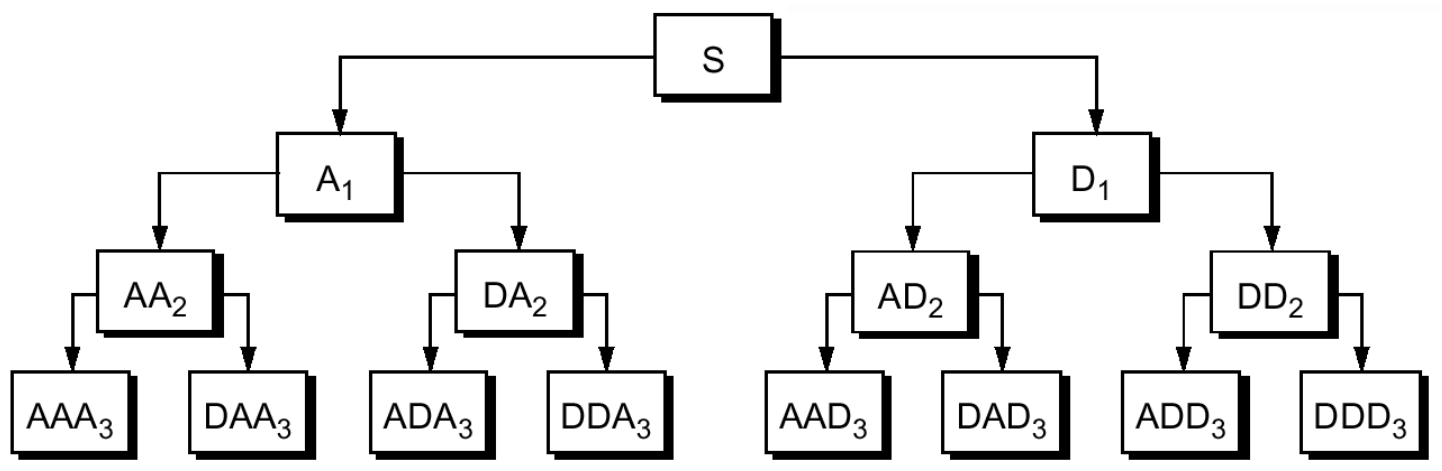

Fig. 29 - Árvore de decomposição mostrando todos os nós terminais possíveis até o $3^{\circ}$ nível de decomposição. (MISITI et al., 1996) 


\subsubsection{Análise Multiresolução}

Com a decomposição de um sinal utilizando a transformada wavelet é possível realizar uma análise multiresolução deste sinal, ou seja, analisando cada componente terminal da decomposição pode-se observar as características no domínio do tempo, de cada faixa de frequência contidas no sinal. Na figura 30 é ilustrado um sinal (s) e os valores dos nós terminais de uma decomposição até $03^{\circ}$ nível, utilizando uma árvore de decomposição tradicional.
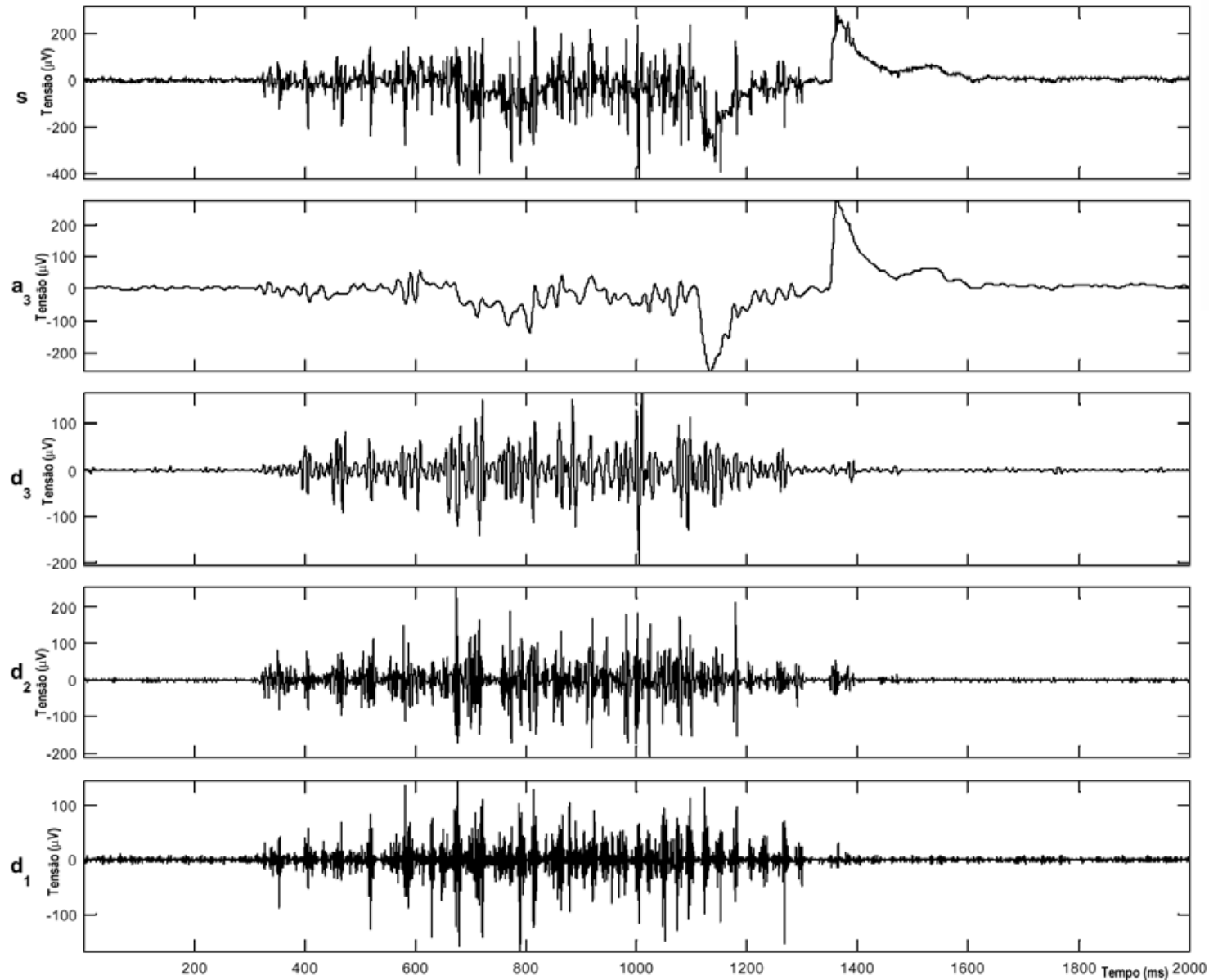

Fig. 30 - Decomposição do sinal, s, nas componentes terminais da árvore da fig. 28.

Pelo fato da transformada wavelet ser realizada por um banco de filtros, a seletividade das componentes frequências de um sinal em cada coeficiente $\left(a_{n}\right.$ e $\left.d_{n}\right)$ é determinada pela ordem da wavelet utilizada. Por exemplo, a Daubechies 4 seleciona melhor as frequências nos coeficientes do que a Daubechies 2 que apresenta um espalhamento maior das frequências nos coeficientes vizinhos. 
Utilizando a característica multiresolução que a transformada wavelet proporciona, é possível realizar a filtragem de um sinal contaminado com algum ruído, por meio de sucessivas decomposições deste sinal até encontrar o ruído em algumas componentes da decomposição e então reconstruir o sinal utilizando apenas as componentes que não apresentam o ruído.

Neste capítulo foram apresentadas algumas técnicas de filtragem que são avaliadas no capítulo três para atenuar o ruído da rede elétrica e a interferência causada por artefatos de movimento. 


\section{CAPÍTULO 3 \\ "O primeiro dever da inteligência é desconfiar dela mesma." \\ Albert Einstein.}

\section{AVAliaÇão de TÉCNICAS de FiltrageM APLICADAS AO SME}

Para que um sistema reconheça o SME adequadamente é necessário que este sinal não tenha suas características alteradas por possíveis ruídos. Com o intuito de cancelar a atividade das interferências que corrompem o SME é necessário que seja implementado algum tipo de filtro, que atenue convenientemente estes ruídos e proporcione a menor alteração nas características do sinal.

Para eleger o filtro com melhor desempenho, entre os que foram descritos no capítulo dois, foram simuladas e avaliadas as seguintes técnicas de filtragem: Filtragem digital clássica (FIR e IIR), Cancelamento de ruído adaptativo (algoritmos LMS e RLS) e Reconstrução do sinal utilizando componentes selecionadas do sinal decomposto pela transformada wavelet.

A análise dos filtros foi realizada com sinais contaminados com o ruído da rede elétrica e com a interferência proveniente dos artefatos de movimento.

Definindo a melhor técnica de filtragem do SME para atenuar estes ruídos pode-se implementar em hardware, um sistema de aquisição do sinal mioelétrico assim como realizado por BAGWELL \& CHAPPELL (1994). 


\subsection{Materiais e Métodos}

Toda a análise foi realizada por meio de simulação computacional utilizando o software Matlab da Mathworks Inc.

Os sinais mioelétricos foram captados por meio de eletrodos de superfície ativos diferenciais com ganho de 20 vezes (PA602 da empresa Lin $x^{1}$ ), em seguida o sinal foi amplificado mais 50 vezes em uma placa condicionadora de sinais (MCS 1000-V2 da Linx), totalizando um ganho de 1000 vezes. Este sinal foi então amostrado, por uma interface de aquisição de dados (CAD 1256 também da Linx) a uma taxa de amostragem de $1000 \mathrm{~Hz}$.

Foram obtidos sinais da extensão e flexão do punho de um mesmo indivíduo em datas e lugares diferentes. Os eletrodos foram localizados nos grupos extensor e flexor do antebraço do voluntário. Dentre os sinais obtidos haviam sinais sem ruído, com ruído da rede elétrica e com a interferência dos artefatos de movimento.

\subsubsection{Filtragem do Ruído dos Artefatos de Movimento}

Para eliminar os ruídos proveniente dos artefatos de movimento foi utilizada a transformada wavelet da família Daubechies de ordem 4. A árvore de decomposição utilizada é ilustrada na figura 31. Foi utilizada a árvore tradicional, pois este tipo de ruído apresenta baixas frequências conforme já mencionado no capítulo 2.

\footnotetext{
${ }^{1}$ Linx Tecnologia Eletrônica LTDA - http://www.lynxtec.com.br
} 
O sinal mioelétrico com ruído, representado por $x$ na figura 31 , foi separado nas componentes $a_{m}$ (componentes de baixa frequência) e $d_{m} \quad$ (de alta frequência). A decomposição do sinal $x$ pode ser descrita pela seguinte fórmula:

$$
x=s+n=a_{m}+\sum_{i=1}^{m} d_{i}
$$

Sendo:

m o maior nível de decomposição s o sinal mioelétrico $n$ o ruído

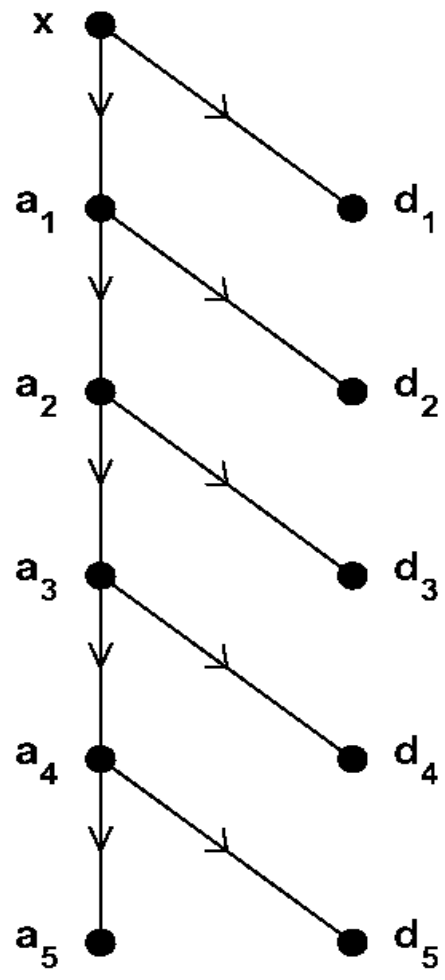

Fig. 31 - Árvore de decomposição utilizada para cancelar os artefatos de movimento.

A partir do conhecimento prévio das características do sinal mioelétrico e do ruído, foi realizada inicialmente uma análise nas duas primeiras componentes do sinal $\left(a_{1}\right.$ e $\left.d_{1}\right)$, observando a presença do ruído e do sinal mioelétrico em cada uma delas. Constatou-se, conforme esperado, que a componente $a_{1}$ apresentava o ruído e uma parcela do sinal mioelétrico. Foi então realizada uma nova decomposição nesta componente e analisadas as componentes resultantes $\left(\begin{array}{lll}a_{2} & \mathrm{e} & d_{2}\end{array}\right)$. Este procedimento foi feito sucessivamente até encontrar uma componente que fosse aproximadamente igual ao ruído.

Como os artefatos de movimento induzem ruídos de baixa frequência, estes sinais foram encontrados na componente de mais baixa frequência de uma árvore de 5 níveis de decomposição $\left(a_{5}\right)$. Para um sinal amostrado com $1 \mathrm{KHz}$, esta componente apresenta frequências de 0 a $15,625 \mathrm{~Hz}$.

A componente que contém o ruído foi então suprimida e o sinal foi reconstruído utilizando as outras componentes, $\left(d_{5}, d_{4}, d_{3}, d_{2}\right.$ e $\left.d_{1}\right)$. 
Para avaliar o desempenho desta técnica de filtragem utilizando a transformada wavelet foram desenvolvidos outros dois filtros passa alta digitais: um filtro de $100^{\mathrm{a}}$ ordem FIR com janela de Kaiser e outro de $6^{\mathrm{a}}$ ordem IIR Chebyshev tipo II.

\subsubsection{Filtragem da Interferência da rede elétrica}

Como a interferência da rede e suas harmônicas têm frequências bem definidas então a filtragem deste sinal é realizada por meio de filtros Notch.

Com relação ao cancelador de ruído adaptativo como filtro notch, foram realizadas filtragens utilizando a configuração proposta por WIDROW et al. (1975) e um cancelador de ruído adaptativo de referência simples, com um sinal de $60 \mathrm{~Hz}$ aplicando a esta entrada. Para diferenciá-los, estes filtros serão chamados de 'cancelador de ruído proposto por Widrow' e 'cancelador de ruído adaptativo'. Para as duas configurações foram utilizados os algoritmos adaptativos LMS e RLS.

A filtragem da interferência de rede elétrica foi realizada em dois grupos de sinais. Um grupo utilizando sinais mioelétricos captados sem ruído e este acrescido matematicamente, para que se pudesse calcular a relação sinal ruído na saída dos filtros; e outro utilizando sinais captados com a interferência da rede, para avaliar o desempenho real entre as técnicas utilizadas.

\section{SME obtido sem ruído}

Como nesta análise a idéia foi de avaliar o desempenho dos filtros por meio da relação sinal ruído em sua saída, foram utilizados apenas técnicas de filtragem adaptativas. Isso porque filtros não adaptativos atenuam um nível pré-determinado do ruído, ou seja, a relação sinal-ruído na saída do filtro depende da relação sinal-ruído em sua entrada. 
Foram gerados ruídos da rede elétrica com fase aleatória, para evitar que sejam iguais ao sinal de referência, e somados aos sinais mioelétricos. O ruído gerado também teve três níveis diferentes de amplitude: 10 vezes maior que a máxima amplitude do SME, igual e 10 vezes menor que o pico de amplitude do SME, desta forma foram obtidas diferentes SNR para o sinal ruidoso a ser filtrado.

Estes sinais ruidosos foram então aplicados na entrada de canceladores de ruído adaptativos com referência simples e com duas referências conforme proposto por Widrow. Estes dois filtros foram implementados com os algoritmos adaptativos LMS e RLS, ou seja, nesta análise foram utilizados quatro filtros.

Com estes filtros adaptativos foram realizados dois tipos de teste: um fixando a ordem dos filtros e analisando a SNR na saída; e outro obtendo uma SNR na saída do filtro em torno de um valor estipulado e analisando as configurações dos filtros.

Primeiramente os filtros foram desenvolvidos para ter desempenhos parecidos (SNR de saída $\approx 17 \mathrm{~dB}$ ). Em virtude da maior dificuldade em obter uma performance parecida, o ruído da rede foi adotado como um sinal puro de $60 \mathrm{~Hz}$. O sinal de referência foi gerado matematicamente com fase e amplitude aleatórias.

Para o caso em que a ordem dos filtros foi fixa foram utilizados canceladores de ruído adaptativo com 5 coeficientes $\left(\mathrm{M}=5 \Rightarrow 4^{\mathrm{a}}\right.$ ordem) e canceladores de ruído conforme proposto por Widrow utilizando apenas a amostra atual do sinal $(M=1)$. O sinal de interferência da rede, adicionado ao SME, neste caso conteve também informações da sua primeira harmônica $(60 \mathrm{~Hz}+120 \mathrm{~Hz})$ sendo estas duas frequências geradas com fase aleatórias. Para este caso os canceladores de ruído são multireferenciais, pois também necessitam de um sinal de referência de $120 \mathrm{~Hz}$. 


\section{SME obtido com ruído}

Um dos sinais obtidos com ruído da rede elétrica é apresentado na figura 32.

Para esta análise foram utilizados os filtros adaptativos desenvolvidos para o item anterior em conjunto com filtros não adaptativos e a reconstrução do sinal utilizando componentes da decomposição pela transformada wavelet.

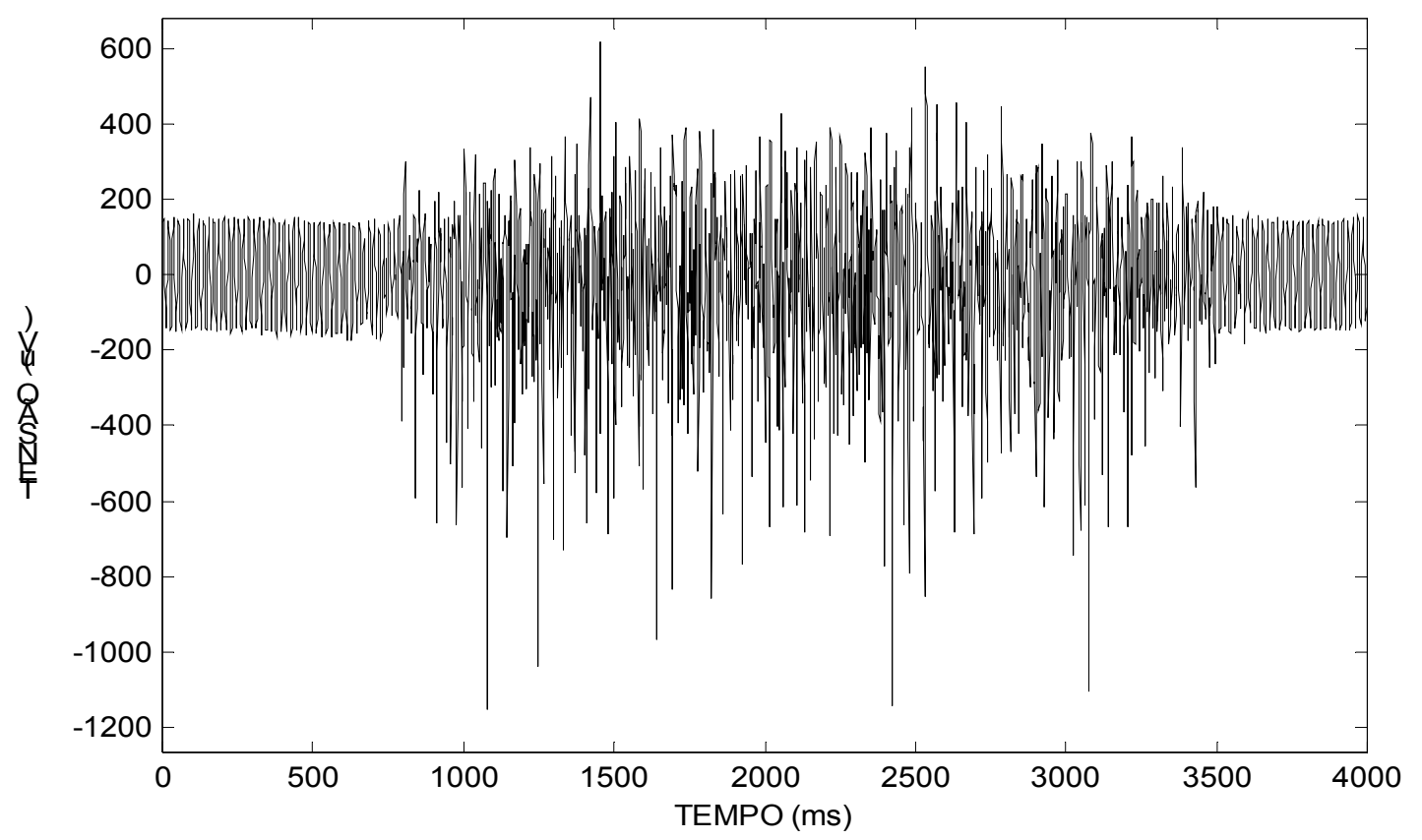

Fig. 32 - Sinal mioelétrico obtido com o ruído da rede elétrica

Foram implementadas duas configurações de filtragem clássica utilizando filtros notch: uma com um Filtro FIR de ordem 664 com janela de Kaiser; e outra com um Filtro de $2^{\text {a }}$ ordem IIR chebyshev tipoll.

A transformada wavelet utilizada foi novamente uma Daubechies de $4^{\mathrm{a}}$ ordem. A árvore de decomposição utilizada é apresentada na figura 33. Pode-se observar que esta decomposição difere da árvore tradicional de decomposição, que foi a utilizada para retirar os ruídos dos artefatos de movimento. Como a frequência de amostragem foi de $1 \mathrm{KHz}$ a componente $(0,0)$ compreende todas as componentes do sinal $(0 \mathrm{~Hz}$ a $500 \mathrm{~Hz})$, a componente $(1,0)$ apresenta as componentes frequenciais de $0 \mathrm{~Hz}$ a $250 \mathrm{~Hz}$, e assim sucessivamente. 


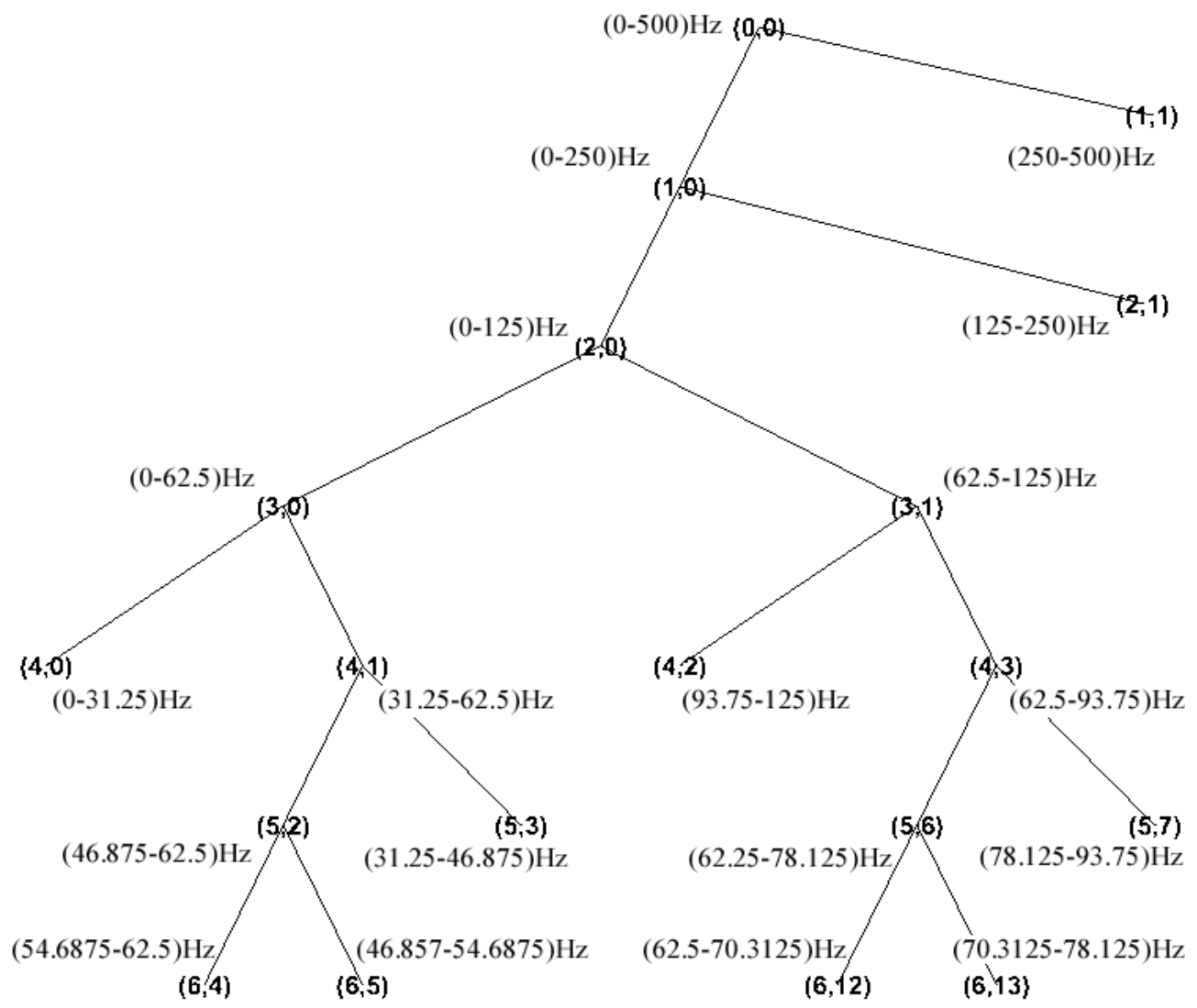

Fig. 33 - Árvore de decomposição utilizada na decomposição do sinal por meio da transformada wavelet para atenuar a interferência de rede elétrica.

Pelo fato do nó $(3,0)$ apresentar componentes frequenciais de $0-62.5 \mathrm{~Hz}$, o ruído da rede elétrica está contido neste nó. No entanto o nó $(3,1)$, que compreende componentes de $62.5-125 \mathrm{~Hz}$, também apresenta uma parcela deste ruído, pois a frequência de corte $(62.5 \mathrm{~Hz})$ é próxima da frequência da rede elétrica. Para filtrar adequadamente o ruído foram divididas novamente as componentes $(3,0)$ e $(3,1)$, gerando assim as quatro componentes $(4,0),(4,1),(4,2),(4,3)$ com as respectivas faixas de frequência $0-31.25 \mathrm{~Hz}, \quad 31.25-62.5 \mathrm{~Hz}, \quad 93.75-125 \mathrm{~Hz}, \quad 62.5-93.72 \mathrm{~Hz} \quad$ (WAVELET TOOLBOX, 2001), ou seja as componentes $(4,1)$ e $(4,3)$ contêm parcelas do ruído.

Na figura 34 é apresentada a intensidade de energia dos nós terminais até o quarto nível de decomposição, pode-se observar que as componentes $(4,1)$ e $(4,3)$ apresentam alta densidade de sinal durante todo o período, caracterizando a parcela do ruído, que está presente durante todo o intervalo de aquisição. 


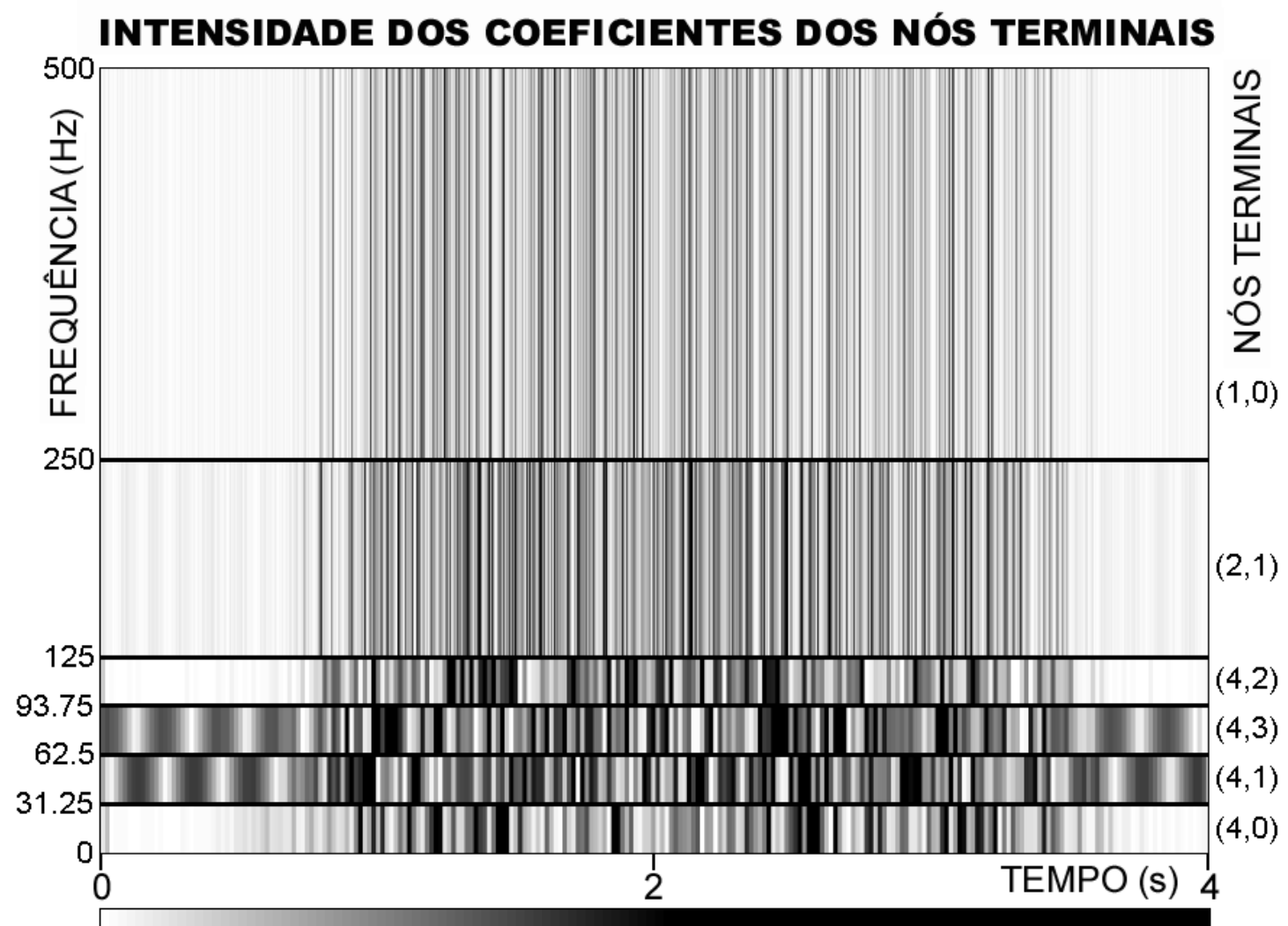

Escala de Intensidade - Mínimo a Máximo

Fig. 34 - Intensidade de energia dos nós terminais de uma árvore com 4 níveis de decomposição. $O$ eixo das abcissas representa o intervalo de captação do sinal. Análise realizada no sinal apresentado na figura 32.

Foram feitas então sucessivas divisões a partir das componentes $(4,1)$ e $(4,3)$ de forma a obter a árvore de decomposição descrita na figura 33. A decomposição foi realizada até o nível 6 pois foi constatado que no nível 7 perde-se a seletividade com relação a este ruído, ou seja dividindo os termos $(6,4)$ e $(6,12)$, que contêm a interferência de $60 \mathrm{~Hz}$, este sinal era apresentado nas 4 componentes seguintes obtidas no nível 7.

Desta forma os nós terminais obtidos foram $(4,0),(5,3),(6,5),(6,4)$, $(6,12),(6,13),(5,7),(4,2),(2,1)$ e $(1,1)$ com as respectivas larguras de banda: 0-31.25Hz; $\quad 31.25-46.875 \mathrm{~Hz} ; \quad 46.876-54.6875 \mathrm{~Hz} ; \quad 54.6875-62.5 \mathrm{~Hz}$; 62.5-70.3125Hz; $\quad 70.3125-78.3125 \mathrm{~Hz} ; \quad 78.3125-93.75 \mathrm{~Hz} ; \quad 93.75-125 \mathrm{~Hz}$; 125-250Hz e 250-500Hz, (WAVELET TOOLBOX, 2001). Na figura 35 é ilustrada a intensidade de energia dos nós terminais descritos acima. 


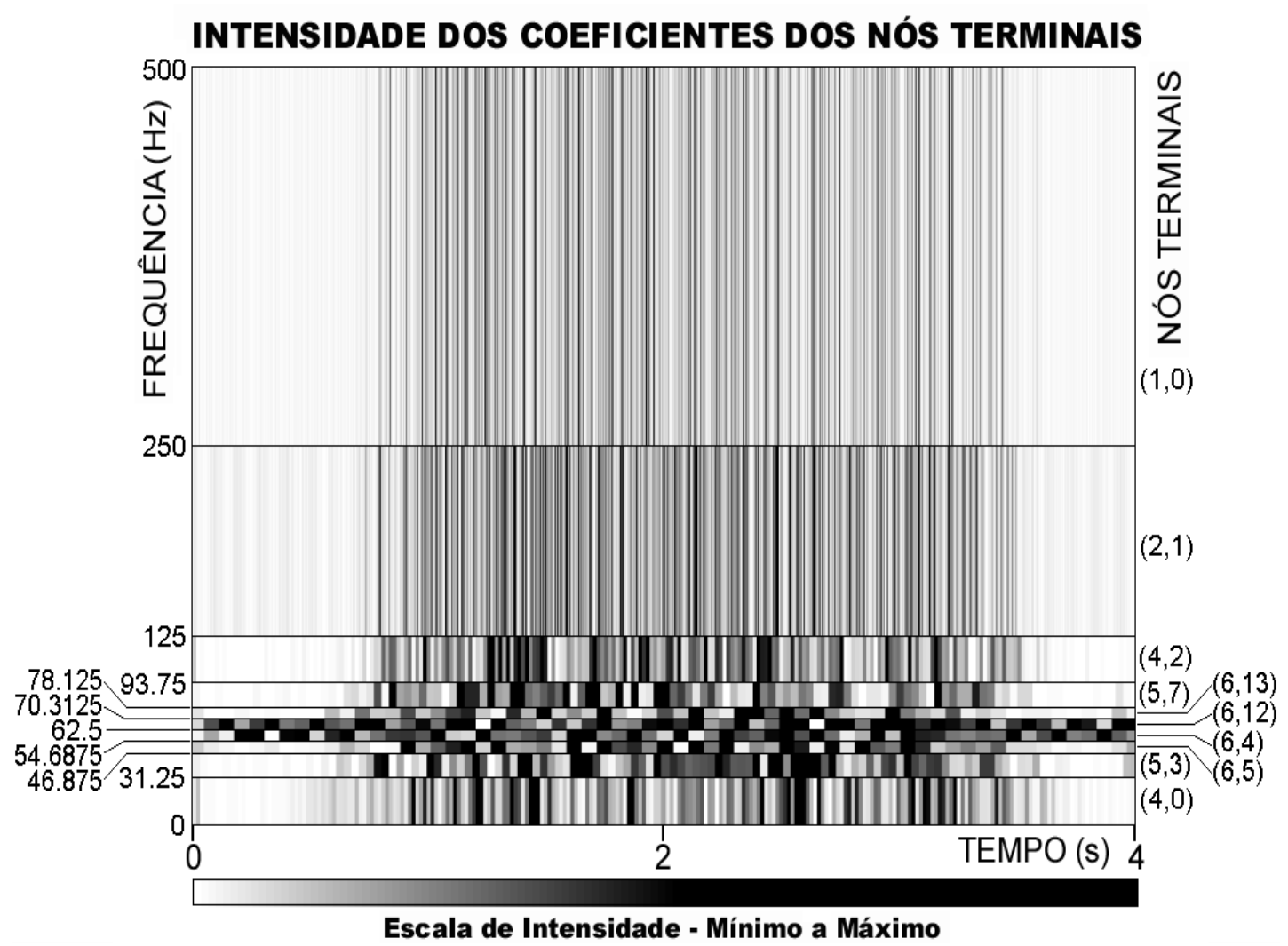

Fig. 35 - Intensidade de energia dos nós terminais da árvore de decomposição ilustrada na figura 33. O eixo das abcissas representa o intervalo de captação do sinal. Análise realizada no sinal apresentado na figura 32.

Como o ruído da rede elétrica está presente nos termos $(6,4)$ e $(6,12)$ então o sinal foi reconstruído utilizando os coeficientes $(4,0),(5,3),(6,5)$, $(6,13),(5,7),(4,2),(2,1)$ e $(1,1)$. 


\subsection{Resultados}

Os resultados são apresentados em dois blocos, um relacionado com os artefatos de movimento e outro com a interferência da rede elétrica.

\subsubsection{Filtragem do Ruído dos Artefatos de movimento}

Pelo fato de todos sinais captados com ruídos dos artefatos de movimento apresentarem características próximas, foi escolhido um sinal ruidoso arbitrário para exemplificar os resultados obtidos. A figura 36 apresenta um sinal mioelétrico contaminado com artefato de movimento. Nesta figura pode ser observada a variação na tensão média do sinal.

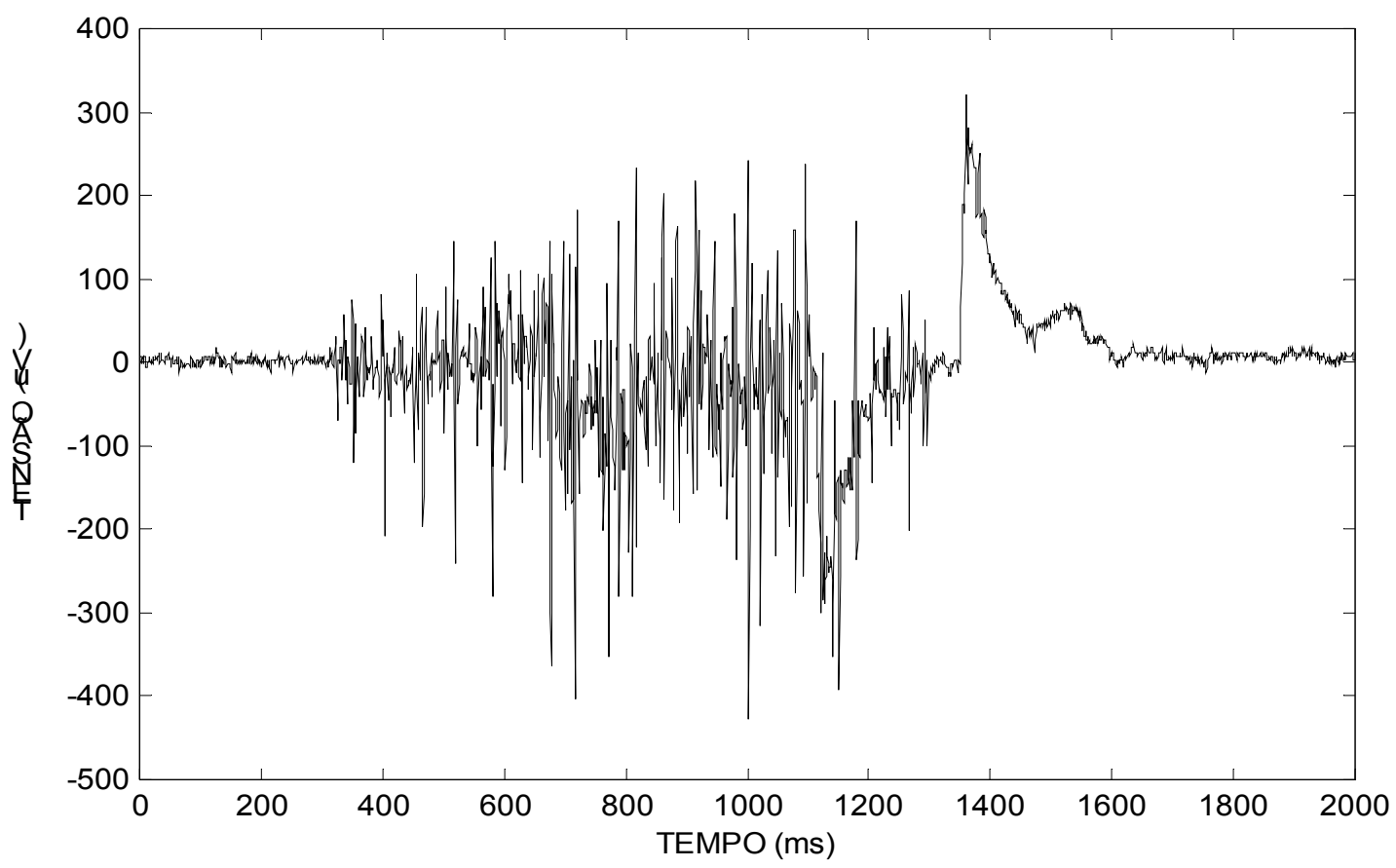

Fig. 36 - Sinal mioelétrico contaminado com ruído de artefato de movimento.

Utilizando a decomposição do sinal pela transformada wavelet, a variação da tensão média foi encontrada no termo de mais baixa frequência do sinal $\left(a_{5}\right)$, com frequências entre $0-16.625 \mathrm{~Hz}$, a componente $a_{5}$ do sinal da figura 36 é apresentada na figura 37. 


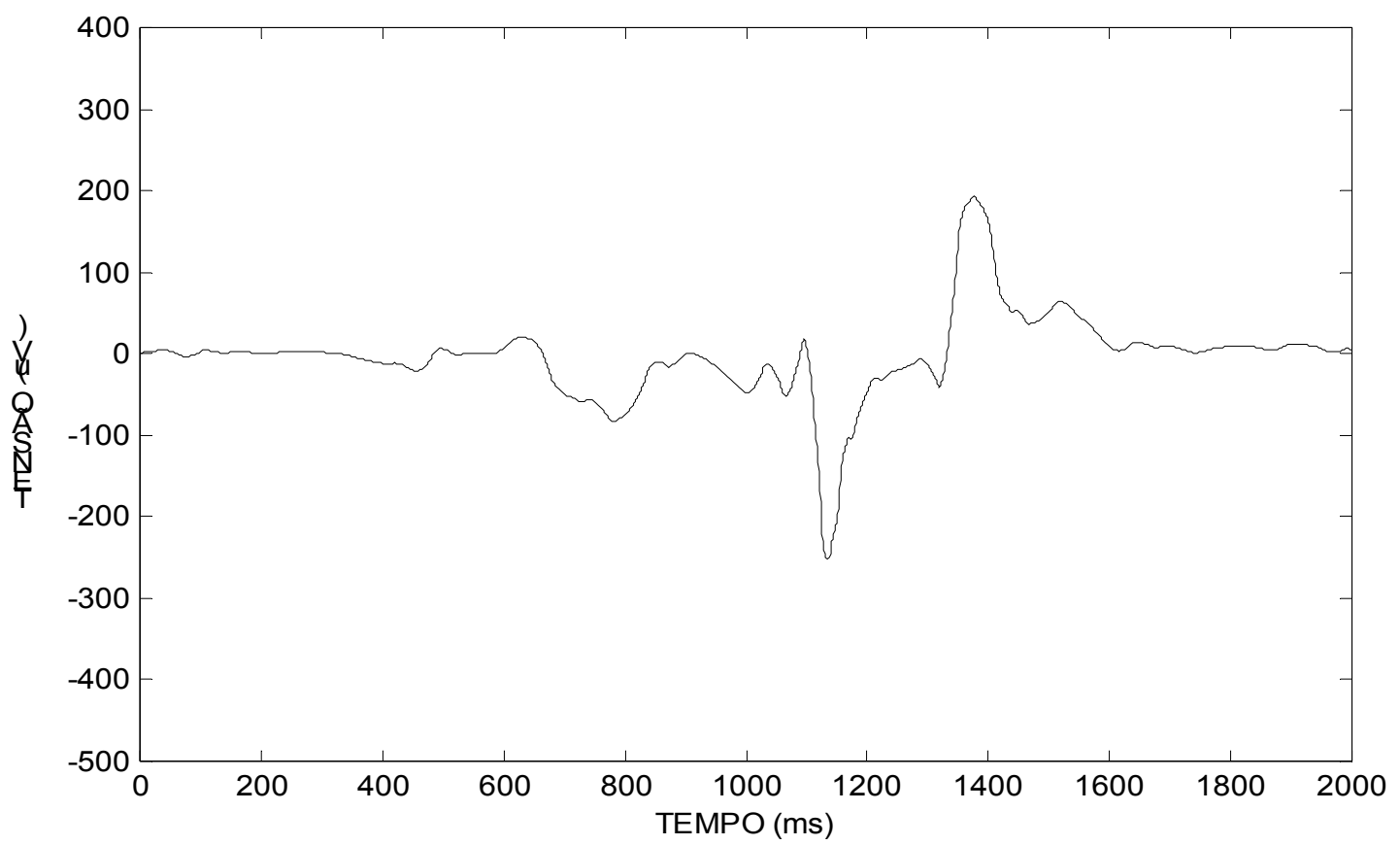

Fig. 37 - Sinal obtido do termo $a_{5}$ da decomposição através da transformada wavelet. Pelas baixas frequências que compõem este sinal pode-se dizer que ele representa a variação da tensão média do sinal ilustrado na figura 36.

Com a finalidade de avaliar a frequência de corte do sistema, foi reconstruído o sinal proveniente das componentes $a_{5}$ e $d_{5}$ da decomposição utilizando a transformada wavelet. Na figura 38 é ilustrado este sinal.

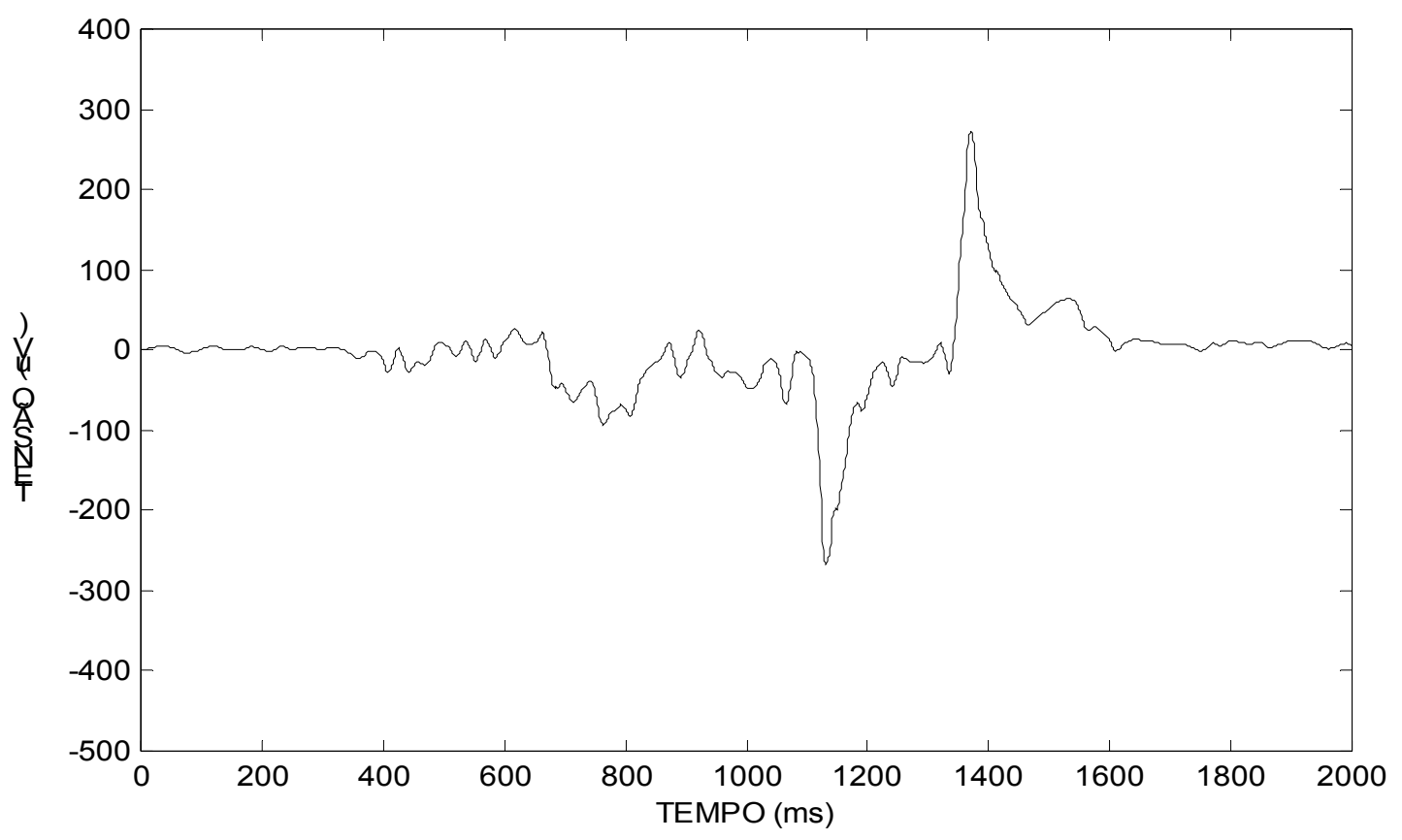

Fig. 38 - Sinal reconstruído com os termos $a_{5}$ e $d_{5}$ da decomposição utilizando a transformada wavelet. Este sinal apresenta componentes frequenciais de 0 a $31.25 \mathrm{~Hz}$ 
Apesar do pico positivo do ruído ser melhor representado no sinal da figura 38, este sinal contêm informações de frequências mais altas que na verdade são características do SME e chegam a ser muito rápidas para representar a variação da tensão média do sinal. Foi então reconstruído, o sinal, utilizando os termos $\mathrm{d}_{1}, \mathrm{~d}_{2}, \mathrm{~d}_{3}, \mathrm{~d}_{4}$ e $\mathrm{d}_{5}$ com o intuito de cancelar a variação da tensão média que o contaminava. Na figura 39 é apresentada esta reconstrução.

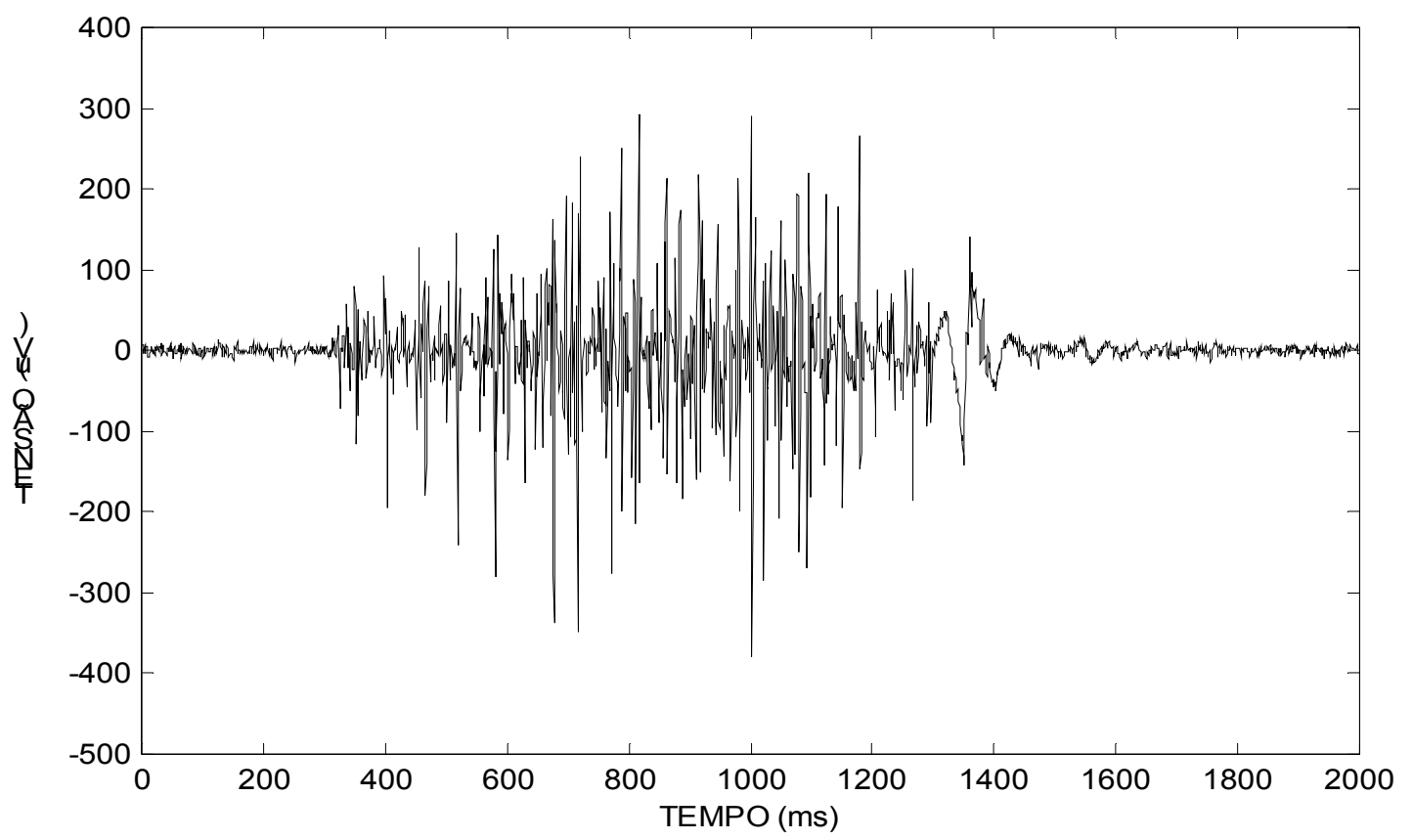

Fig. 39 - SME com ruído de artefato de movimento atenuado, reconstruído com os coeficientes da transformada wavelet $d_{1}, d_{2}, d_{3}, d_{4}$ e $d_{5}$.

Para comparar o desempenho da transformada wavelet com os métodos tradicionais foram realizadas filtragens dos ruídos de artefatos de movimento utilizando um filtro FIR e um filtro IIR. A frequência de corte destes filtros foi de $20 \mathrm{~Hz}$, pois segundo a resposta da reconstrução do sinal utilizando a transformada wavelet, a melhor frequência de corte para filtrar os ruídos dos artefatos de movimento está entre $15.625 \mathrm{~Hz}$ e $31.25 \mathrm{~Hz}$. Além disso, $20 \mathrm{~Hz}$ é o valor indicado para evitar a aquisição do sinal da taxa de disparo das unidades motoras, que são particularmente instáveis em virtude de suas características semi-aleatórias (DELSYS INC., 1996).

O filtro FIR utilizado foi de ordem 100 com janela de Kaiser. A resposta deste filtro para o sinal ruidoso da figura 36 é apresentada na figura 40 . 


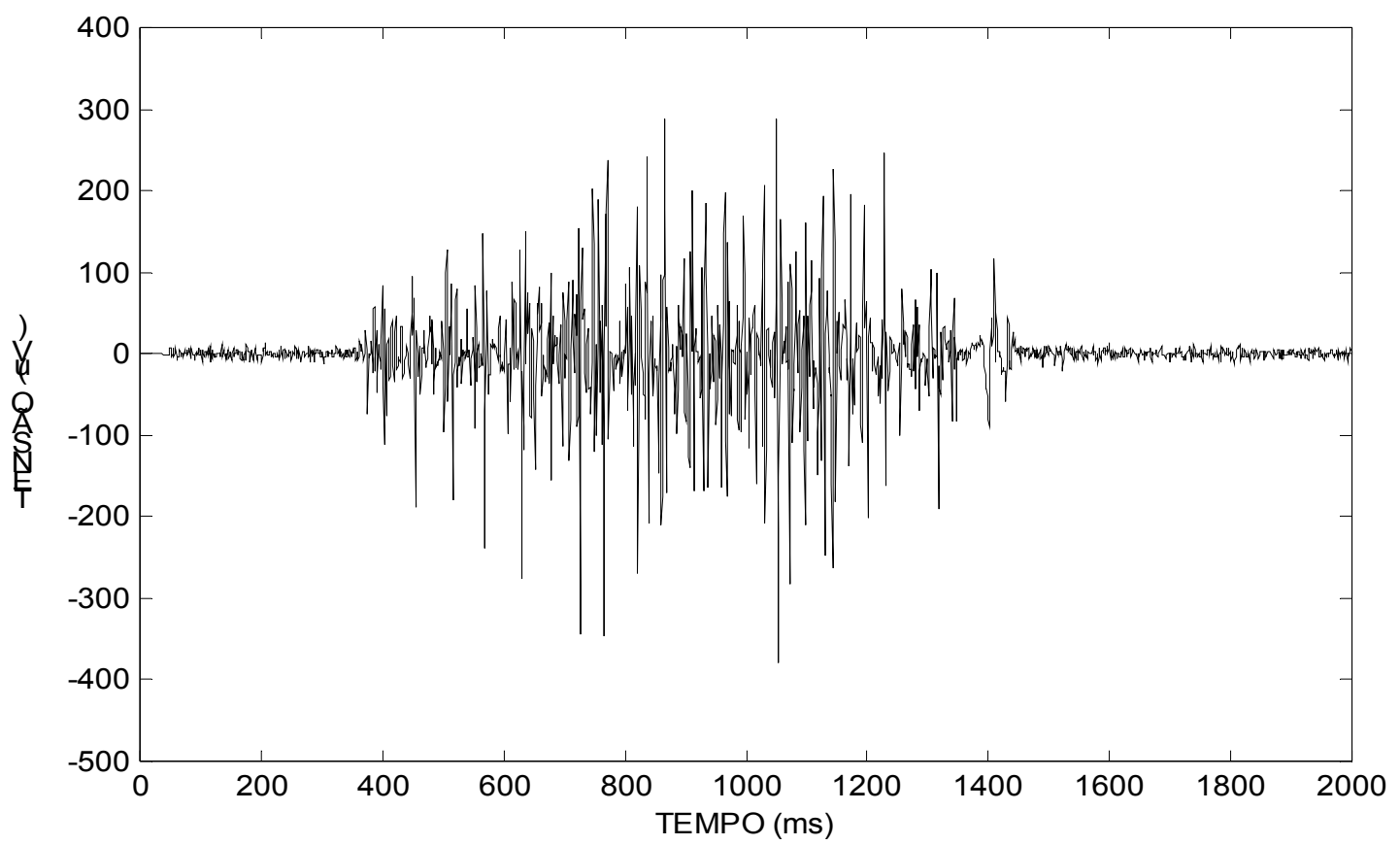

Fig. 40 - Saída do filtro FIR passa alta de ordem 100 (janela de Kaiser) com frequência de corte de $20 \mathrm{~Hz}$. Na entrada do filtro foi aplicado o sinal apresentado na figura 36 .

Foi avaliado também o desempenho de um filtro passa alta de $6^{a}$ ordem IIR chebyshev tipo II com frequência de corte igual a $20 \mathrm{~Hz}$. A figura 41 apresenta a resposta deste filtro quando é aplicado em sua entrada o sinal ilustrado na figura 36 .

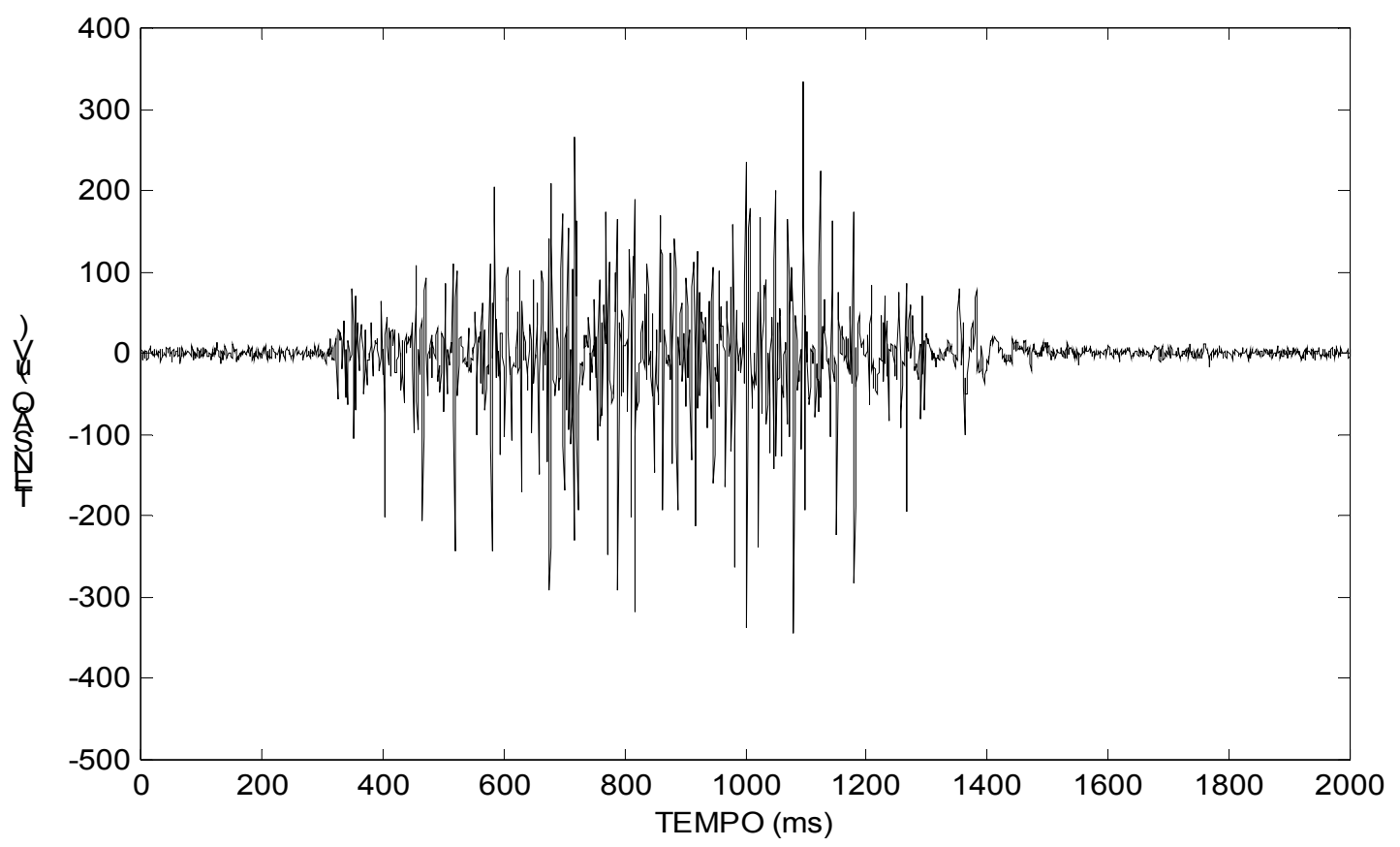

Fig. 41 - Saída do filtro IIR passa alta de $6^{a}$ ordem (Chebyshev tipo II) com frequência de corte de $20 \mathrm{~Hz}$, para o sinal de entrada apresentado na figura 36. 


\subsubsection{Filtragem da Interferência da rede elétrica}

Os resultados da filtragem da interferência da rede elétrica são apresentados conforme a captação do sinal.

$\underline{\text { SME obtido sem ruído e este inserido matematicamente. }}$

Como o SME foi somado a ruídos com três amplitudes diferentes, foram obtidas as seguintes relações sinal-ruído para o sinal a ser filtrado: $1.99 \mathrm{~dB},-18 \mathrm{~dB}$ e $-38 \mathrm{~dB}$. Aplicando estes sinais na entrada dos filtros adaptativos foram feitos testes fixando a SNR desejada e observando os parâmetros dos filtros, e vice versa.

Primeiramente foi encontrada a melhor relação sinal-ruído, na saída dos filtros adaptativos, que foi de aproximadamente $17 \mathrm{~dB}$.

A tabela 2 apresenta as médias das SNR nas saídas dos filtros para os algoritmos LMS e RLS. É interessante observar que a respostas do cancelador de ruído adaptativo e do cancelador de ruído proposto por Widrow apresentaram respostas praticamente iguais quando o algoritmo de adaptação utilizado é o mesmo (LMS ou RLS).

Tab. 2 - Melhor relação sinal ruído alcançada nas saídas dos filtros adaptativos, a SNR de entrada foi de $1.99 \mathrm{~dB},-18 \mathrm{~dB}$ e $-38 \mathrm{~dB}$.

\begin{tabular}{|c|c|c|}
\hline Algoritimo & LMS & RLS \\
\hline SNR & $\sim 16.4 \mathrm{~dB}$ & $\sim 17.5 \mathrm{~dB}$ \\
\hline
\end{tabular}

Para alcançar a resposta de acordo com a tabela 2 foram utilizados os parâmetros indicados na tabela 3 .

Tab. 3 - Parâmetros utilizados nos filtros, para atingir as SNRs descritas na tabela 2

\begin{tabular}{|c|c|c|c|c|}
\hline Filtro & $\begin{array}{c}\text { Adaptivo } \\
\text { LMS }\end{array}$ & $\begin{array}{c}\text { Proposto por } \\
\text { Widrow LMS }\end{array}$ & $\begin{array}{c}\text { Adaptivo } \\
\text { RLS }\end{array}$ & $\begin{array}{c}\text { Proposto por } \\
\text { Widrow RLS }\end{array}$ \\
\hline $\begin{array}{c}M \\
\text { (No de Coeficientes) }\end{array}$ & 15 & 12 & 2 & 1 \\
\hline Parâmetros & $\mu=\frac{\mathbf{0 . 0 0 3}}{\lambda_{\max }}$ & $\mu=\frac{\mathbf{0 . 0 0 6}}{\lambda_{\max }}$ & $\gamma=\mathbf{0 . 9 9 5}$ & $\gamma=\mathbf{0 . 9 9 5}$ \\
\hline
\end{tabular}


A outra avaliação dos filtros adaptativos foi realizada fixando o número de coeficientes $(M)$ dos filtros em 5 para os canceladores de ruído adaptativo e 1 para os canceladores de ruído como proposto por Widrow. As médias das relações sinal-ruído obtidas para cada configuração são apresentadas na tabela 4.

Tab. 4 - Relações Sinal Ruído das saídas dos filtros adaptativos com características iguais

\begin{tabular}{|c|c|c|c|c|}
\hline Filtro & $\begin{array}{c}\text { Adaptativo } \\
\text { LMS }\end{array}$ & $\begin{array}{c}\text { Proposto por } \\
\text { Widrow LMS }\end{array}$ & $\begin{array}{c}\text { Adaptativo } \\
\text { RLS }\end{array}$ & $\begin{array}{c}\text { Proposto por } \\
\text { Widrow RLS }\end{array}$ \\
\hline SNR & $\sim \mathbf{8 . 2} \mathbf{d B}$ & $\sim \mathbf{1 2 . 5 1} \mathbf{d B}$ & $\sim \mathbf{1 0 . 2 3} \mathbf{d B}$ & $\sim \mathbf{1 4 . 2} \mathbf{~ d B}$ \\
\hline Parâmetros & $\mu=\frac{\mathbf{0 . 0 2}}{\lambda_{\max }}$ & $\mu=\frac{\mathbf{0 . 0 2}}{\lambda_{\max }}$ & $\gamma=\mathbf{0 . 9 9}$ & $\gamma=\mathbf{0 . 9 9}$ \\
\hline
\end{tabular}

A seguir são apresentadas as respostas dos canceladores de ruído adaptativo conforme proposto por Widrow com $M=1$ e algoritmos LMS e RLS para um sinal mioelétrico arbitrário.

A figura 42 ilustra um SME obtido sem a interferência da rede elétrica.

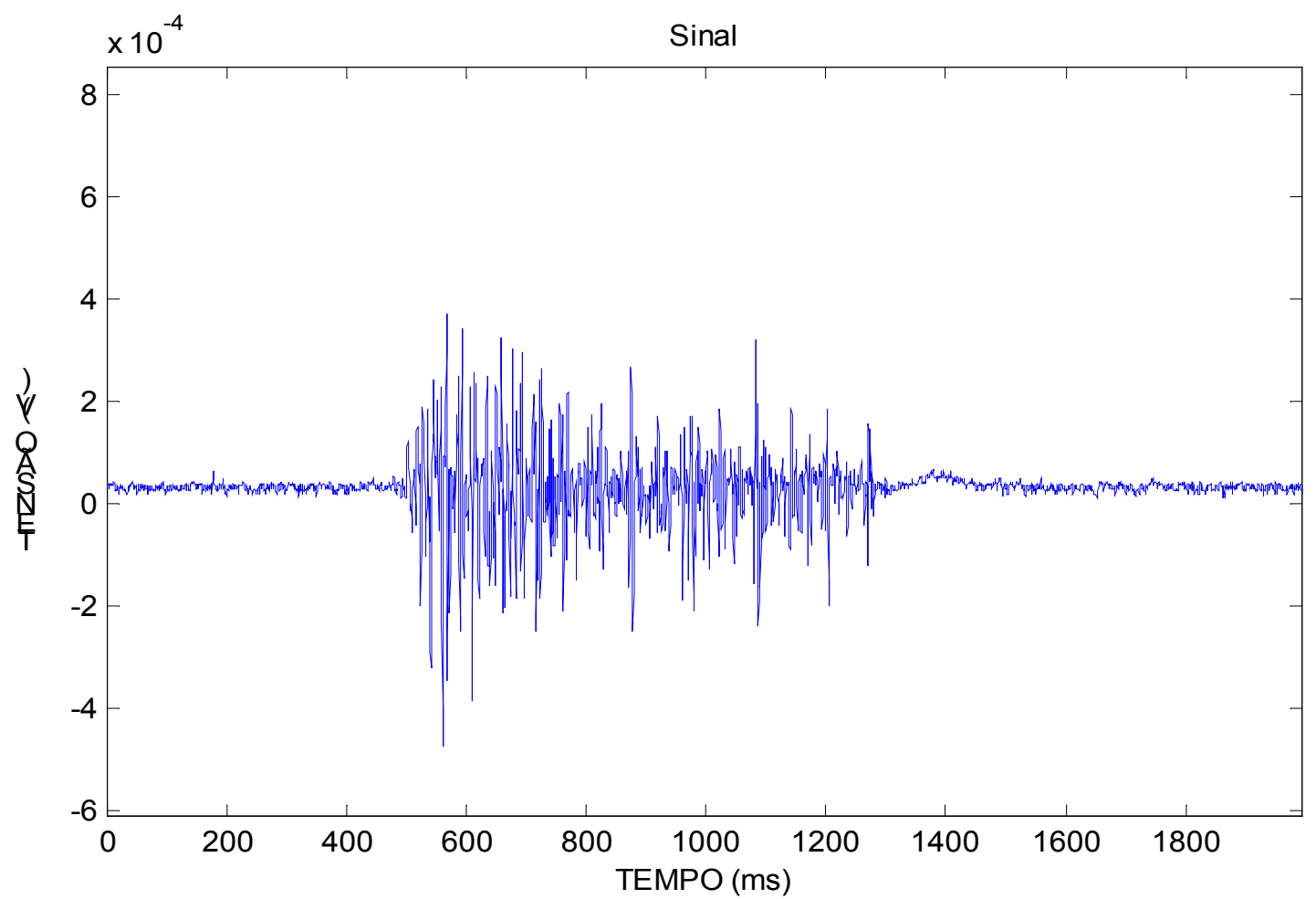

Fig. 42 - SME do grupo extensor do punho obtido durante extensão, $x(k)$. 
Na figura 43 é apresentado o SME contaminado com um ruído da rede elétrica de amplitude igual à máxima amplitude do SME (SNR = -18 dB).

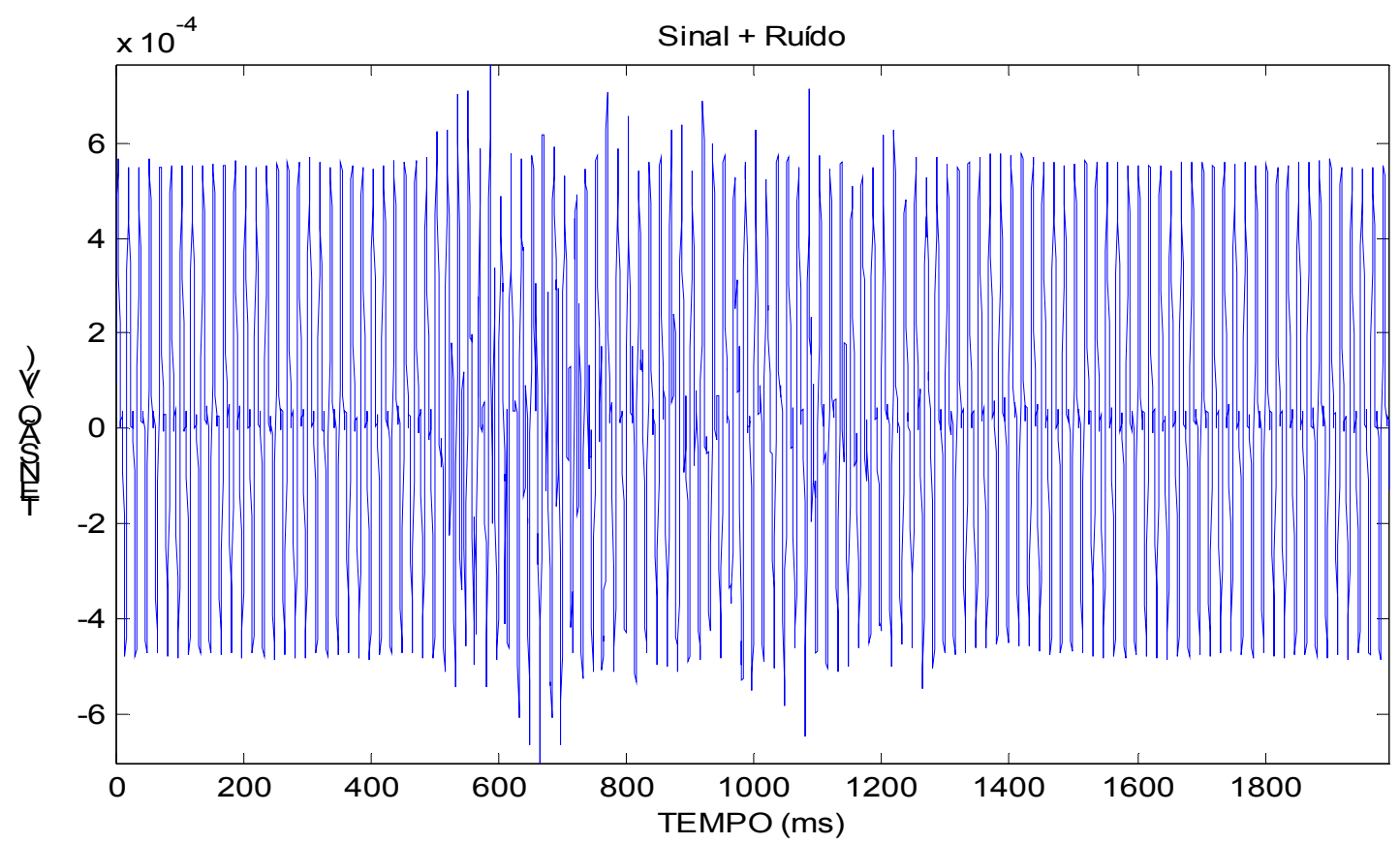

Fig. 43 - SME da figura 42 com um ruído da rede adicionado, $x(k)=s(k)+n(k)$, obtendo uma SNR de $-18 \mathrm{~dB}$.

Foi então gerado um sinal de referência com as frequência de $60 \mathrm{~Hz}$ e $120 \mathrm{~Hz}$ com fases e amplitudes aleatórias conforme ilustrado na figura 44.

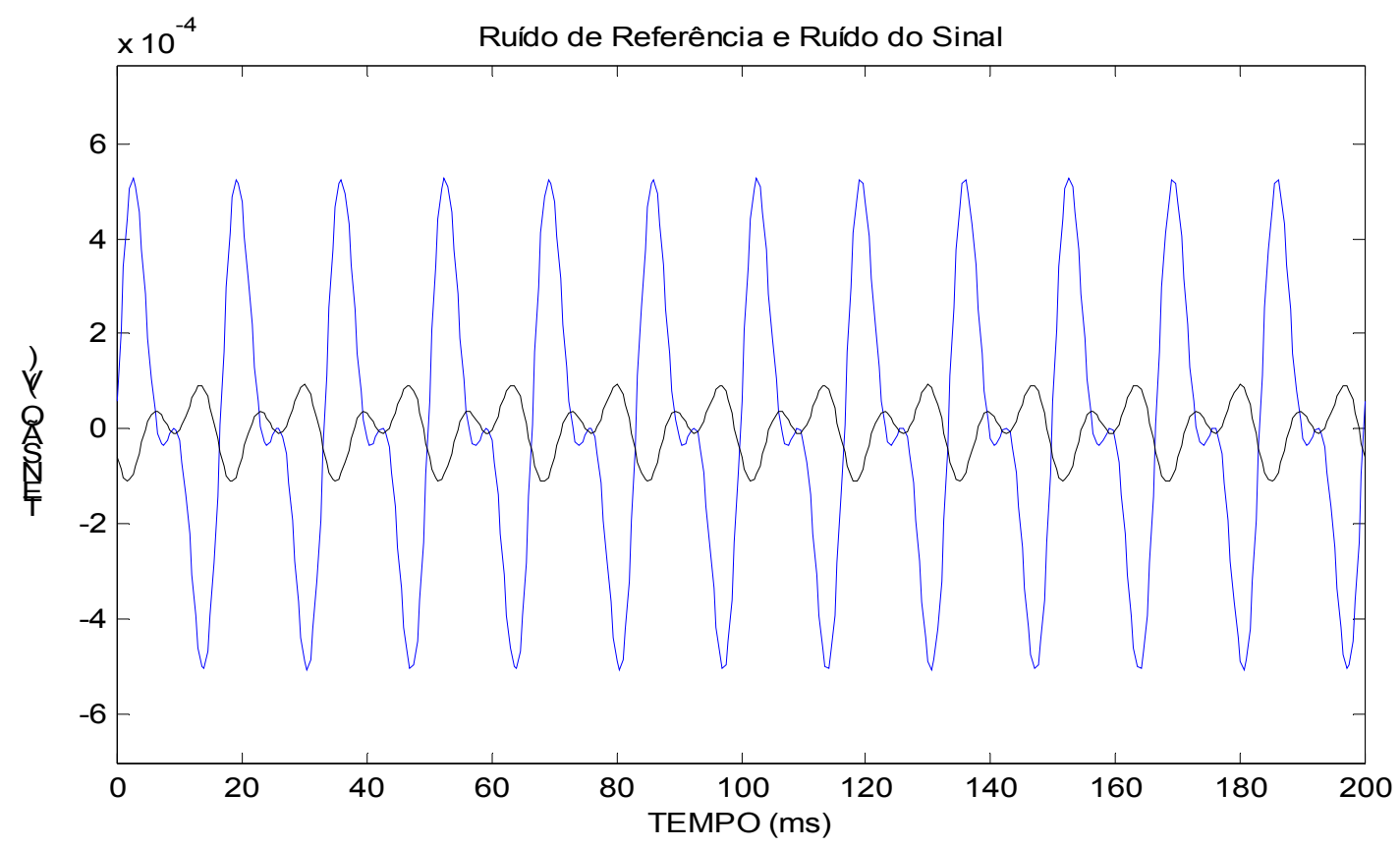

Fig. 44 - Em azul: o ruído da rede elétrica inserido no SME, $n(k)$, e em preto o sinal de referência, $r(k)$, gerado com $60 \mathrm{~Hz}$ e $120 \mathrm{~Hz}$ com valores de fase e amplitude aleatórios. 
Utilizando o algoritmo LMS foi então obtida a estimativa do ruído, $\tilde{n}(k)$. Na figura 45 é ilustrado o início de uma estimativa de $\tilde{n}(k)$ ao passo que o filtro adapta seus parâmetros.

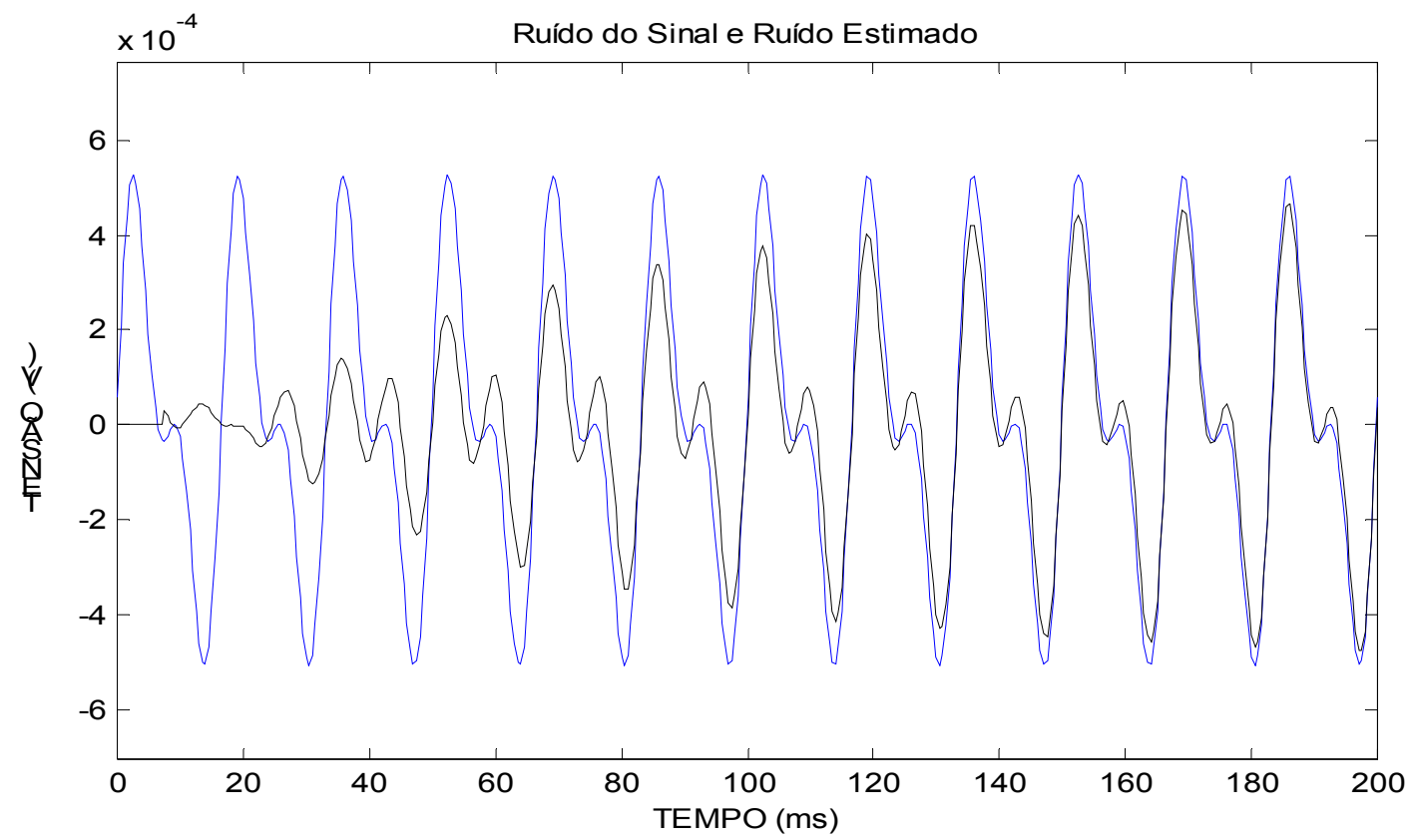

Fig. 45 - Em preto: o início do sinal estimado pelo algoritmo LMS, $\tilde{n}(k)$, se aproximando do ruído, $n(k)$, representado em azul.

Na figura 46 é apresentada o SME e a resposta do filtro adaptativo com algoritmo LMS para o sinal ruidoso da figura 43.

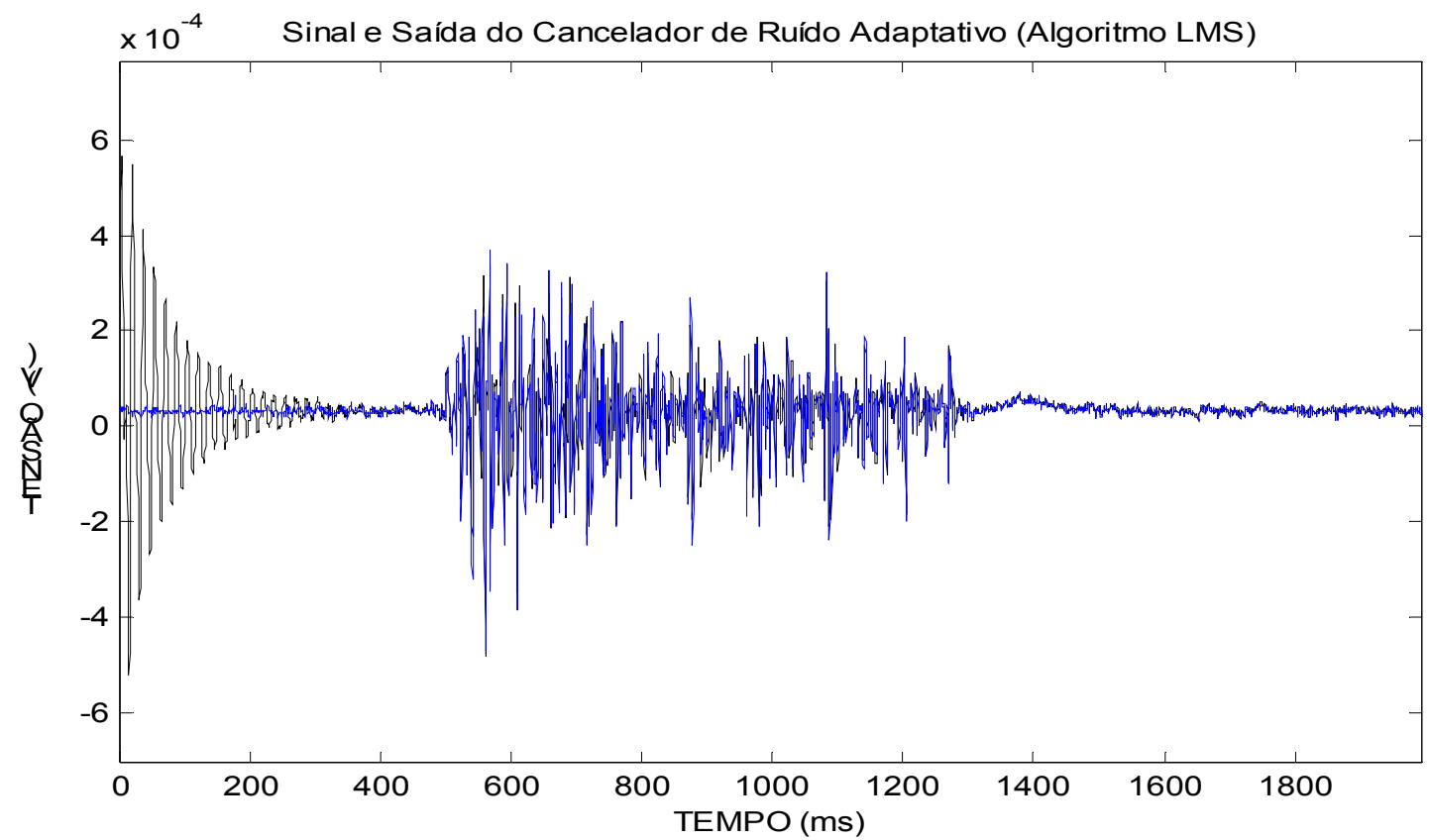

Fig. 46 - Em azul: sinal mioelétrico, $s(k)$. Em preto: saída do cancelador de ruído adaptativo com algoritmo LMS, $y(k)$. 
Na figura 47 são apresentados o SME e a resposta do filtro durante os 200 ms iniciais da contração, referentes ao período determinístico do sinal.

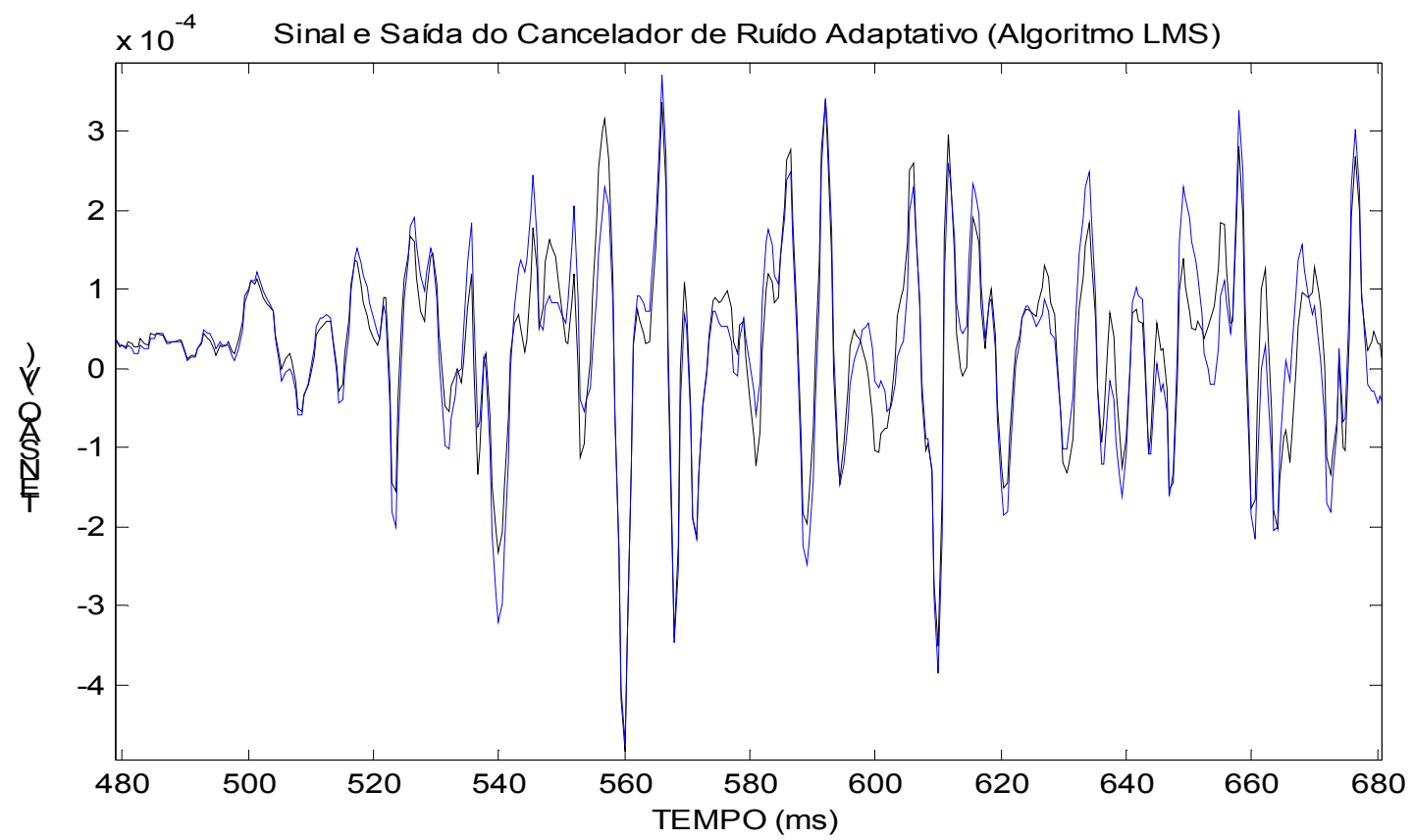

Fig. 47 - Em azul: sinal mioelétrico, $s(k)$. Em preto: saída do cancelador de ruído adaptativo utilizando o algoritmo LMS, $y(k)$, durante os $\mathbf{2 0 0} \mathbf{~ m s}$ iniciais de contração.

Na figura 48 é apresentado um intervalo de uma estimativa do ruído, $\tilde{n}(k)$, se aproximando do ruído, $n(k)$, ao passo que o filtro confeccionado com o algoritmo RLS adapta seus parâmetros.

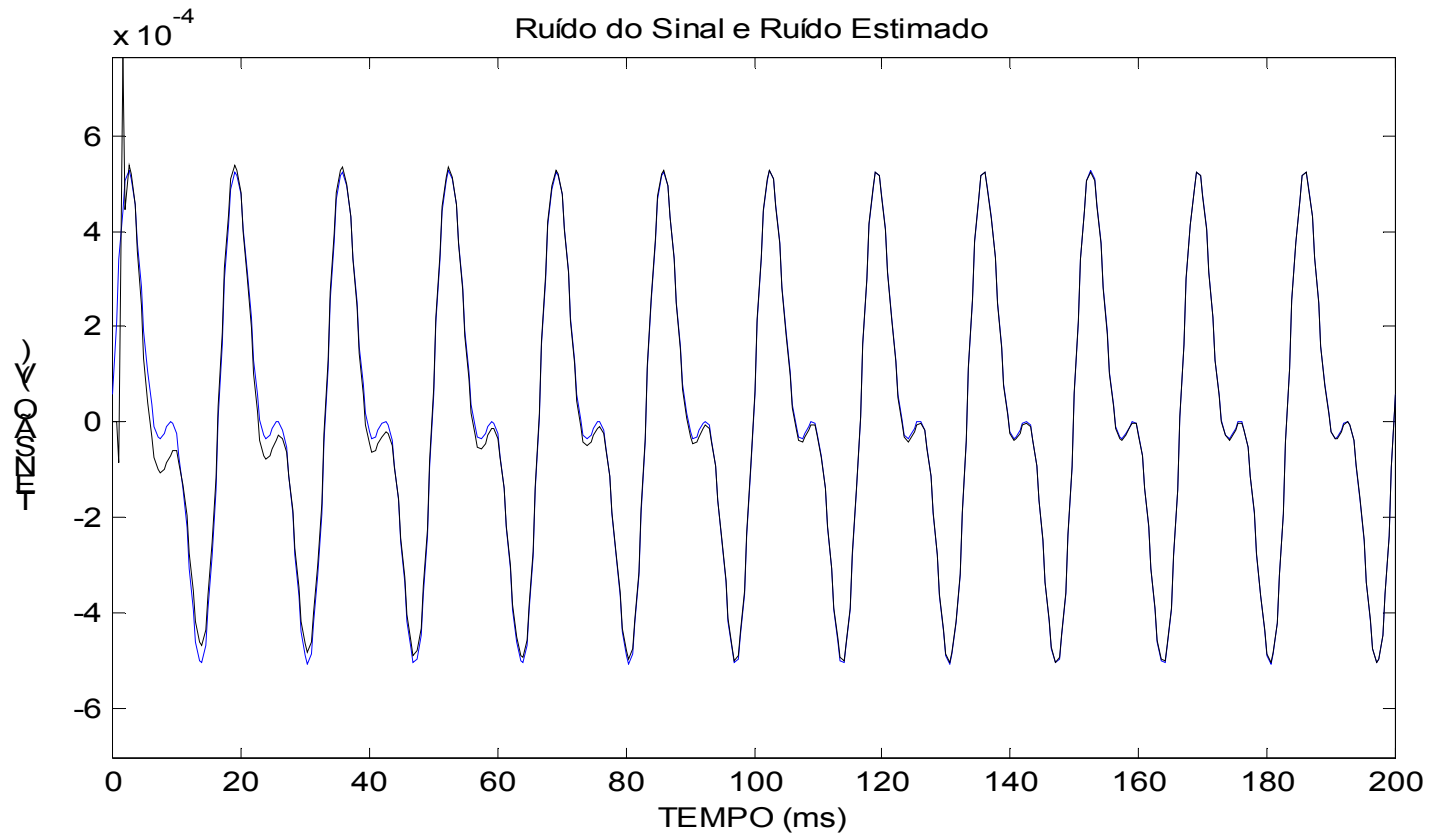

Fig. 48 - Em preto: Início do sinal estimado pelo filtro com algoritmo RLS, $\tilde{n}(k)$, se aproximando do ruído, $n(k)$, apresentado em azul. 
Na figura 49 é apresentada a resposta do filtro com algoritmo RLS, $y(k)$, juntamente com o sinal mioelétrico.

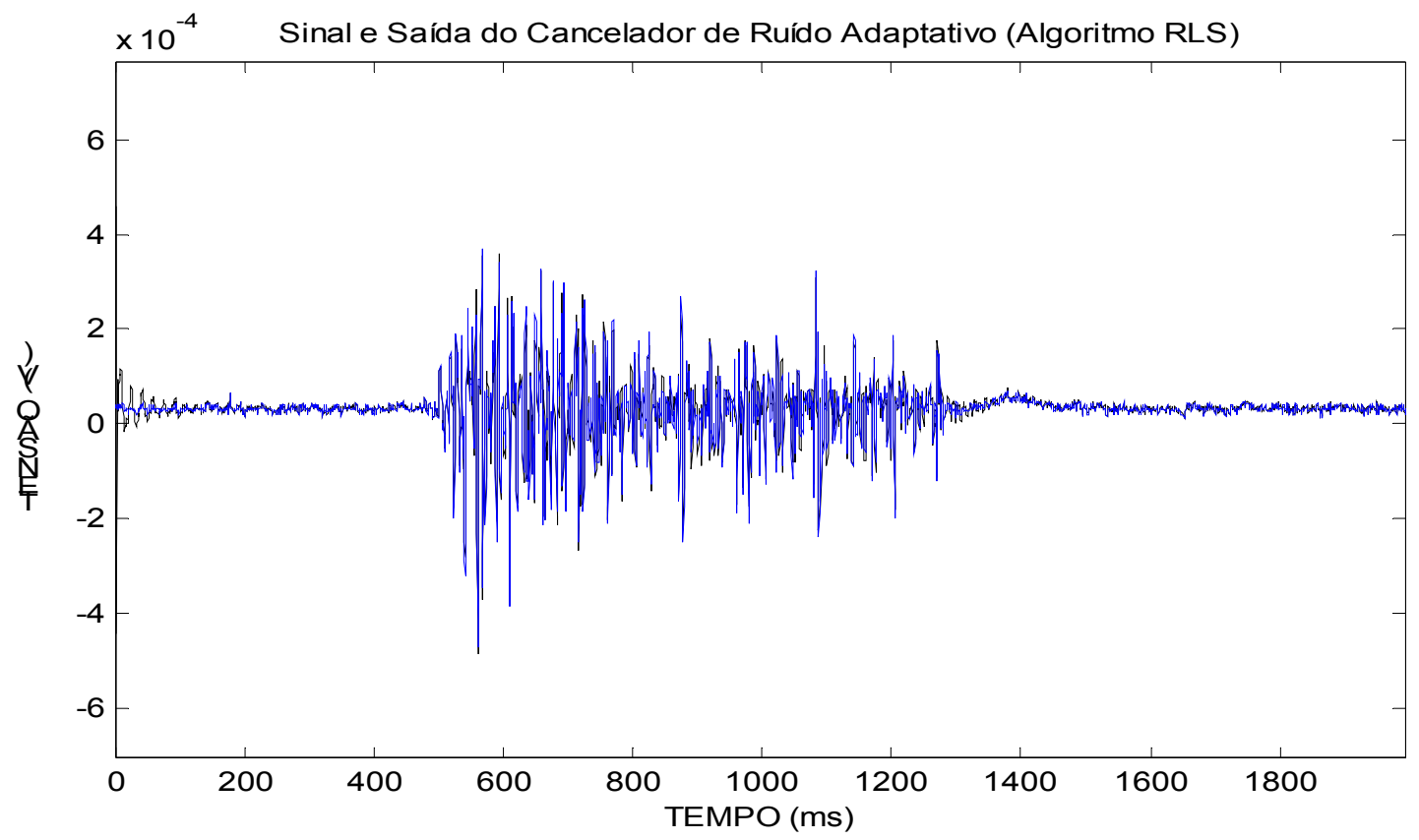

Fig. 49 - Em azul: sinal mioelétrico, $s(k)$. Em preto: saída do cancelador de ruído adaptativo com algoritmo RLS, $y(k)$.

$\mathrm{Na}$ figura 50 são apresentados o SME e a resposta do filtro com algoritmo RLS durante os $200 \mathrm{~ms}$ iniciais da contração, referentes ao período determinístico do sinal.

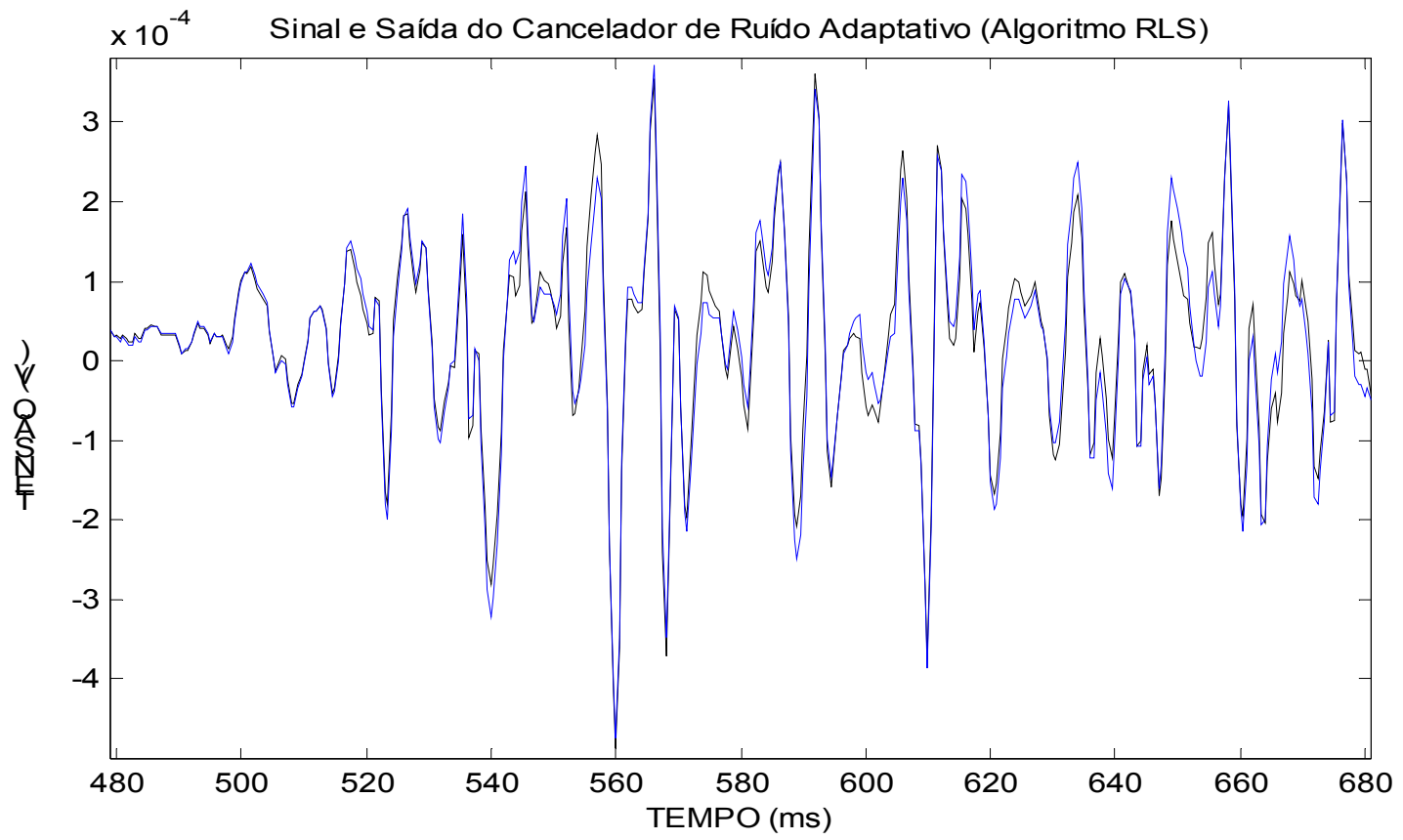

Fig. 50 - Em azul: SME, $s(k)$. Em preto: saída do cancelador de ruído adaptativo utilizando o algoritmo RLS, $y(k)$, durante o inicio da contração. 


\section{SME obtido com o ruído da rede elétrica}

Um dos sinais mioelétricos obtidos com o ruído da rede está apresentado na figura 32. Na figura 51 é apresentada a DFT deste sinal.

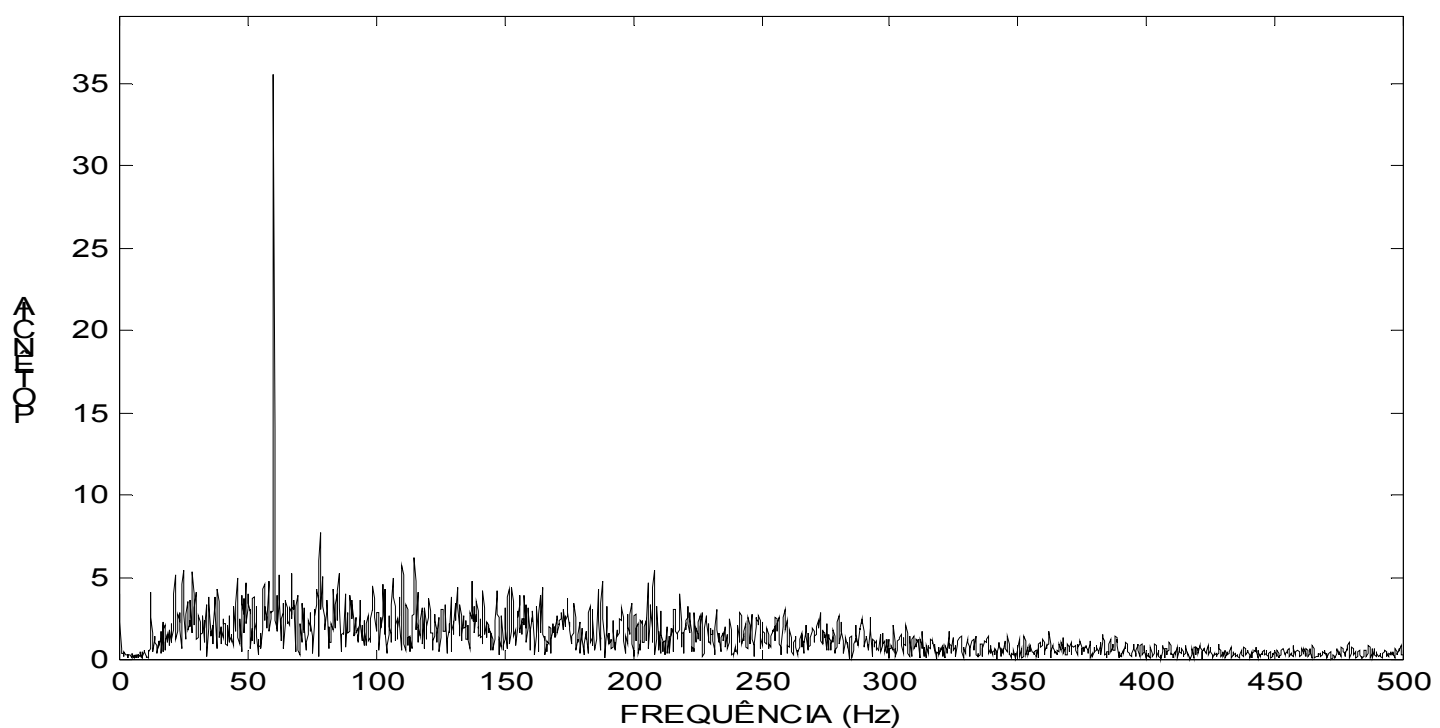

Fig. 51 - DFT do SME contaminado com ruído da rede elétrica apresentado na fig. 32.

Como já foram apresentados os resultados da comparação entre os filtros adaptativos utilizando o sinal captado sem a interferência da rede, então será apresentada aqui a resposta de apenas um dos filtros adaptativos a fim de comparar seu desempenho com as outras técnicas de filtragem. $\mathrm{Na}$ figura 52 é apresentada a resposta do cancelador de ruído adaptativo com algoritmo RLS e parâmetros de acordo com a tabela 3.

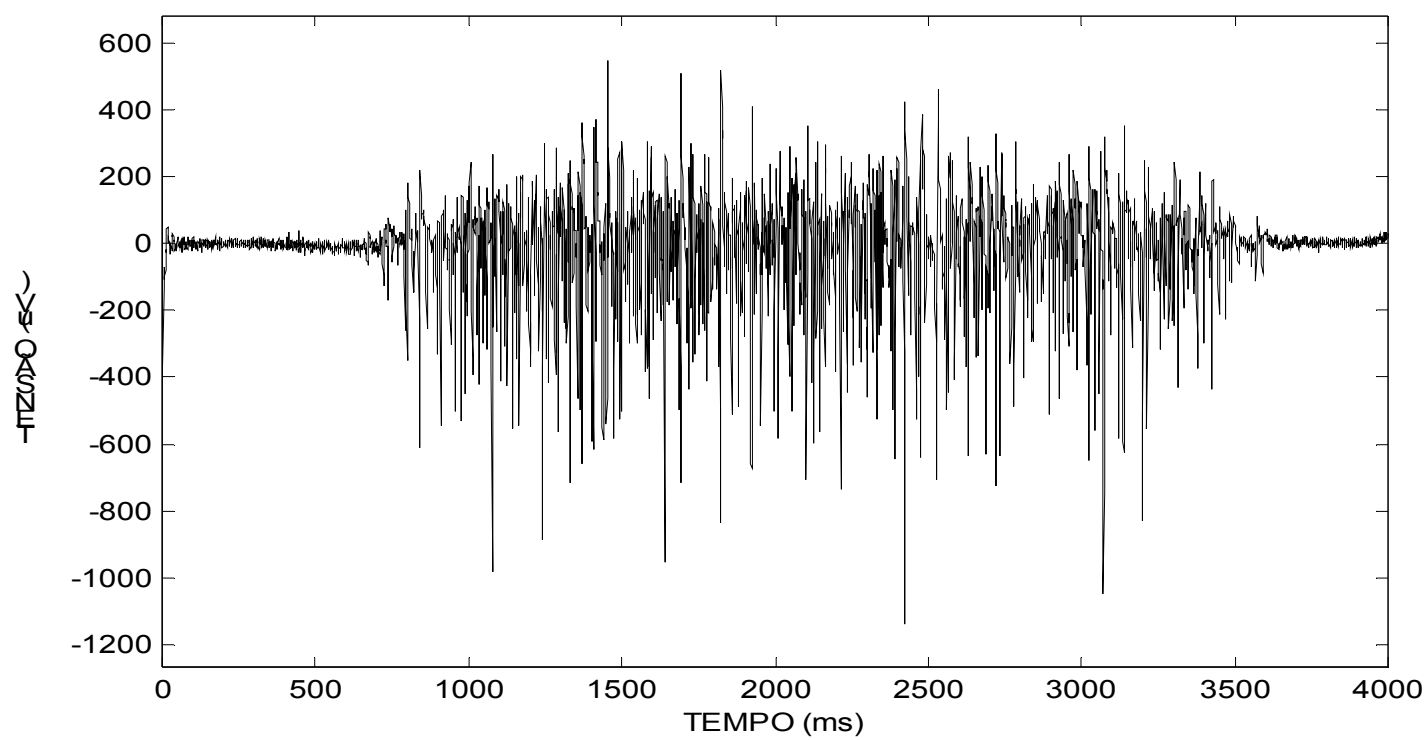

Fig. 52 - Resposta do cancelador de ruído adaptativo com os parâmetros indicados na tabela 3. O sinal aplicado no filtro é o sinal apresentado na figura 32. 
$\mathrm{Na}$ figura 53 é apresentada a DFT do SME contaminado com a interferência da rede (sinal tracejado) e a resposta da filtragem adaptativa (sinal contínuo), na região próxima à frequência de ressonância do filtro.

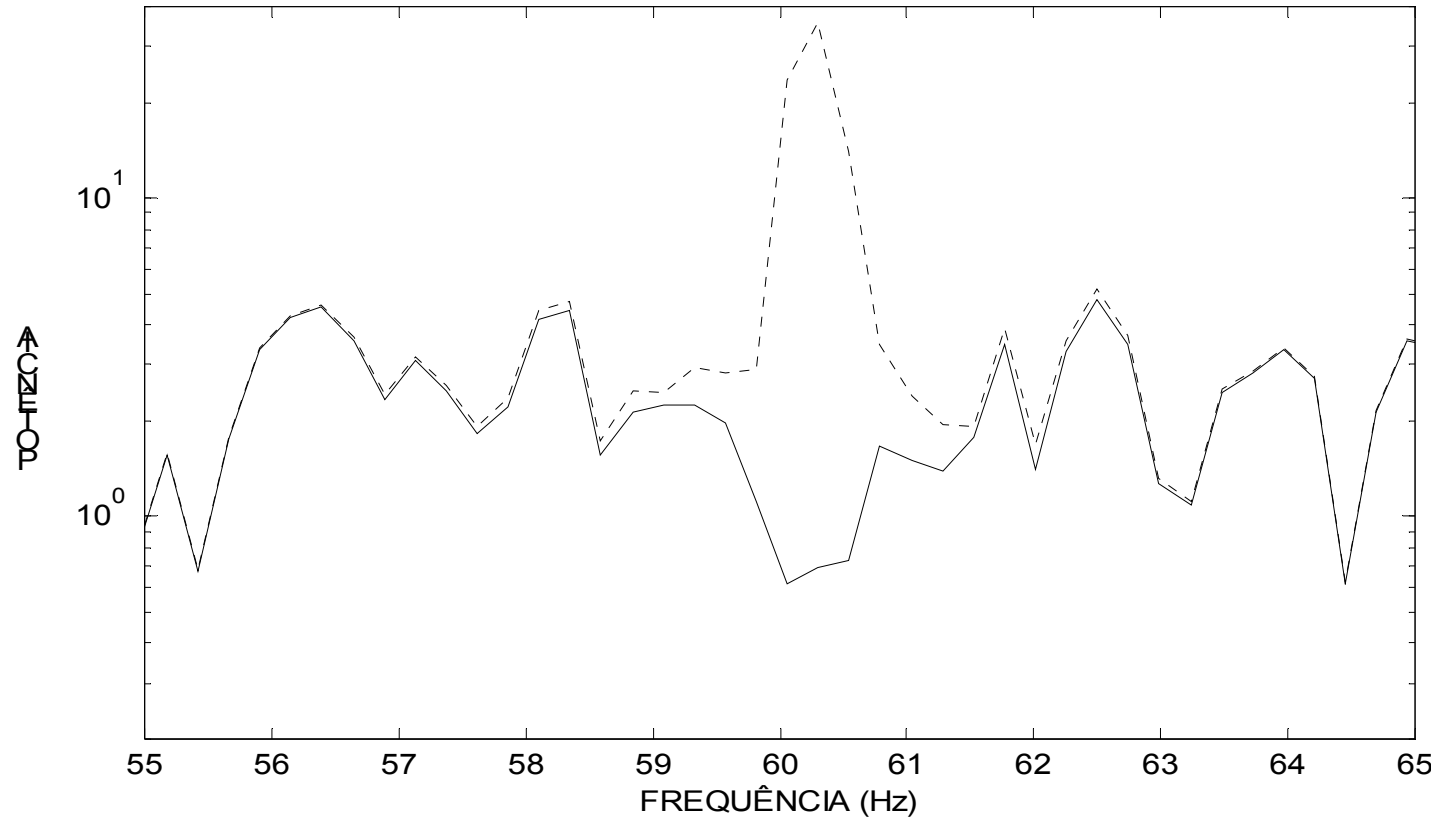

Fig. 53 - DFT do SME contaminado com a interferência da rede (sinal tracejado) e a resposta da filtragem adaptativa (sinal contínuo) próximos à região da frequência de ressonância.

A resposta em frequência do Filtro FIR, de $664^{a}$ ordem com janela de Kaiser, utilizado para atenuar o ruído da rede é apresentada na figura 54.
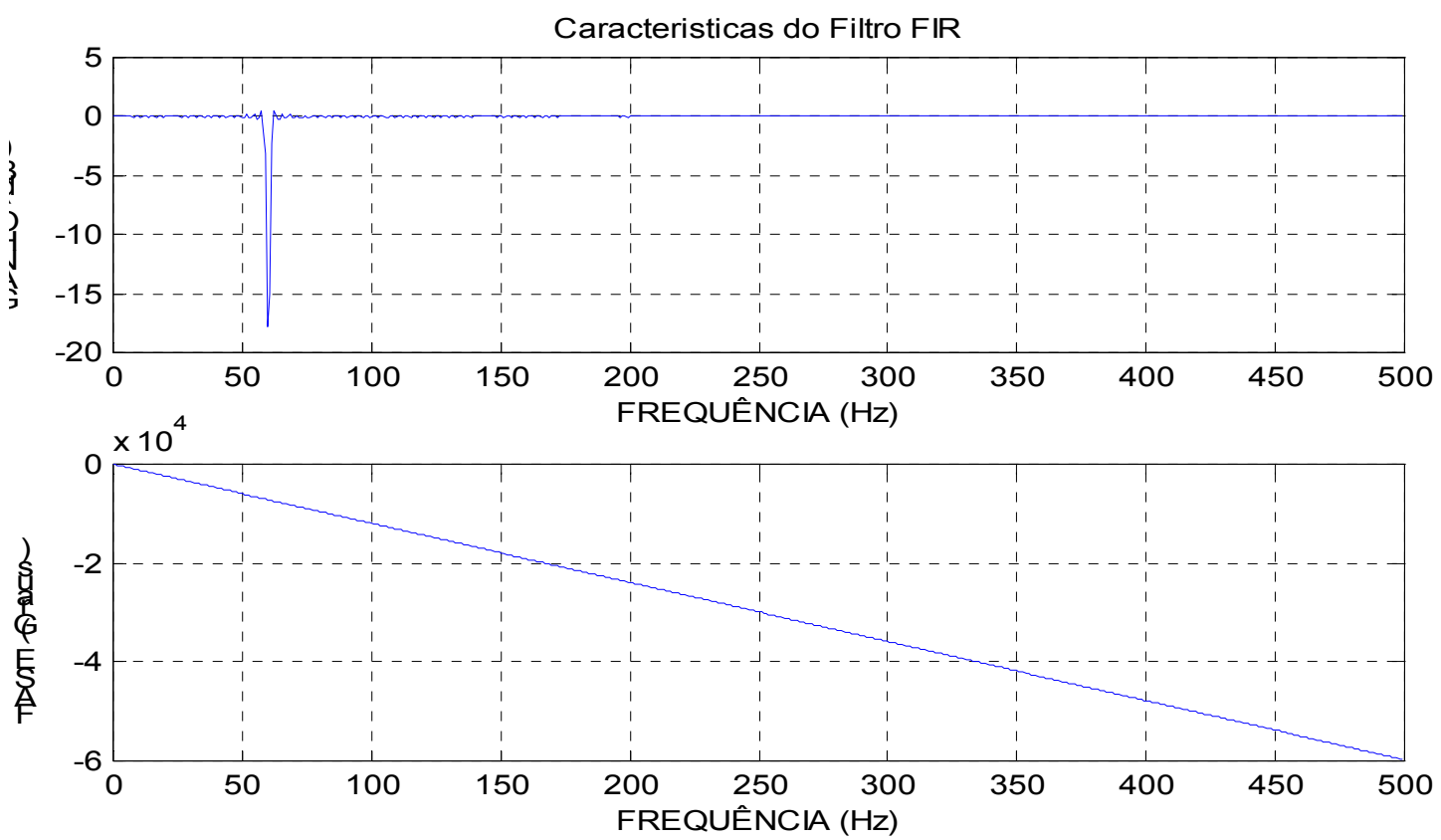

Fig. 54 - Resposta frequencial ao impulso, do filtro FIR notch de $664^{\mathrm{a}}$ ordem com janela de Kaiser. 
Na figura 55 é apresentado o sinal de saída do filtro FIR, com resposta conforme figura 54, quando é aplicado a sua entrada o SME contaminado com ruído ilustrado na figura 32. É interessante observar o atraso no sinal de 664 amostras (1 amostra em cada ms) referente à ordem do filtro utilizada.

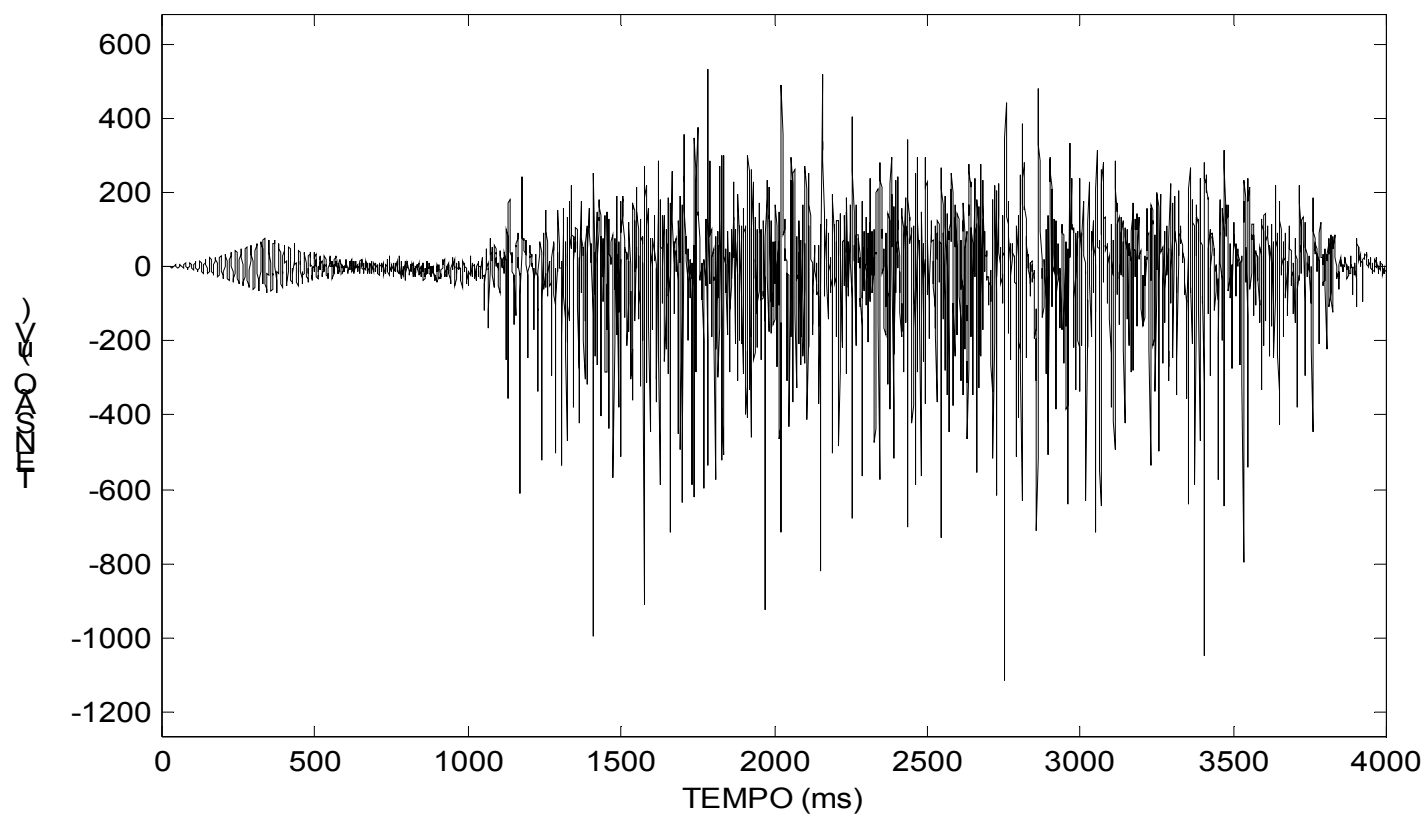

Fig. 55 - Resposta do filtro FIR notch de $664^{\mathrm{a}}$ ordem com janela de Kaiser para o sinal de entrada descrito na figura 32.

Na figura 56 é apresentada a DFT do SME contaminado com a interferência da rede (sinal tracejado) e a resposta do filtro FIR (sinal contínuo), na região próxima à frequência de ressonância do filtro.

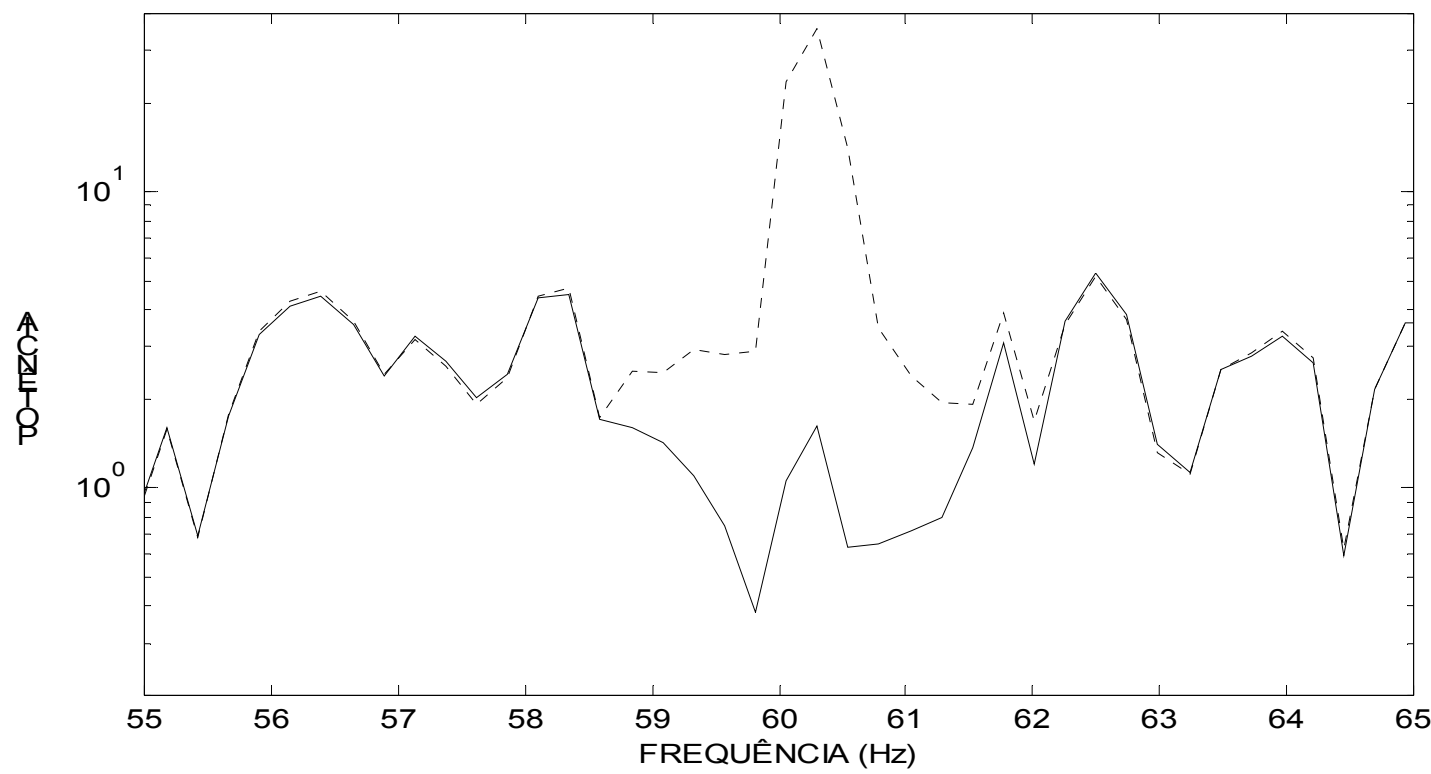

Fig. 56 - DFT do SME contaminado com a interferência da rede (sinal tracejado) e a saída do filtro FIR (sinal contínuo) próximos à frequência de ressonância. 
A figura 57 apresenta a resposta em frequência do filtro notch de $2^{a}$ ordem IIR, chebyshev tipo II. Note a não linearidade na resposta da fase.
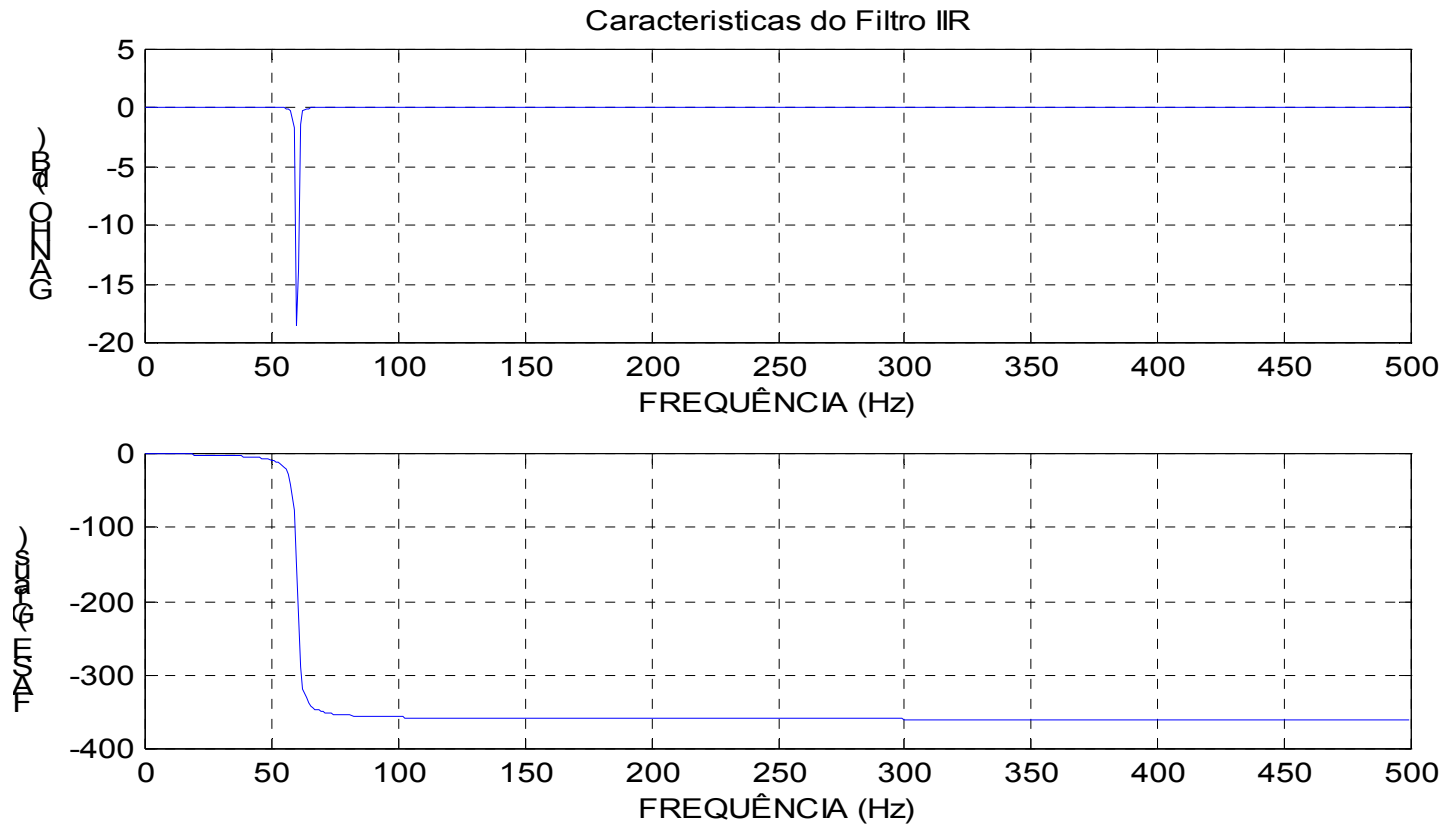

Fig. 57 - Resposta frequencial ao impulso. Filtro de $2^{\text {a }}$ ordem IIR Chebishev tipo II.

Na figura 58 é apresentado o sinal de saída do filtro IIR, com resposta conforme figura 57, quando é aplicado a sua entrada o SME contaminado com ruído ilustrado na figura 32.

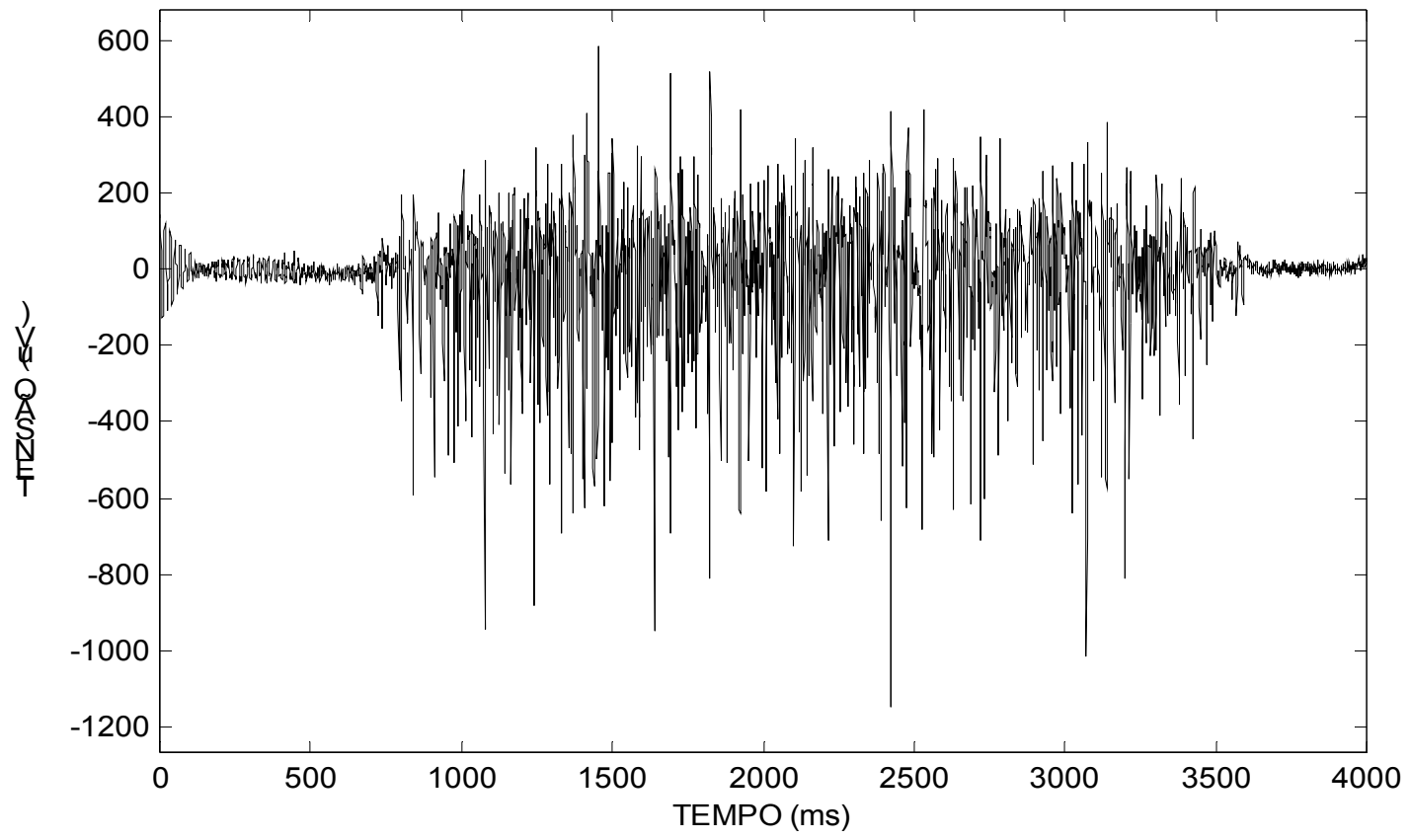

Fig. 58 - Resposta do filtro notch de $2^{a}$ ordem IIR chebishev tipo II para o sinal de entrada descrito na figura 32 . 
Na figura 59 é apresentada a DFT do SME contaminado com a interferência da rede (sinal tracejado) e a resposta do filtro IIR (sinal contínuo), na região próxima a frequência de ressonância do filtro.

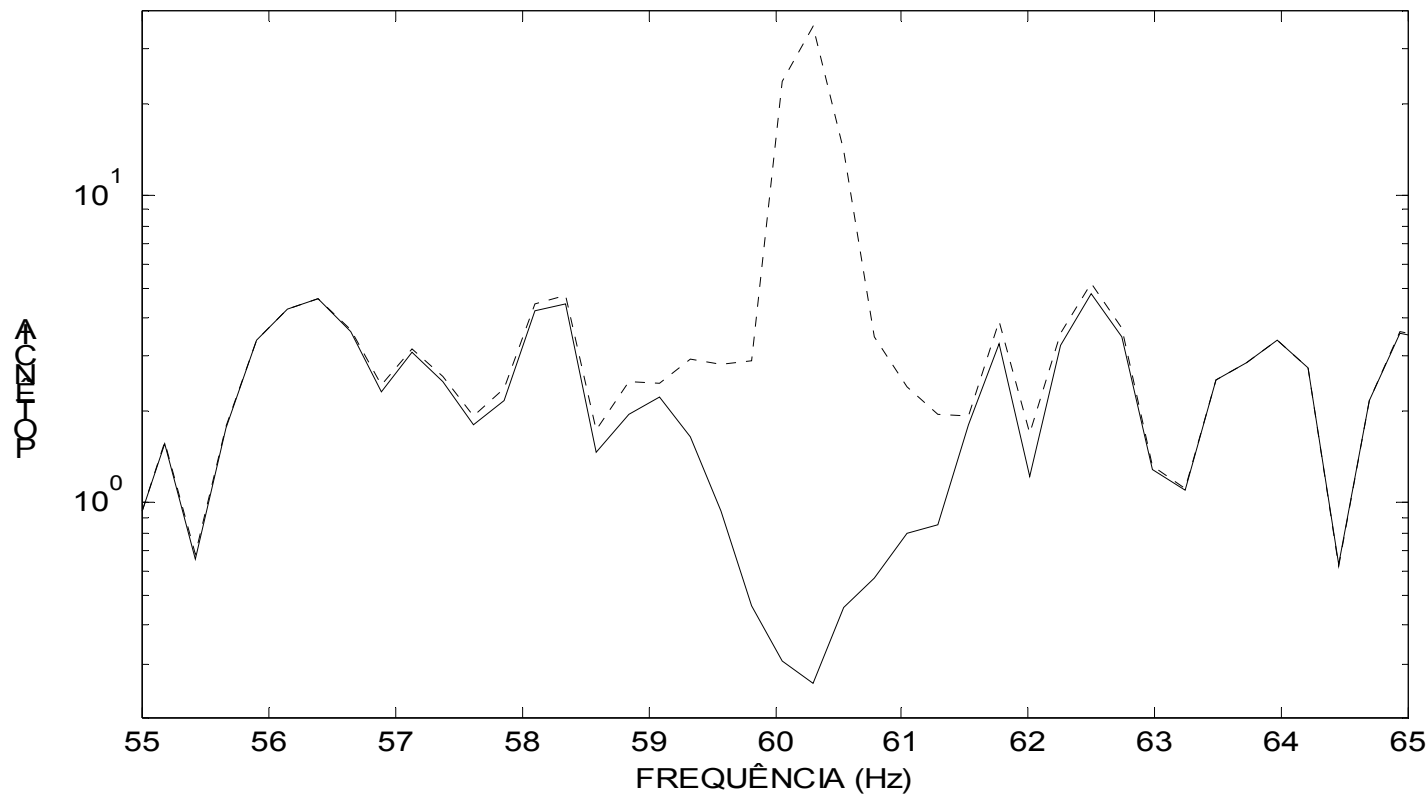

Fig. 59 - DFT do SME contaminado com a interferência da rede (sinal tracejado) e a saída do filtro IIR (sinal contínuo) próximos à frequência de ressonância.

A figura 60 apresenta a reconstrução do sinal ulilizando as componentes $(4,0),(5,3),(6,5),(6,13),(5,7),(4,2),(2,1)$ e $(1,1)$ da transformada wavelet, com a árvore de decomposição ilustrada na figura 33.

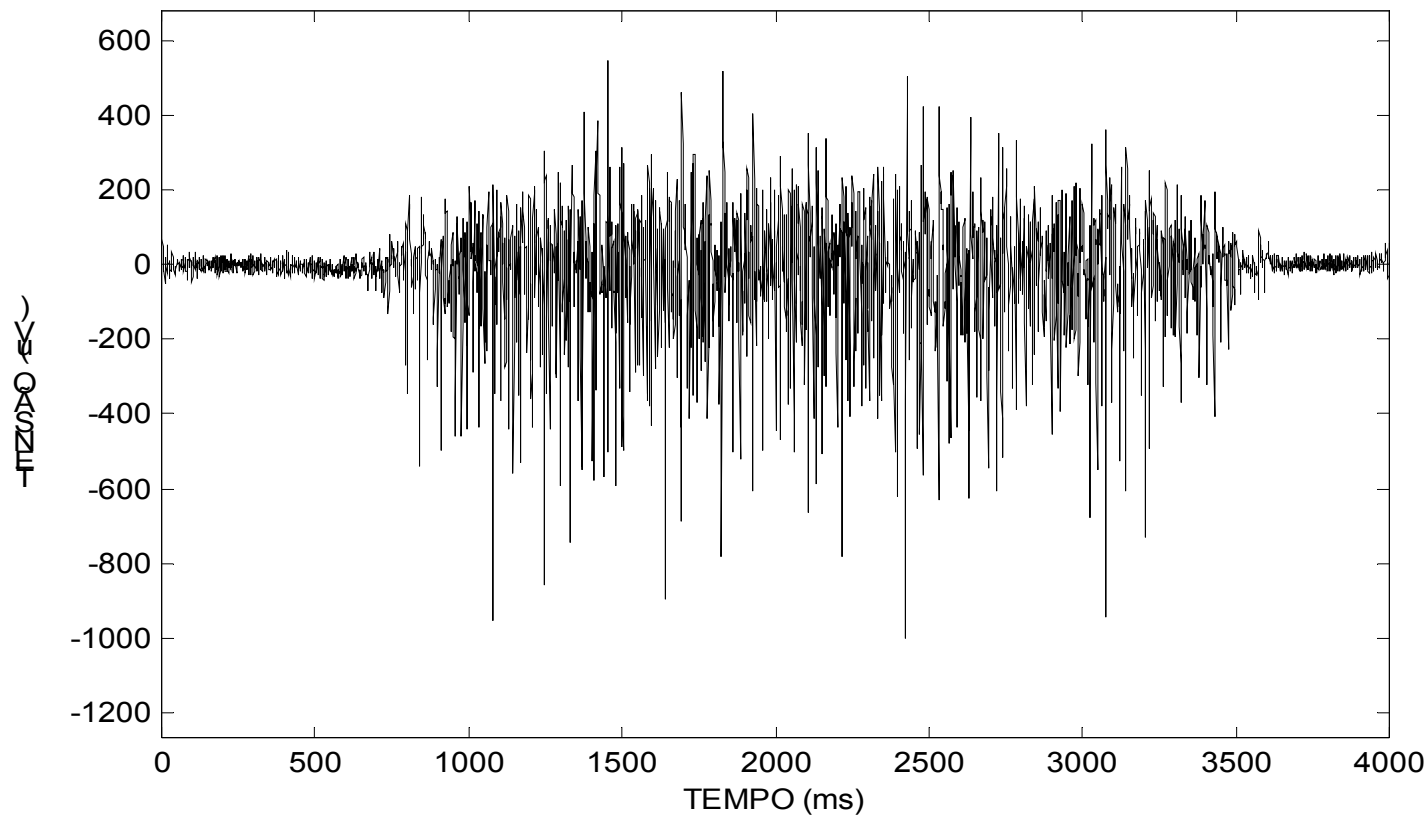

Fig. 60 - Sinal reconstruído com as componentes $(4,0),(5,3),(6,5),(6,13),(5,7),(4,2)$, $(2,1)$ e $(1,1)$ do sinal decomposto pela transformada wavelet, com a árvore de decomposição ilustrada na fig. 33. 
Na figura 61 é apresentada a DFT do SME contaminado com a interferência da rede (sinal tracejado) e a DFT do sinal apresentado na figura 60 (sinal contínuo).

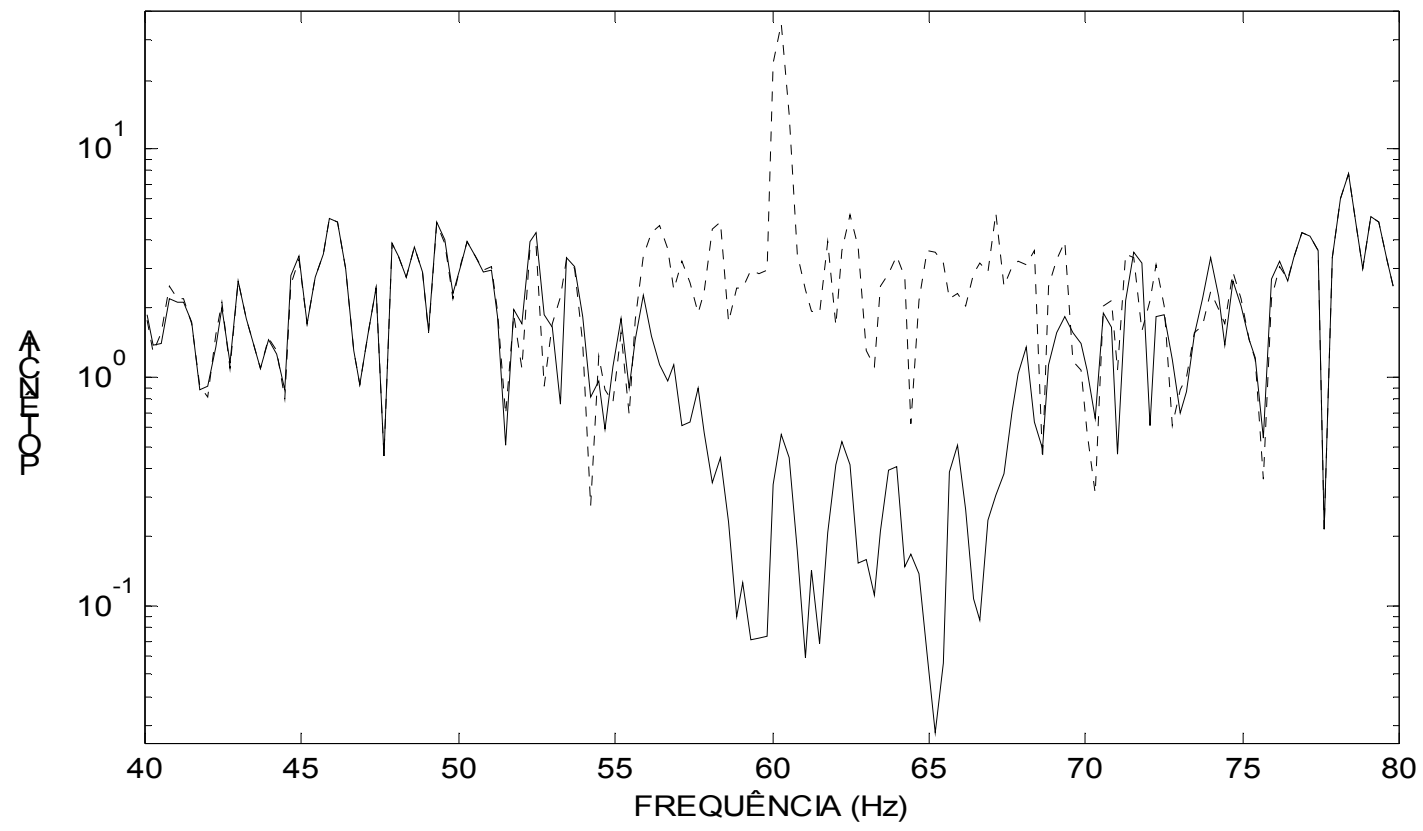

Fig. 61 - DFT do SME contaminado com a interferência da rede (sinal tracejado) e a DFT do sinal reconstruído com as componentes $(4,0),(5,3),(6,5),(6,13),(5,7)$, $(4,2),(2,1)$ e $(1,1)$ do sinal decomposto pela transformada wavelet, com a árvore de decomposição ilustrada na fig. 33. 


\subsection{Discussão}

Pode-se observar que os ruídos provenientes dos artefatos de movimento foram atenuados satisfatoriamente pelos filtros digitais (FIR e IIR) e por meio da reconstrução do sinal utilizando as componentes da transformada wavelet. No entanto o processamento computacional requerido para realizar a transformada wavelet é muito maior se relacionada com filtros FIR e IIR. Outra desvantagem do uso da transformada wavelet é que as frequências de corte dos nós são determinadas pela frequência de amostragem do sinal, não sendo possível escolher a frequência de corte, como é feito quando se projeta um filtro.

Com relação aos filtros FIR e IIR pode-se observar que a ordem do filtro FIR foi muito alta $(\mathrm{N}=100)$ para um desempenho similar ao filtro IIR, que teve ordem mais baixa $(\mathrm{N}=6)$. Portanto se não é necessária a resposta de fase linear, o método mais recomendado para retirar os ruídos causados pelos artefatos de movimento é o uso de filtros IIR.

Apesar das restrições que o uso da transformada wavelet apresenta quando utilizada para filtrar um sinal em tempo real, esta técnica de processamento consiste em uma poderosa ferramenta de análise graças à sua característica multiresolução. Em virtude da resposta que a transformada wavelet apresenta é possível observar facilmente as componentes frequenciais do ruído no domínio do tempo, desta forma ao realizar uma análise do sinal com esta transformada pode-se obter parâmetros para o projeto de filtros, como por exemplo, frequências de rejeição e passagem do sinal. A transformada wavelet (TW) também já foi utilizada em outros trabalhos fornecendo informações do sinal mioelétrico para reconhecer os padrões deste sinal (ENGLEHART et al., 1999; POPE et al., 2000).

Com relação à interferência da rede elétrica a transformada wavelet foi adequada para analisar as diferentes componentes frequenciais do ruído, podendo ainda indicar a presença de harmônicos da rede elétrica no sinal. No entanto a reconstrução do sinal utilizando componentes da TW para 
filtrar ruído de $60 \mathrm{~Hz}$, atenuou uma banda relativamente alta em torno de $60 \mathrm{~Hz}$, como pode ser observado na figura 61. O inconveniente do uso da TW é que a largura de banda é definida pelo nível de decomposição e no caso apresentado não foi possível diminuí-la, visto que não foi possível aumentar o nível de decomposição (máximo nível de decomposição foi 6, pois a partir deste nível o filtro perde a seletividade e o sinal de $60 \mathrm{~Hz}$ se apresenta nas duas componentes seguintes).

Para realizar a filtragem com o filtro FIR foi necessária uma alta ordem ( $N=664)$ o que gera um atraso relativamente grande no sinal de saída, portanto, se não é de interesse obter uma resposta de fase linear é conveniente utilizar filtros IIR que podem ter ordens muito menores, como no caso apresentado que foi utilizado um filtro IIR de $2^{\mathrm{a}}$ ordem.

Os filtros não adaptativos apresentaram desempenhos similares aos filtros adaptativos, quando o ruído da rede não tem amplitude muito alta em relação ao SME (como na figura 32), porém a ordem utilizada para os filtros adaptativos $(M \leq 15)$ foi muito menor que a ordem do filtro FIR. Para interferências com amplitude acima da taxa de atenuação dos filtros não adaptativos a filtragem não é realizada convenientemente, já com o uso de filtros adaptativos a interferência pode ter altas amplitudes (como na figura 43), pois o sistema se adapta de forma a estimar este ruído. Para filtrar ruídos de outros sinais biomédicos os filtros adaptativos também mostram bons resultados (HAMILTON, 1996).

Apesar dos filtros adaptativos apresentarem respostas melhores que as outras técnicas houve algumas diferenças entre eles:

a) O algoritmo LMS apresenta garantia de convergência e demonstrou ser de implementação mais simples, por isso este algoritmo normalmente é a primeira opção utilizada na tentativa de implementar um filtro adaptativo. No entanto o algoritmo LMS pode apresentar dificuldades na determinação do coeficiente de amortecimento $(\mu)$, que estabelece a velocidade de convergência do filtro, pois o valor de $\mu$ é encontrado de forma empírica e o intervalo que compreende esta constante é relativamente grande (entre 0 e $\left.1 / \lambda_{\text {Max }}\right)$. Além disso, $\mu$ deve ser escolhido de forma cuidadosa, pois a 
velocidade de convergência do algoritmo LMS é proporcional ao valor de $\mu$, mas a largura de banda de rejeição do filtro aumenta quando $\mu$ apresenta altos valores. O algoritmo LMS também é utilizado para convergir os coeficientes de outras aplicações, como por exemplo, Redes Neurais Artificiais (SZILÁGYI et al., 1997).

b) Com relação ao algoritmo RLS, este convergiu mais rapidamente e apresentou uma filtragem ligeiramente melhor que o filtro com algoritmo LMS. Foi necessária também uma ordem menor para uma resposta similar entre estes algoritmos. No entanto o algoritmo RLS requer um maior esforço computacional, pois a cada adaptação o número de multiplicações é maior se comparadas ao algoritmo LMS.

c) A velocidade de convergência do algoritmo RLS está diretamente relacionada com $\gamma$ e foi observado que a largura de banda é inversamente proporcional a $\gamma$. Desta forma o melhor valor desta constante seria 1. Porém quando o valor de $\gamma$ é 1 a largura de banda é tão estreita que o filtro não atenua convenientemente ruídos com alta amplitude. A convergência do sinal também depende do valor inicial de $P$. Para altos valores de $P \circ$ sistema é subamortecido e para baixos valores de $\mathrm{P}$ o sistema é sobreamortecido.

d) Foi constatado que quando são usadas altas ordens no cancelador de ruído adaptativo com algoritmo RLS este filtro apresenta instabilidades.

e) A vantagem do uso de canceladores de ruído conforme proposto por Widrow é que podem ser confeccionados com filtros de apenas um coeficiente $(M=1)$. Outra vantagem se deve ao fato desta configuração utilizar dois sinais de referência ortogonais, desta maneira a estimação do ruído é encontrada de forma mais rápida se comparada aos canceladores de ruído adaptativos com referência simples. 


\section{CAPÍTULO 4}

"A desobediência é uma virtude nescessária à criatividade."

Raul Seixas.

\section{RECONHECIMENTo dos PADRões do SME}

O SME é composto pela soma dos diversos MUAPs de cada unidade motora, que apresentam características diferentes entre si. Em razão desta soma de sinais diferentes e considerando que a taxa de disparo das unidades motoras não ocorrerem sincronamente, o SME foi descrito como um processo estocástico (KREIFELDT \& YAO, 1974; DeLUCA, 1979), com uma distribuição de amplitude Gaussiana com média zero (PARKER et al., 1977). No entanto foram encontradas características determinísticas dentro dos primeiros 200 ms de uma contração muscular (HUDGINS et al., 1991; HUDGINS et al., 1993; BASHA et al., 1994). Portanto é possível obter um padrão do SME utilizando o início da contração.

Como dito anteriormente, diferentes movimentos de um membro são realizados pelo recrutamento diferenciado dos músculos localizados no membro anterior (KENDALL \& McCREARY, 1986). Considerando que eletrodos de superfície captam sinais referentes às atividades dos vários grupos musculares localizados nas proximidades dos eletrodos, então podese captar diferentes padrões do SME para cada tipo de movimento. Utilizando um sistema que reconhece estes padrões é possível diferenciar os sinais relativos a cada tipo de contração.

Vários autores têm utilizado diferentes técnicas de reconhecimento do SME. HUDGINS et al. (1991, 1993 e 1994) utilizaram uma rede neural artificial de 3 camadas, com algoritmo de treinamento por backpropagation 
(retropropagação ) e aplicaram na entrada da rede os seguintes parâmetros do intervalo determinístico dos sinais mioelétricos captados: número de cruzamentos pelo zero, média do valor absoluto, ângulo de inclinação da média do valor absoluto e comprimento do traço do sinal. KURUGANTI et al., (1995) fizeram uma análise da melhor forma de captação do sinal utilizando a mesma técnica de reconhecimento citada acima, e concluiram que para o caso de aquisição dos sinais do antebraço o sistema reconhece melhor o sinal, quando utilizados dois eletrodos de captação, um localizado no grupo extensor e outro no grupo flexor do punho.

ENGLEHART et al. (1999) obtiveram características das transformadas wavelet e Fourier do intervalo determinístico do SME e as aplicaram em uma rede neural similar à utilizada por HUDGINS et al. (1991, 1993 e 1994) e também em um classificador estatístico LDA (linear discriminant analysis). A combinação que apresentou menor erro foi o reconhecimento por meio do classificador estatístico com as características do sinal obtidas utilizando a transformada wavelet.

Além das técnicas citadas pode-se ainda aplicar o espectrograma (GALLANT et al., 1998) ou os coeficientes do modelamento auto-regressivo do intervalo determinístico do sinal em redes neurais artificiais (LATWESEN \& PATTERSON, 1994; QUEVEDO \& CLIQUET, 1992 e 1993). Também é possível realizar o reconhecimento por meio de lógica fuzzy (PARK \& LEE, 1998).

Entretanto o pré-processamento do SME, a fim de obter suas características, necessita de um tempo relativamente grande, quando aplicado em microprocessadores. Como o objetivo é reconhecer os padrões do sinal de uma janela de 200 ms, supõe-se que seria mais interessante diminuir o tempo de processamento, realizando o reconhecimento de padrões por meio do próprio sinal e não das características extraídas dele.

Ao realizar o reconhecimento dos padrões do SME dois fatores devem ser levados em conta: a provável localização dos eletrodos em pontos diferentes cada vez que o paciente se conectar ao equipamento e a grande variação nas características do sinal capturado entre indivíduos diferentes. 
Entre os amputados isto é agravado graças as diferentes alterações na estrutura muscular remanescente (O'NEILL et al., 1994). Para contornar estes problemas é interessante que o método de reconhecimento de padrões seja baseado em redes neurais, pois desta forma o sistema pode ser "ensinado" a reconhecer cada tipo de sinal. Por este motivo o método de reconhecimento de padrões executado neste trabalho foi baseado em Redes Neurais Artificiais (RNA) com treinamento por backpropagation (CLAUDILL \& BUTLER, 1996). 


\subsection{Materiais e Métodos}

O reconhecimento dos padrões do SME foi realizado em computador por meio de um programa desenvolvido em linguagem $\mathrm{C}$ e as entradas da rede neural foram obtidas por intermédio de um programa desenvolvido com o auxílio do software Matlab.

Os sinais mioelétricos foram captados utilizando o mesmo equipamento descrito na avaliação de técnicas de filtragem (eletrodo PA602, placa condicionadora MCS 1000-V2 e interface de aquisição de dados CAD 1256 da empresa Linx) e o sinal foi amostrado com frequência de $1000 \mathrm{~Hz}$.

Utilizou-se dois eletrodos localizados no antebraço de um voluntário, um disposto sobre o grupo extensor e outro sobre o grupo flexor do punho. Foram captados 10 sinais mioelétricos resultantes da contração do grupo flexor e 10 para o grupo extensor, totalizando 20 sinais para um voluntário. Cada sinal foi gravado durante 2 segundos.

O próximo passo foi a extração dos pontos equivalentes aos primeiros 200 ms da contração muscular. Este processo foi realizado por meio de uma rotina implementada com o software MatLab. Esta rotina procura um ponto $\delta$ do sinal com valor acima de um determinado limiar $(\gamma)$, e calcula o valor RMS de uma janela dos $N$ pontos seguintes a partir de $\delta$. Caso o valor RMS desta janela tenha valor acima de $\gamma$ então o ponto $\delta$ é considerado o ponto do inicio da contração, caso contrário é procurado outro ponto $\delta$, e conferido novamente se este é o inicio da contração. Os valores de $\gamma$ e $N$ foram determinados empiricamente, sendo $\gamma$ igual a $80 \mu \mathrm{V}$ para os sinais das extensões e $40 \mu \mathrm{V}$ para os sinais das flexões, e $\mathrm{N}$ igual a 40 pontos.

Quando o ponto $\delta$ é encontrado são obtidas mais quatro janelas de 40 pontos, totalizando 200 valores seguintes ao ponto $\delta$, referentes aos $200 \mathrm{~ms}$ iniciais da contração. Nas figuras 62 e 63 são apresentados os sinais mioelétricos captados nos grupos extensor e flexor localizados no antebraço durante o início da extensão e flexão do punho. Nestas figuras é possível observar a diferença dos padrões dos sinais destes dois tipos de contração. 

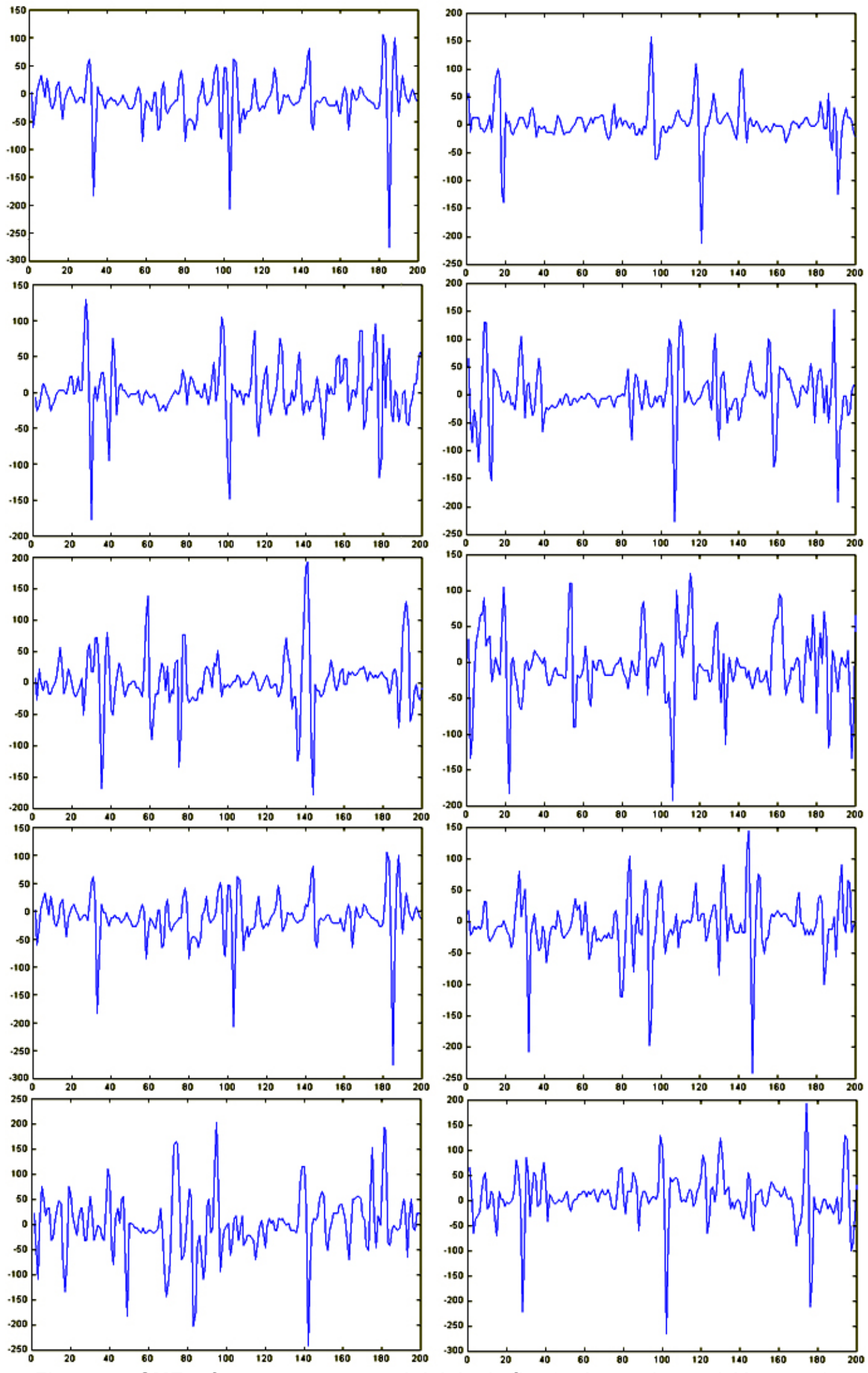

Fig. 62 - SME referente aos $200 \mathrm{~ms}$ iniciais da flexão do antebraço ( $\mu \mathrm{V}$ por ms). 

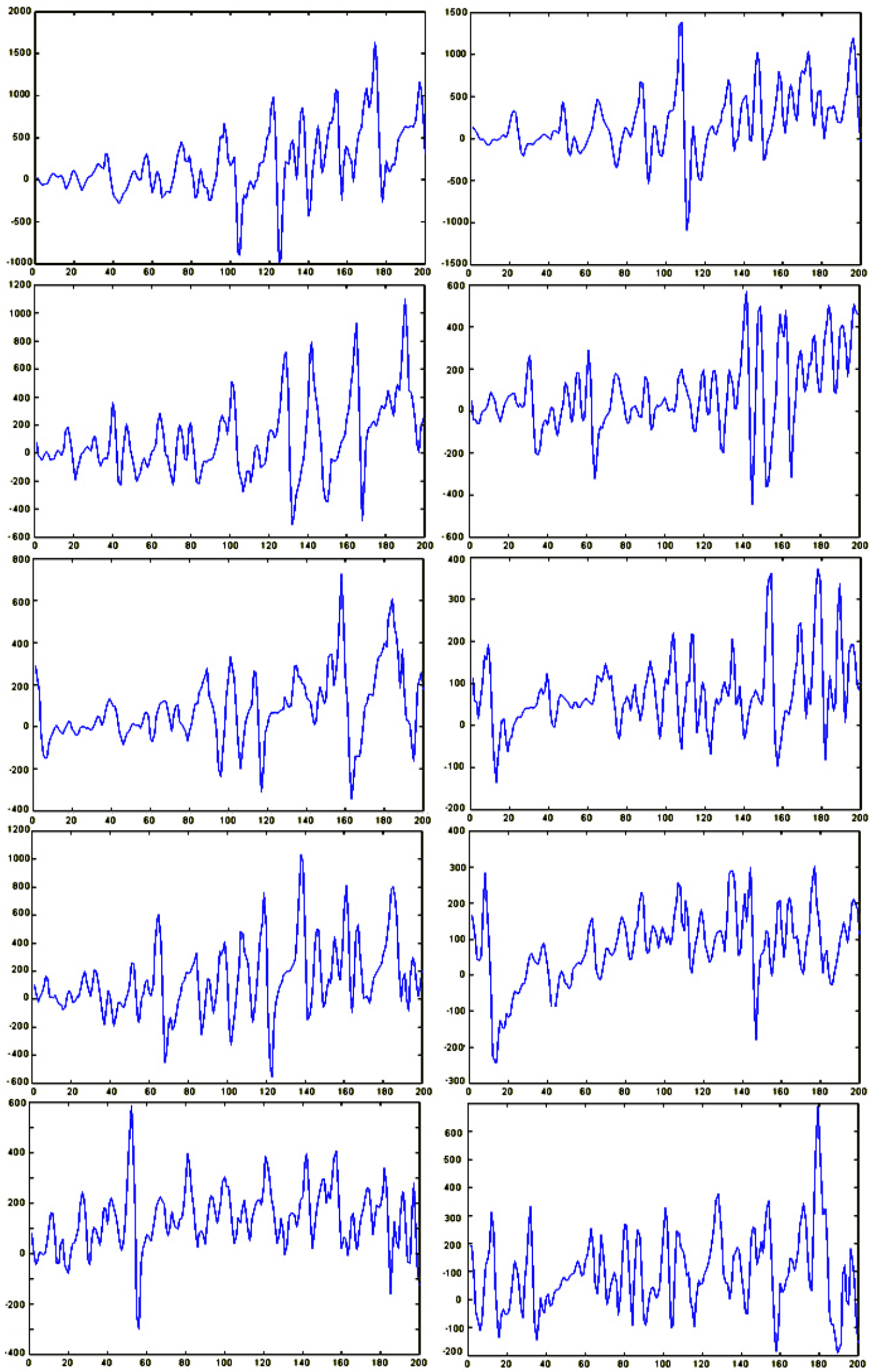

Fig. 63 - SME referente aos 200 ms iniciais da extensão do antebraço ( $\mu \mathrm{V}$ por ms). 
Estes sinais referentes ao início da contração foram normalizados entre -1 e 1, visando seu uso em uma RNA. Nas figuras 64 e 65 é apresentado um sinal de cada tipo de contração, indicando a janela encontrada de $200 \mathrm{~ms}$, referente ao início da contração e o sinal deste intervalo normalizado.

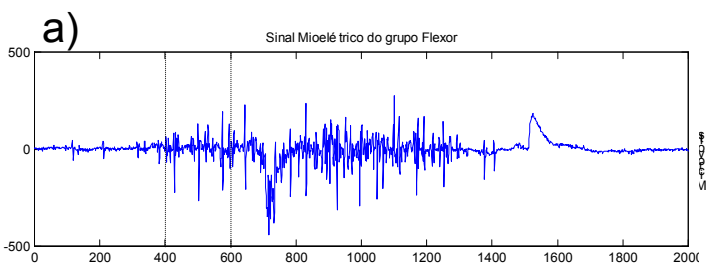

b)

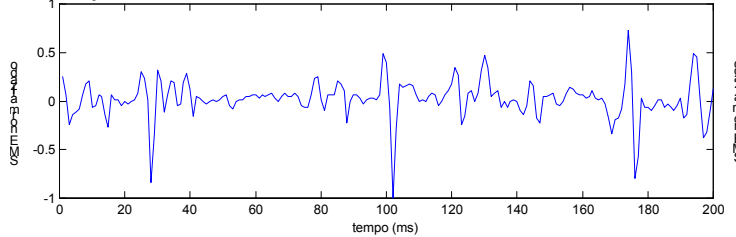

Fig. 64 - Exemplo de SME captado pelo eletrodo situado no grupo flexor durante a flexão do punho.

a) Todo o sinal captado durante $2 \mathrm{~s}$, mostrando a janela de $200 \mathrm{~ms}$;

b) $200 \mathrm{~ms}$ iniciais após o início da contração, já normalizado. a)

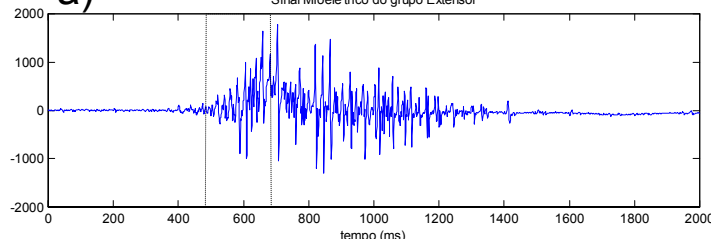

b)

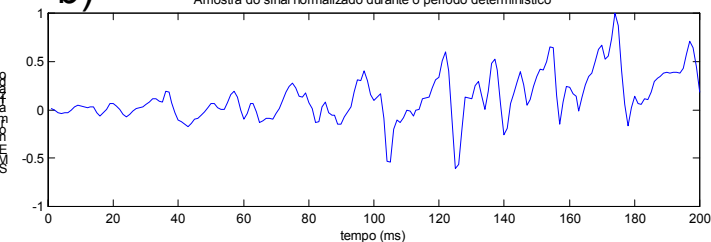

Fig. 65 - Exemplo de SME captado pelo eletrodo situado no grupo extensor durante a extensão do punho.

a) Todo o sinal captado durante $2 \mathrm{~s}$, mostrando a janela de $200 \mathrm{~ms}$;

b) $200 \mathrm{~ms}$ iniciais após o início da contração, já normalizado.

Para aumentar o número de amostras foram gerados mais seis sinais referentes ao início de cada tipo de contração. Foram utilizadas as amostras normalizadas acrescidas de um ruído com média zero e amplitude máxima de $10 \%$ do sinal original.

Como já comentado, objetivou-se o projeto de uma RNA relativamente simples, evitando o pré-processamento do sinal, visando assim uma maior velocidade de processamento. Desta forma, foi escolhida uma rede que tivesse como entrada todos os 200 pontos do SME relativos ao início da contração e como saída o tipo de contração.

A rede utilizada foi implementada com três camadas e aprendizagem supervisionada. A primeira camada apenas propaga o sinal de entrada e as camadas intermediárias e de saída encarregam-se do processamento. $\mathrm{O}$ algoritmo usado teve pequenas modificações do sugerido por CAUDILL \& BUTLER (1996), e foi implementado em linguagem C em um computador pessoal. 
Foram utilizadas 200 unidades de processamento na camada de entrada, relativas aos 200 pontos do SME, e duas unidades na saída, sendo que $\left[\begin{array}{l}1 \\ 0\end{array}\right]$ representava uma extensão e $\left[\begin{array}{l}0 \\ 1\end{array}\right]$ uma flexão do punho.

As unidades de saída tiveram uma função de ativação tipo sigmóide (equação 32) com a constante $k$ igual a 1 . Foi adotado o limiar de 0.5 para que as unidades de saída apresentem os valores 0 e 1. Estes valores foram obtidos empiricamente.

$$
f(x)=\frac{1}{1+e^{-k x}}
$$

Foram testadas quatro arquiteturas com 1, 2, 3 e 5 unidades na camada intermediária. Na figura 66 é apresentado o diagrama da rede neural utilizada com 3 neurônios na camada intermediária.

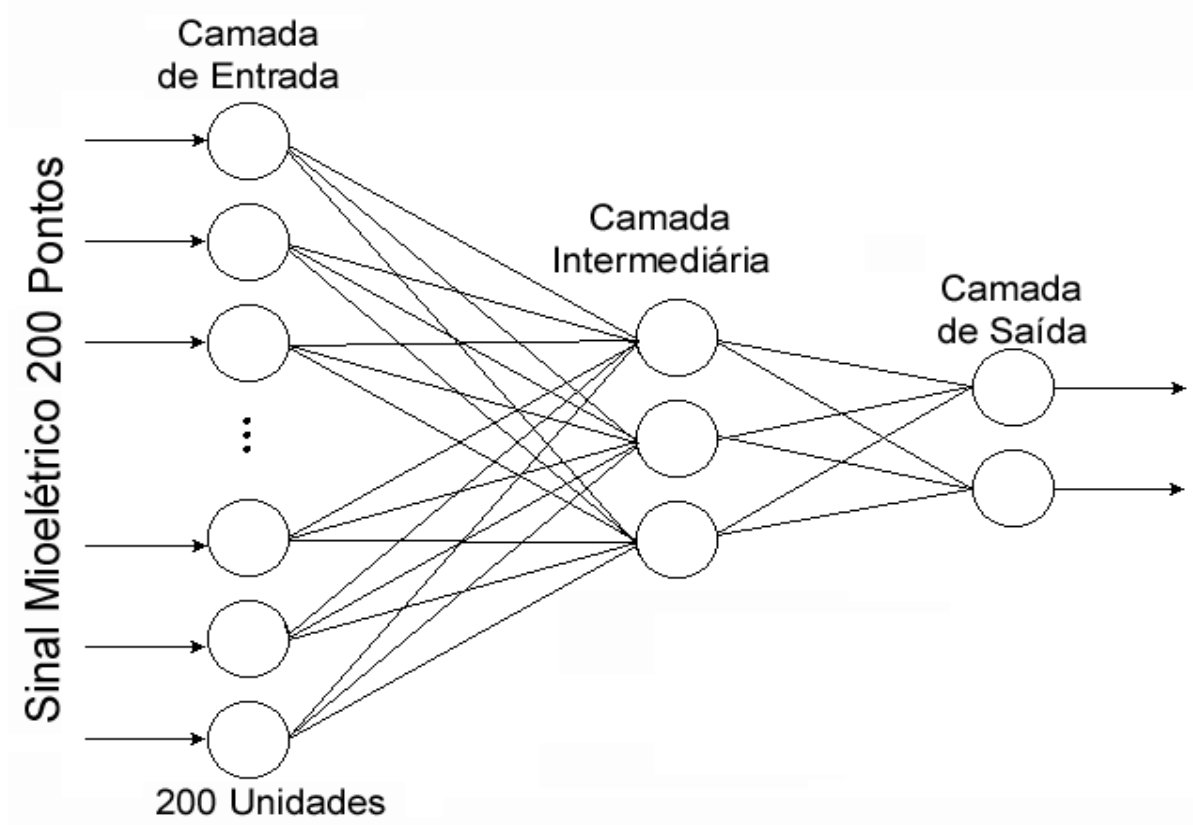

Fig. 66 - Diagrama da rede neural utilizada com três unidades na camada intermediária.

O treinamento da rede foi realizado com 1000 iterações, a fim de encontrar os valores das conexões entre os neurônios. Este número foi obtido empiricamente, levando em consideração que um número alto de iterações faz com que a rede reconheça apenas as amostras utilizadas durante o treinamento e um número baixo não é suficiente para os valores das conexões convergirem. 


\subsection{Resultados}

O treinamento foi feito com metade dos sinais obtidos escolhidos de forma aleatória e sem repetições, apresentados em conjunto com as saídas desejadas. Os sinais restantes foram separados em um conjunto para validação e outro para testes. Este procedimento foi repetido entre as quatro arquiteturas separadamente.

Os resultados das simulações de teste para as quatro arquiteturas, com os dados de um voluntário normal podem ser vistos na figura 67 .

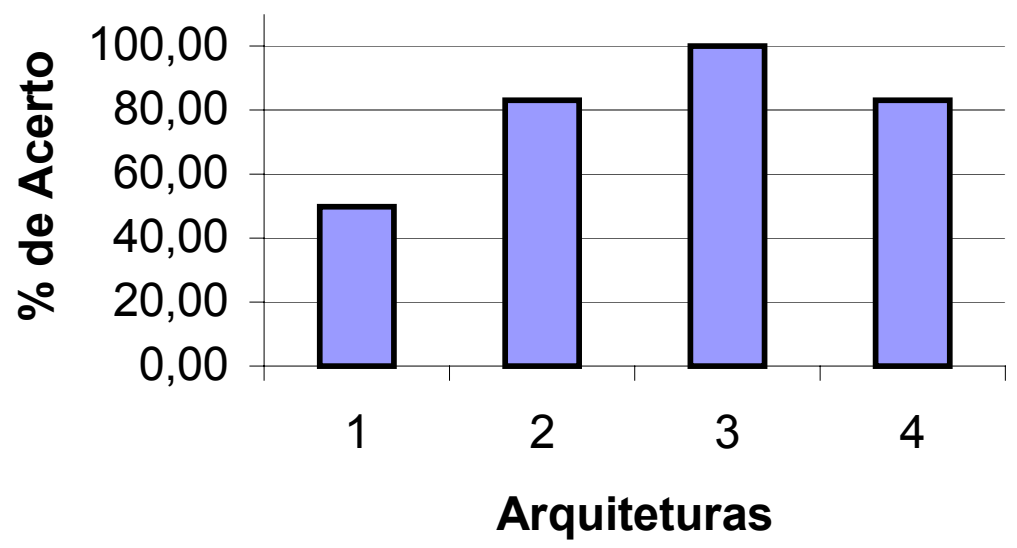

Fig. 67 - Resultados dos testes da rede para as quatro arquiteturas utilizadas.

A arquitetura 1 apresentou um resultado pobre, dado a inadequada quantidade de unidades na camada intermediária. Já as arquiteturas 2 e 4 apresentaram resultados bons, levando em consideração os poucos pontos para teste. Dentre os testes realizados, o melhor resultado foi obtido pela arquitetura 3 , com três neurônios na camada intermediária. 


\subsection{Discussão}

O uso de redes neurais mostra-se adequado para reconhecer os padrões do SME, pois apresenta a possibilidade de ser treinada toda vez que o paciente se conectar ao equipamento, podendo também ser usada por diversos pacientes. Outra vantagem da técnica de reconhecimento analisada é que o treinamento da rede é realizado antes do sistema estar apto a reconhecer o sinal, desta forma a resposta da rede é mais rápida quando o reconhecimento dos padrões é realizado.

O sistema de reconhecimento proposto apresentou-se como uma técnica diferente das técnicas observadas nos trabalhos analisados, pois não foram extraídas características do sinal mioelétrico para aplicar à entrada da rede. Desta forma não foi necessário o pré-processamento do sinal, portanto simplificando o sistema.

De acordo com os resultados obtidos, a arquitetura com três unidades na camada intermediária se mostrou a mais indicada para esta aplicação, somando um bom desempenho com um bom custo computacional.

Imaginou-se que este tipo de reconhecimento de padrões poderia apresentar problemas em virtude da defasagem entre as amostras, pois os níveis de tensão dos sinais mioelétricos não coincidiriam sempre com as mesmas unidades de entrada da rede. No entanto, pode-se observar que os sinais utilizados com mesmo padrão não apresentam mesmas amplitudes nos instantes de amostragem do sinal e mesmo assim o sistema foi capaz de diferenciar os dois padrões.

Entretanto este resultado apenas abre espaço para maiores investigações no reconhecimento do SME, utilizando o sinal propriamente dito como entrada do sistema, visto que o número de amostras utilizadas foi relativamente baixo. 


\section{CONCLUSÕES}

"Posso não concordar com todas as palavras que tu dizes, mas defenderei até o fim o teu direito de dizê-las."

Voltaire.

\section{CONCLUSÕeS}

O objetivo deste trabalho foi de avaliar algumas técnicas de filtragem do sinal mioelétrico, para atenuar os principais ruídos que o corrompem e também analisar um método simples para o reconhecimento dos padrões deste sinal, tendo em vista a aplicação em sistemas de reabilitação.

Diante dos resultados obtidos na filtragem dos ruídos, pôde-se observar que a transformada wavelet se apresentou como uma poderosa ferramenta de análise do sinal, graças à sua característica multiresolução, a qual pode fornecer informações que auxiliam no projeto de filtros. No entanto, a reconstrução do sinal utilizando as componentes da transformada wavelet apresentou resultados inferiores às outras técnicas analisadas, em virtude da limitação na escolha das frequências de corte dos nós na árvore de decomposição e do máximo nível de decomposição alcançado.

Quando os ruídos apresentam amplitudes constantes, e não é de interesse obter uma resposta de fase linear, é conveniente utilizar filtros IIR pois apresentam ordens muito menores que as altas ordens adotadas para filtros FIR, que geram um atraso relativamente grande no sinal de saída.

Conclui-se que os canceladores de ruído adaptativos apresentam melhor desempenho, entre as técnicas avaliadas, para filtrar sinais mioelétricos somados a ruídos de amplitudes variáveis e frequências dentro da banda do sinal. Estes filtros adaptativos também têm a vantagem de 
poderem ser implementados com filtros FIR, apresentando resposta similar aos filtros FIR com ordens muito menores.

Quanto ao algoritmo de adaptação, o algoritmo LMS é de implementação mais simples e apresenta bons resultados. O algoritmo RLS apresenta resultados um pouco melhor que o LMS, porém requer maior recurso computacional, em virtude do maior número de multiplicações executadas. Por causa da simplicidade de implementação, garantia de convergência e resultados satisfatórios, é interessante que o algoritmo LMS seja utilizado como primeira opção na tentativa de implementar um filtro adaptativo.

Entre os canceladores de ruído adaptativos com referência simples e com duas referências ortogonais entre si, conforme proposto por WIDROW et al. (1975), pode-se concluir que o sistema proposto por Widrow tem um desempenho melhor, pois apresenta menor ordem e uma velocidade maior na estimativa do ruído.

Com relação ao reconhecimento de padrões do SME foi implementado um sistema não usual diante dos trabalhos analisados, onde não são extraídas características do sinal, mas sim analisadas as semelhanças entre os próprios sinais. Apesar de terem sido testadas poucas amostras, o sistema apresentou bons resultados, chegando a reconhecer todos sinais quando utilizados três neurônios na camada intermediária da rede neural artificial. Desta forma, com os resultados apresentados, conclui-se que um sistema de reconhecimento dos padrões do sinal também pode ser implementado utilizando o próprio sinal como entrada do sistema.

A rede neural implementada reconheceu dois padrões de contração diferentes, no entanto é possível implementar uma rede que seja treinada para mais tipos de contração. Com os diferentes padrões reconhecidos, o sistema é capaz de apresentar vários sinais referentes a cada contração, controlando de forma diferenciada algum sistema de reabilitação.

Com os resultados obtidos nas simulações é possível fornecer subsídios para implementar um circuito que processe o SME e apresente um sinal de controle a ser utilizado em equipamentos de reabilitação. 


\section{Propostas Para Futuros Trabalhos}

Pretende-se estudar a viabilidade do uso de outras técnicas de reconhecimento de padrões, simular as técnicas viáveis e analisá-las com o intuito de eleger qual é a melhor maneira de reconhecer os padrões do SME.

Definindo a técnica de reconhecimento de padrões a ser utilizada podese então programar algum microprocessador a fim de implementar o sistema em hardware. Para isso, também é necessário que sejam desenvolvidos eletrodos ativos e implementado um pré-processamento analógico para o condicionamento do sinal.

Para filtrar os ruídos do sinal pode-se utilizar um cancelador de ruído adaptativo com duas referências ortogonais, conforme proposto por WIDROW et al. (1975) e a princípio adotar o algoritmo de adaptação LMS e caso seja necessário pode-se alterar o algoritmo de adaptação para o RLS.

Com a implementação de um circuito que reconheça o sinal mioelétrico é possível então obter um sinal de controle para ser utilizado em sistemas de reabilitação, com o intuito de melhorar a interface equipamento paciente. 


\section{ANEXO}

\section{RESPOSTA EM FREQUÊNCIA PARA}

\section{FiltrageM ANALÓGICA E Digital IIR}

A seguir serão descritos os tipos mais comuns de resposta em frequência de filtragens analógicas e filtragens digitais de Resposta Infinita ao Impulso (IIR).

\section{FILTRO DE BUTTERWORTH}

O filtro de Butterworth apresenta uma resposta de amplitude maximamente plana na faixa de passagem conforme pode ser visualizado na figura $A 1$.

Este filtro apresenta uma taxa de atenuação de $20 \mathrm{~N} \mathrm{~dB}$ por década, onde $\mathrm{N}$ é a ordem do filtro.

Considerando $\quad \Omega \quad$ a frequência e $\Omega_{c}$ a frequência de corte do filtro, pode-se escrever a função de transferência do filtro analógico de Butterworth de acordo com a equação A1.

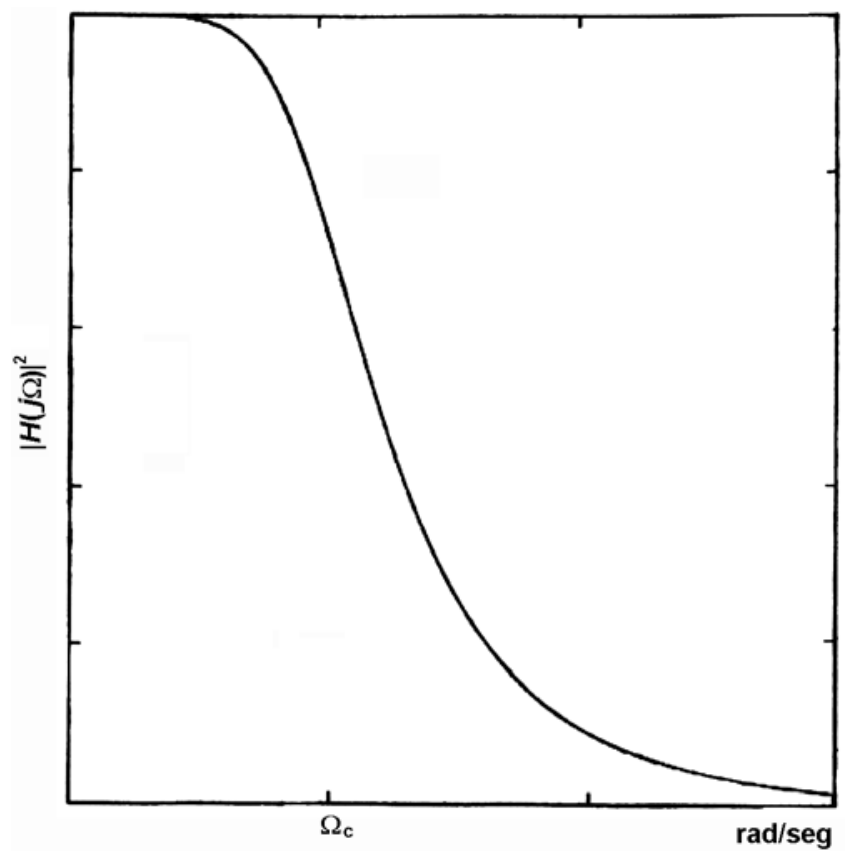

Fig . A1 - Espectro de amplitude de um filtro com resposta de Butterworth. (adaptado de PARKS \& BURRUS, 1987)

$$
|H(j \Omega)|^{2}=\frac{1}{1+\left(\Omega / \Omega_{c}\right)^{2 N}}
$$




\section{Filtro de Chebyshev}

O filtro de Chebyshev apresenta maior taxa de atenuação na banda de transição do que o filtro de Butterworth, porém apresenta ondulação (ripple) na faixa passante ou de corte. Os filtros de Chebyshev são classificados em Tipo I e Tipo II.

Filtros de Chebyshev Tipo I apresentam comportamento oscilatório na banda de passagem e os filtros Tipo II apresentam comportamento oscilatório na banda de atenuação, conforme pode ser observado na figura A2.
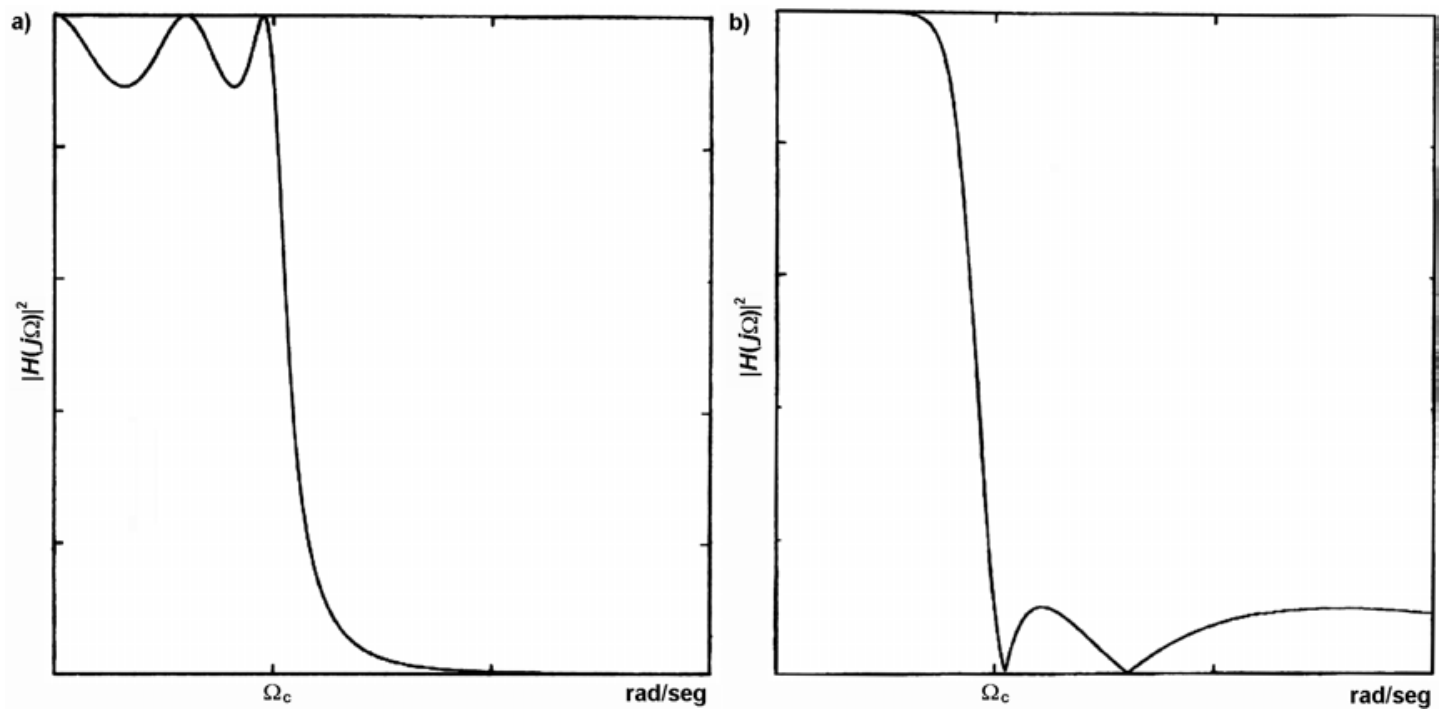

Fig . A2 - Espectro de amplitude da resposta dos filtros de Chebyshev.

a) Tipo I e b) Tipo II. (adaptado de PARKS \& BURRUS, 1987)

A Função de Transferência do filtro analógico de Chebyshev é dada por:

$$
|H(j \Omega)|^{2}=\frac{1}{1+\varepsilon^{2} \cdot C_{N}{ }^{2}\left(\Omega / \Omega_{c}\right)}
$$

Sendo $\varepsilon$ o parâmetro relacionado com a ondulação e $C_{N}(x)$ o polinômio de Chebyshev (ZVEREV, 1967). 


\section{Filtro Elíptico}

O filtro elíptico apresenta comportamento oscilatório tanto na banda de passagem quanto na banda de atenuação, porém tem a vantagem de fornecer ordem menor que os outros filtros. Este tipo de filtro apresenta a maior atenuação na faixa de corte se comparado com as outras configurações. $\mathrm{Na}$ figura A3 é ilustrada a resposta de amplitude de um filtro elíptico.

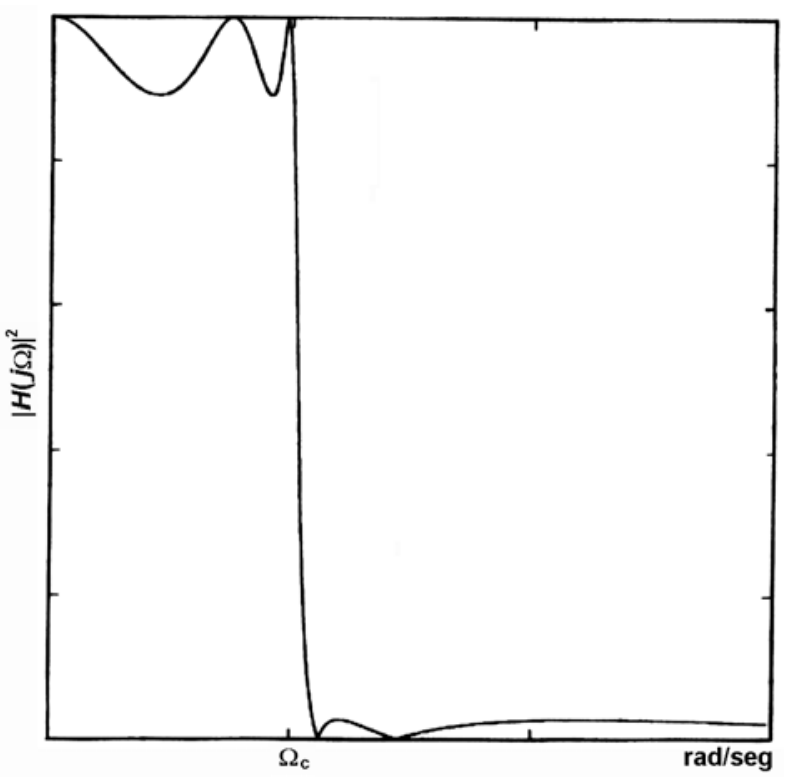

Fig . A3 - Espectro de amplitude da resposta do filtro elíptico. (adaptado de PARKS \& BURRUS, 1987)

A função de transferência do filtro elíptico é dada por:

$$
|H(j \Omega)|^{2}=\frac{1}{1+\varepsilon^{2} \cdot U_{N}^{2}\left(\Omega / \Omega_{c}\right)}
$$

Sendo $U_{N}(x)$ a função elíptica jacobiana (ZVEREV, 1967).

\section{Filtro de Bessel}

Apresenta fase linear dentro da banda passante. Em sistemas digitais, no lugar de filtros de bessel, normalmente utiliza-se filtros FIR que também apresentam fase linear. A Função de transferência do filtro analógico de Bessel é dada pela equação A4.

$$
H(j \Omega)=\frac{1}{B_{N}(j \Omega)}
$$

Sendo $B_{N}(j \Omega)$ o polinômio de Bessel de ordem $N$, calculado de acordo com a equação A5.

$$
B_{N}(j \Omega)=\sum_{k=0}^{N} \frac{(2 N-k) !}{2^{N-k} \cdot k ! \cdot(N-k) !}(j \Omega)^{k}
$$




\section{REFERÊNCIAS}

ALMEIDA, M.A.F. (1997). "Filtragem Digital de Sinais Biomédicos". Florianópolis. 116p. Dissertação (Mestrado) - Programa de PósGraduação em Engenharia Elétrica, Universidade Federal de Santa Catarina.

ANTONINO, P.H.; CLIQUET Jr, A. (1992). "Sistema de estimulação táctil para recepção de informações ópticas". In: I FÓRUM NACIONAL DE CIÊNCIA E TECNOLOGIA EM SAÚdE. Anais. Caxambu, MG, 20-24 nov., 1992, p.196-198.

BAGWELL, P.J.; CHAPPELL, P.H. (1995). "Real Time Microcontroller Implementation of an Adaptive Myoelectric Filter". Med. Eng. Phys., v.17, n.2, p.151-160, Mar. 1995.

BASHA, T.; SCOTT, R.N.; PARKER, P.A.; HUDGINS, B.S. (1994). "Deterministic components in the myoelectric signal". Med. \& Biol. Eng. \& Comput., v.32, p.233-235, Mar. 1994.

BASMAJIAN, J.V.; DeLUCA, C.J. (1985). "Muscle Alive: Their Functions Revealed by Electromyography". ISBN:O-683-00414-X. $5^{\text {th }}$ ed. Baltimore, Williams \& Wilkins, 561p.

BELTRAMINI, L.M. (1999). "Elementos de Histologia e Anatomo-fisiologia Humana”.[capturado:11/12/2000].http://biologia.ifqsc.sc.usp.br/cap5/MU SCULAR.html.

BIEDERMAN, W. (1898). "Electrophysiology". London.

BODE, H.; SHANNON, C. (1950). "A Simplified Derivation of Linear Least Square Smoothing and Prediction Theory". Proc. IRE, v.38, p.417-425, Abr. 1950.

CAUDILL, M; BUTLER, C. (1996). "Understanding Neural Networks: Computer Explorations" - v.1, Massachusetts, The MIT Press, p.171-180.

CHAPPELL, P.H.; KYBERD, P.J. (1991). "Prehensile Control of a Hand Prosthesis by a Microcontroller". J. Biomed. Eng., v.13, n.5, p.363-369, Set. 1991. 
CHEN, Y.L. et al. (1999). "The New Design of an Infrared-Controlled HumanComputer Interface for the Disabled". IEEE Trans. Rehabilitation Eng., v.7, n.4, p.474-481, Dec. 1999.

CHESLER, N.C.; DURFEE, W.K. (1997). "Surface EMG as a Fatigue Indicator During FES-induced Isometric Muscle Contractions". J. Electromyogr. Kinesiol.,v.7, n.1, p.27-37, Mar. 1997.

CLARYS, J.P.P.; LEWILLIE, L. (1992). "Clinical and kinesiological electromyography by Le Dr. Duchenne (De Boulogne)". In: CAPOZZO, A.; MARCHETTI, M.; TOSI, V. Biolocomotion: a century of research using moving pictures. Roma, Promograph, p.89-114.

CLIQUET Jr, A. (1989). "Paraplegic locomotion with neuromuscular electrical stimulation based systems - a feasibility study". Glasgow, UK. (Ph.D. thesis) - University of Stratchclyde.

CLIQUET Jr., A. (1991). "Paraplegic gait restoration through neuromuscular electrical stimulation based strategies". Medical \& Biological Engineering \& Computing, 29 (Supplement), 711p.

CLIQUET Jr, A. et al. (1992). "A neural network-voice controlled neuromuscular electrical stimulation system for tetraplegics". Rehabilitation Engineering Society of North America-RESNA. ISBN:0932101-30-5/ISBN:0883-4741. Washington, DC, RESNA press, p.29-31.

CLIQUET Jr., A. (1997). "Bioengenharia já consegue 'milagres'; Milagres viram referência dentro da Bioengenharia; Equipamentos entram na 'batalha pela vida'". Jornal A Tribuna de Campinas, Campinas, SP, 23 nov., capa e p.6.

CUNHA, F.L.; SCHNEEBELI, H.A.; DYNNIKOV, V.I. (2000). "Development of Anthropomorphic Upper Limb Prostheses With Human-Like Interphalangian and Interdigital Couplings", Artificial Organs. ISSN: 0160-564X. v.24, n.3, p.193-197, Mar. 2000.

DeFATTA, D.J.; LUCAS, J.G.; HODGKISS, W.S. (1988). "Digital Signal Processing: A System Design Approach". ISBN:0-471-63765-3. New York , John Wiley \& Sons Inc., 661p.

DELSYS INC. (1996) Tutorials \& WhitePapers: "A discussion on Surface Electromyography: Detection and recording". [capturado:21/03/2000] http://www.delsys.com/library/tutorials.htm.

DeLUCA, C.J. (1979). "Physiology and Mathematics of Myoelectic Signals". IEEE Trans. Biomedical Eng., v.26, n.6, p.313-325, Jun. 1979.

DIAS, C. (1999). "Quase melhor que o original". Revista Super Interessante, n.136, p.42-46, jan. 1999. 
DuBOIS-REYMOND, F. (1849). “Untersuchngen ueber thierische elektricitaet". v.2, Berlin.

ENGLEHART, K.; HUDGINS, B.; PARKER, P.A.; STEVENSON, M. (1999). "Classification of the Myoelectric Signal using Time-Frequency Based Representations”. Medical Eng. \& Physics, v.21, p.431-438.

EVANS, D.G.; DREW, R.; BLENKHORN, P. (2000). "Controlling Mouse Pointer Using an Infrared Head-Operated Joystick". IEEE Trans. Rehabilitation Eng., v.8, n.1, p.107-117, Mar. 2000.

FRANCA, J.E.M.; ORTOLAN, R.L.; CUNHA, F.L.; DINNIKOV, V.I.; CLIQUET Jr., A. (2002). "A Specific Control System for an Anthropomorphic Myoelectric Hand Prosthesis". In: BALTHAZAR, J.M. et al. Nonlinear Dynamics, Chaos, Control and Their Applications to Engineering Sciences, Vol. 6: Applications of Nonlinear Phenomena. ISBN:85.900351-6-6. p.356-365.

GALLANT, P.J.; MORIN, E.L.; PEPPARD, L.E. (1998). "Feature-based classification of myoelectric signals using artificial neural networks". Med. \& Biol. Eng. \& Comput.,v.36, p.485-489, Jul. 1998.

GASSER, H.S.; ERLANGER, J. (1925). "The nature of conduction of an impulse in the relatively refractory period". American J. Physiol., v.73, p.613.

GHEZ, C. (1991). "Muscle: effectors of the motor systems". In: KARDEL, E.R.; SCHWARTZ, J.H.; JESSEL, T.M. Principles of neural science. 3.ed, Norwalk, Apleton \& Lange, p.548-563.

GRAUPE, D.; KORDYLEWSKI, H. (1997). "Neural Network Control of Neuromuscular Stimulation In Paraplegics for Independent Ambulation", Proc. 19th Inter. Conf. IEEE/EMBS, Oct.30-Nov.2, Chicago, IL, p.1088-1091.

GUYTON, A.C. (1988). "Fisiologia Humana". 6.ed. Rio de Janeiro, Guanabara Koogan S.A., 564p.

HAMILTON, P.S. (1996). "A Comparison of Adaptive and Nonadaptive Filters for Reducing of Power Line Interference in the ECG". IEEE Trans. Biomedical Eng., v.43, n.1, p.105-109, Jan. 1996.

HODGKIN, A.L.; HUXLEY, A.F. (1952). "Propagation of Electrical Signals Along Giant Nerve Fibers". Proc. Royal Society of London Series B Biological Sciences, v.140, n.899, p.177-183.

HODGKIN, A.L.; HUXLEY, A.F. (1952). "Currents Carried by Sodium and Potassium lons Through the Membrane of the Giant Axon of Loligo". J. Physiol., London, v.116, n.4, p.449-472. 
HODGKIN, A.L.; HUXLEY, A.F. (1952). "The Components of Membrane Conductance in the Giant Axon of Loligo". J. Physiol., London, v.116, n.4, p.473-496.

HODGKIN, A.L.; HUXLEY, A.F. (1952). "The Dual Effect of Membrane Potential on Sodium Conductance in the Giant Axon of Loligo". J. Physiol., London, v.116, n.4, p.497-506.

HODGKIN, A.L.; HUXLEY, A.F. (1952). "A Quantitative Description of Membrane Current and its Application to Conduction and Excitation in Nerve". J. Physiol., London, v.117, n.4, p.500-544.

HOWELLS, P. (1965): "Intermediate Frequency Side-lobe Canceller". U.S.Patent 3202 990, 24 Ago.,1965.

HUDGINS, B.; PARKER, P.; SCOTT, R.N. (1991). "A neural network classifier for multifunction myoelectric control". Proc. 13th Inter. Conf. IEEE/EMBS, Orlando, FL., v.13, n.3, p.1454-1455,

HUDGINS, B.; PARKER, P.; SCOTT, R.N. (1993). "A New Strategy for Multifunction Myoelectric Control". IEEE Trans. Biomedical Engineering, v.40, n.1, p.82-94.

HUDGINS, B.; PARKER, P.; SCOTT, R.N. (1994). "Control of Artificial Limbs Using Myoelectric Pattern Recognition”, Medical \& Life Sciences Engineering, v.13, p.21-38.

HUHTA, J.C.; WEBSTER, J.G. (1973). "60-Hz Interference in Eletrocardiography”. IEEE Trans. Biomedical Eng., v.20, n.2, p.91-101, Mar. 1973.

IFEACHOR, E.C.; JERVIS, B.W. (1993). "Digital Signal Processing: A Practical Approach". ISBN 020154413X. Wokingham, England, AddisonWesley, p.541-576: Adaptive Digital Filters.

KAILATH, T. (1974). "A View of Three Decades of Linear Filtering Theory". IEEE Trans. Inform. Theory, v.20, p.145-181, Mar. 1974.

KALMAN, R. (1960). "On the General Theory of Control". Proc. 1st IFAC Congress, London, Butterworth.

KALMAN, R.; BUCY, R. (1961). "New Results in Linear Filtering and Prediction Theory". Trans. ASME, ser. D, J. Basic Eng., v.83, p.95-107, Dez. 1961.

KENDALL, F.P.; McCREARY, E.K. (1986). "Músculos: Provas e Funções". 3.ed. São Paulo, Ed. Manole, 380p.

KOVÁKS, Z.L. (1997). "O Cérebro e sua Mente: Uma Introdução a Neurociência Computacional”. São Paulo, Edição acadêmica, 215p. 
KREIFELDT, J.G.; YAO, S. (1974). "A signal-to-noise investigation of nonlinear electromyographic processors". IEEE Trans. Biomed. Eng., v.21, n.4, p.298-308.

KURUGANTI, U.; HUDGINS, B.; SCOTT, R.N. (1995). "Two-Channel Enhancement of a Multifunction Control System". IEEE Trans. Biomedical Engineering, v.42, n.1, p.109-111, Jan. 1995.

KYBERD, P.J. et al. (1995). "MARCUS: A Two Degree of Freedom Hand Prosthesis with Hierarchical Grip Control", IEEE Trans. Reabilitation Engineering, v.3, n.1, p.70-76, Mar. 1995.

LaCOURSE, J.; HLUDIK, F.C.Jr. (1990). "An eye communication-control system for the disabled". IEEE Trans. Biomedical Engineering, v.37, n.12, p.1215-1220, Dec. 1990.

LATWESEN, A.; PATTERSON, P.E. (1994). "Identification of lower arm motions using the EMG signals of shoulder muscles". Med. Eng. Phys., v.16, p.113-121, Mar. 1994.

MALLAT, S. (1989). "A Theory for Multiresolution Signal Decomposition: The Wavelet Representation". IEEE Pattern Anal. and Machine Intell., v.11, n.7, p.674-693.

MISITI, M.; MISITI, Y.; OPPENHEIM, G.; POGGI, J. M. (1996). "Wavelet Toolbox User's Guide - For Use With Matlab ". Natick, MA, The MathwWorks Inc, p.626.

MORETTIN, P.A. (1999). "Ondas e Ondaletas: da Análise de Fourier à Análise de Ondaletas”. ISBN:85-314-0509-2. São Paulo, Edusp, 272p.

OLSON, W.H. (1998). "Basics Concepts of Medical Instrumentation". In: WEBSTER, J.G. Medical Instrumentation: Application and Design. ISBN:0-471-15368-0. 3.ed. New York, John Wiley \& Sons, p.1-43.

O'NEILL, P.A.; MORIN, E.L.; SCOTT, R.N. (1994). "Myoelectric signal characteristics from muscles in residual upper limbs". IEEE Trans. Rehabilitation Eng., v.2, n.4, p.266-270, Dez. 1994.

OPPENHEIM, A.V.; SCHAFER, R.W. (1989). "Discrete-Time Signal Processing". ISBN:0-13-21629-X. Englewood Cliffs, New Jersey, Prentice Hall Inc., 879p.

ORTOLAN, R. L. et al. (2000). "Proposta de um Sistema de Controle de uma Prótese Mioelétrica Multifunção para Membros Superiores". In: CONGRESSO IBEROAMERICANO IBERDISCAP 2000, 3ำ CONGRESSO DE COMUNICAÇÃO ALTERNATIVA E AUMENTATIVA, 1 CONGRESSO DE TECNOLOGIAS DE APOIO PARA A DEFICIEENCIA. Anais. ISBN: 84-699-3253-5. Madrid, 18-20 out, 2000, p.111-114. 
ORTOLAN, R.L. et al. (2001). "Tendências em Biomecânica Ortopédica Aplicadas à Reabilitação". Acta Ortopédica Brasileira. ISSN:1413-7852. v.9, n.3, p.44-58, jul/set 2001.

PARKER, P.A.; STULLER, J.; SCOTT, R.N. (1977). "Signal processing for the multistate myoelectric channel”. Proc. IEEE, v.65, n.5, p.662-674.

PARK, S.H.; LEE, S.P. (1998). "EMG pattern recognition based on artificial Intelligence Techniques". IEEE Trans. Rehabilitation Eng., v.6, n.4, p.400-405, Dez. 1998.

PARKS, T.W.; BURRUS, C.S. (1987). "Digital Filter Design". ISBN:0-47182896-3. New York, John Wiley \& Sons Inc., 342p.

PAULA, J.B.; JACOBUCCI, A.L.; SIERRA, X.C.; CLIQUET Jr., A. (1994). "Development of an Electromechanical Artificial Sphincter for Colostomy". In: WORLD CONGRESS ON MEDICAL PHYSICS \& BIOMEDICAL ENG. Anais. ISSN:0031-9155, Rio de Janeiro, pt.1, v.39a, p.20.

PAVANI, D.A.B.; CUNHA, F.L.; ORTOLAN, R.L.; LEITE, F.I.; CLIQUET Jr., A. (2001). "Sistemas de Controle para a Redução da Fadiga Muscular em Pacientes Lesados Medulares via Estimulação Elétrica Neuro Muscular. Uma Comparação entre Técnicas". In: 1 ${ }^{\mathrm{A}}$ ESCOLA BRASILEIRA DE APLICAÇÕES EM DINÂMICA E CONTROLE (APLICON' 2001). Anais. São Carlos, 30 jul.-03 ago., 2001.

POPE, M.H. et al. (2000). "Evaluation of low back muscle surface EMG signals using wavelets". Clin. Biomech., v.15, n.8, p.567-573, Oct. 2000.

PORFÍRIO, R.S.; WOOD, G.A.; CLIQUET Jr, A. (1992). "Myoelectric Hand Prosthesis with Accommodation Device for Grasping". In: VI MEDITERRANEAN CONFERENCE ON MEDICAL \& BIOLOGICAL ENGINEERING. Anais. ISBN: 88-7958-001-9. International Federation for Medical and Biological Engineering, Capri, p.1301-1304.

QUEVEDO, A.A.F.; CLIQUET Jr., A. (1991). "A Myoelectric control system for neuromuscular stimulation". Proc. Word Congress on Medical Physics and Biomedical Engineering - 16th International Conference on Medical and Biological Engineering, Japan, p.1209.

QUEVEDO, A.A.F.; CLIQUET Jr., A. (1992). "Sistema de Análise Digital de Sinais Eletromiográficos". I Forum Nac. de Ciência Tecn. e Saúde, p.213-216. 
QUEVEDO, A.A.F.; CLIQUET Jr., A. (1993). "A System for Digital Analysis of Electromyographic Signals”. Proc. Myo-Electric Control Symposium' 93 (Future Trends in myoelectric technology). ISBN:1-55131-004-X. Institute of Biomedial Engineering, University of New Brunswick, Ago.16-20, Fredericton, Canada, p.128-132.

ROBSON, A.J. (1989). "Physiology of muscle and nerve". In: SNYDERMACKLER, L.; ROBINSON, A.J. Clinical Electrophysiology. Baltimore, Williams \& Wilkins, p.59-94.

SCOTT, R.N.; PARKER, P.A. (1988). "Myoelectric Prostheses: State of the Art”. J. Med. Eng. \& Technology, v.12, n.4, p.143-151, Jul/Ago 1988.

SZILÁGYI, S. M.; SZILÁGYI, L.; DÁVID, L. (1997): “Comparison Between Neural-Network-Based Adaptive Filtering and Wavelet Transformer for ECG Characteristic Point Detection". Proc. 19th Inter. Conf. IEEE/EMBS, Oct.30-Nov.2, Chicago, IL., p.272-274.

WAVELET TOOLBOX (2001). "Wavelet Packet": Wavelet Packet Atoms, [capturado:abril/2001].http://www.mathworks.com/access/helpdesk/help/t oolbox/wavelet/wavelet.shtml

WIDROW, B.; HOFF Jr., M. (1960). "Adaptive Switching Circuits". IRE WESCON Conv. Rec., pt.4, p.96-104.

WIDROW, B.; GLOVER Jr., J.R.; McCOOL, J.M.; KAUNITZ, J.; WILLIAMS, C.S.; HEARN, R.H.; ZEIDLER, J.R.; DONG Jr., E.; GOODLIN, R.C. (1975). "Adaptive Noise Canceling: Principles and Applications". Proc. IEEE, v.63, n.12, p.1692-1716, Dez. 1975.

WIENER, N. (1949). "Extrapolation and Smoothing of Stationary Times Series, with Engineering Applications". New York, Wiley.

ZHANG, Y.T.; PARKER, P.A.; SCOTT, R.N. (1997). "Signal-to-Noise Ratios of the Myoelectric Channel With Additive Noise". Proc. 19th Inter. Conf. IEEE/EMBS, Oct.30-Nov.2, Chicago, IL, p.1582-1584.

ZVEREV, A.I. (1967). "Handbook of FILTER SYNTHESIS". New York, John Wiley \& Sons Inc., 573p. 


\section{APÊNDICE}

\section{Algumas APlicaÇões COM CANCELADORES DE RUÍDO ADAPTATIVO}

Neste item serão apresentadas, em caráter ilustrativo, algumas dentre as inúmeras aplicações dos canceladores de ruído adaptativos.

\section{Cancelamento de Ruído de Fundo em Sinal de Voz}

O sinal de referência deve ser obtido com um microfone que não capta, ou capta pouco, o sinal da voz do locutor.

\section{Cancelamento da Interferência do Lóbulo Lateral em Antenas}

Conforme já citado, o sinal do lóbulo lateral de uma antena pode ser retirado, por meio de uma filtragem adaptativa, utilizando um sinal de referência captado por uma outra antena disposta na lateral da antena principal (região onde são emitidos os sinais do lóbulo lateral).

\section{Cancelamento de Eco em Comunicação Telefônica}

Em comunicação telefônica é comum que o sinal transmitido retorne por um problema de impedância no final da linha de transmissão. Como é fácil obter o sinal da voz emitida, pois este sinal é captado pelo microfone, então pode ser cancelado o sinal que se ouve da própria voz por meio de filtros adaptativos. 


\section{Cancelamento do Sinal Ocular no EEG}

A captação do eletroencefalograma (EEG) é feita com eletrodos localizados na cabeça do paciente. O EEG normalmente é medido durante o sono ou por meio de lampejos de luz, que induzem atividade na região occiptal do cérebro. No entanto este tipo de excitação pode induzir movimento dos olhos durante o sono e potencial na retina ocular da ordem de $10 \mu \mathrm{V}$ a $5 \mathrm{mV}$. Como as amplitudes do eletroencefalograma variam entre $2 \mu \mathrm{V}$ e $200 \mu \mathrm{V}$ (ALMEIDA, 1997), então os sinais oculares (EOG) podem interferir na captação do EEG. Pelo fato do sinal do EOG ter faixa de frequência entre DC até $100 \mathrm{~Hz}$ e do EEG de $0,5 \mathrm{~Hz}$ a $100 \mathrm{~Hz}$ (ALMEIDA, 1997), então é interessante que seja utilizado o cancelamento de ruído adaptativo para atenuar os sinais de EOG sem comprometer o sinal de EEG. $\mathrm{Na}$ figura 1.1 é apresentado um sistema para este tipo de cancelamento de ruído adaptativo e na figura 1.2 são apresentados os sinais deste sistema.

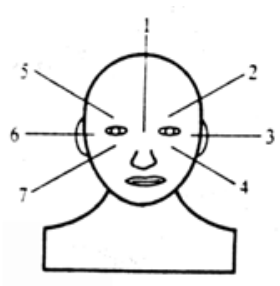

Medida do EOG

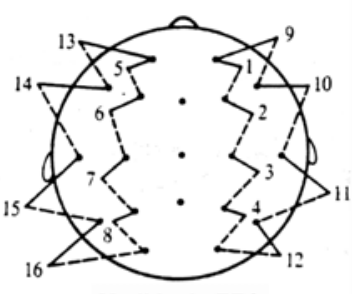

(a)

Medida do EEG

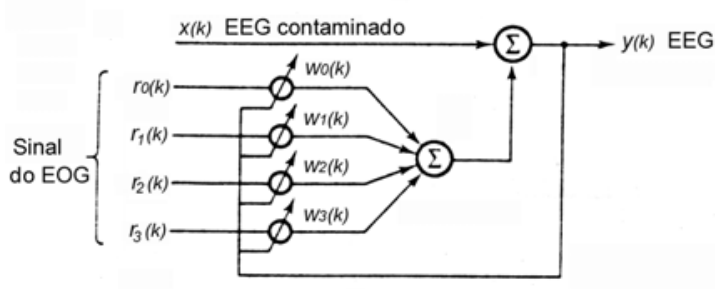

(b)

Fig. 1.1. - Filtragem Adaptativa para retirada de sinais oculares em EEG:

a) Localização dos eletrodo,

b) Filtro adaptativo multireferencial. (adaptado de IFEACHOR \& JERVIS, 1993)
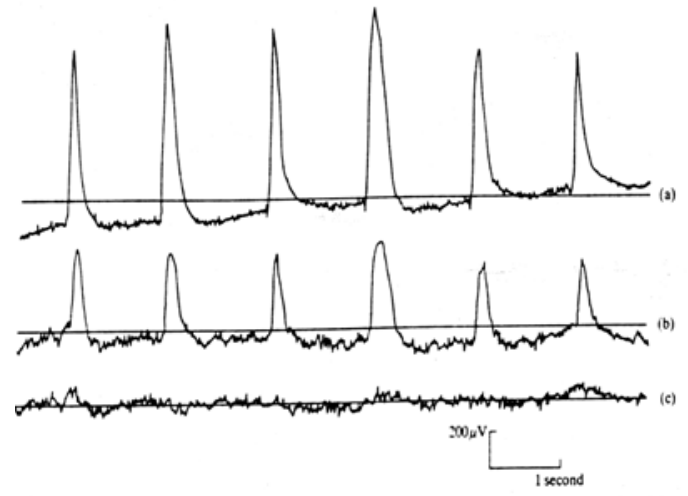

Fig. 1.2. - Filtragem dos sinais oculares em EEG:

a) Sinais Oculares,

b) Sinais Oculares + EEG,

c) EEG sem a interferência dos sinais oculares.

(IFEACHOR \& JERVIS, 1993)

É interessante observar que para este caso foi utilizado o cancelamento multireferencial. 


\section{Cancelamento de ECG Materno em ECG Fetal}

Para captar os sinais cardíacos do feto são dispostos eletrodos na barriga da mãe, porém, como o eletrocardiograma (ECG) do feto tem baixas amplitudes normalmente tem somado a ele os sinais do coração da mãe. Para retirar o sinal cardíaco da mãe, que é fácil de ser captado, do ECG captado na barriga, são dispostos eletrodos na região do coração da mãe, e este sinal é aplicado a entrada de referência do cancelador de ruído adaptativo conforme ilustrado na figura 1.3.

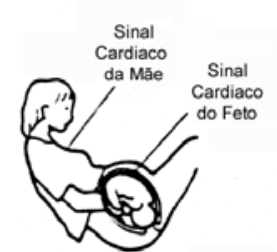

(a)

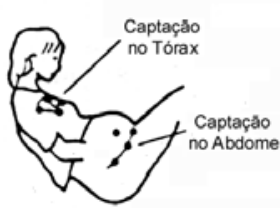

(b)

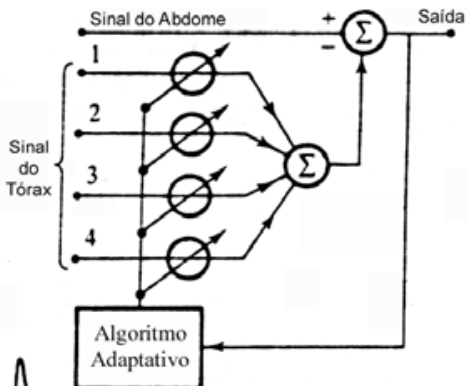

(c)

(d)<smiles>CCCCCCCCCCCCCCCCCCCCCCCC</smiles>

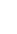

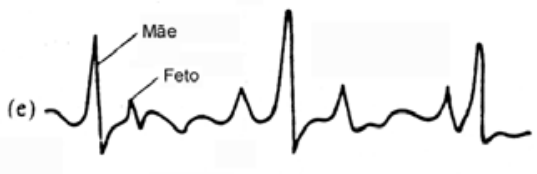

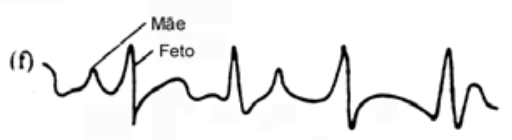

Fig. 1.3. - Cancelamento Adaptativo do ECG materno em ECG Fetal: a) Localização do ECG da mãe e do feto, b) Localização dos eletrodos, c) Filtro adaptativo, d) ECG da mãe, e) ECG da mãe + feto, f) ECG do feto com ECG da mãe atenuado. (adaptado de IFEACHOR \& JERVIS, 1993)

\section{Redução dos efeitos da respiração em sinais cardíacos}

Durante a respiração os sinais dos batimentos cardíacos podem ser afetados com o movimento do tórax. Para retirar estes sinais do ECG os eletrodos de referência são dispostos no tórax do paciente, de forma que captem o movimento torácico da respiração e não captem, ou captem pouco, sinal dos batimentos cardíacos. Com o sinal de referência o ruído é então estimado pelo filtro e retirado do sinal de entrada, obtendo assim um sinal de ECG sem os efeitos da respiração. 


\section{Cancelamento da interferência de $60 \mathrm{~Hz}$ em ECG}

Neste exemplo foi utilizado o cancelamento de ruído adaptativo de $60 \mathrm{~Hz}$ utilizando a configuração de um filtro notch conforme descrito por WIDROW et al. (1975).

$\mathrm{Na}$ figura 1.4 é apresentado um diagrama de blocos do filtro.

O sinal de referência é obtido a partir da própria rede elétrica, mas poderia ser gerado matematicamente já que a sua frequência é bem conhecida.

$\mathrm{Na}$ figura 1.5 são apresentados os sinais do filtro.

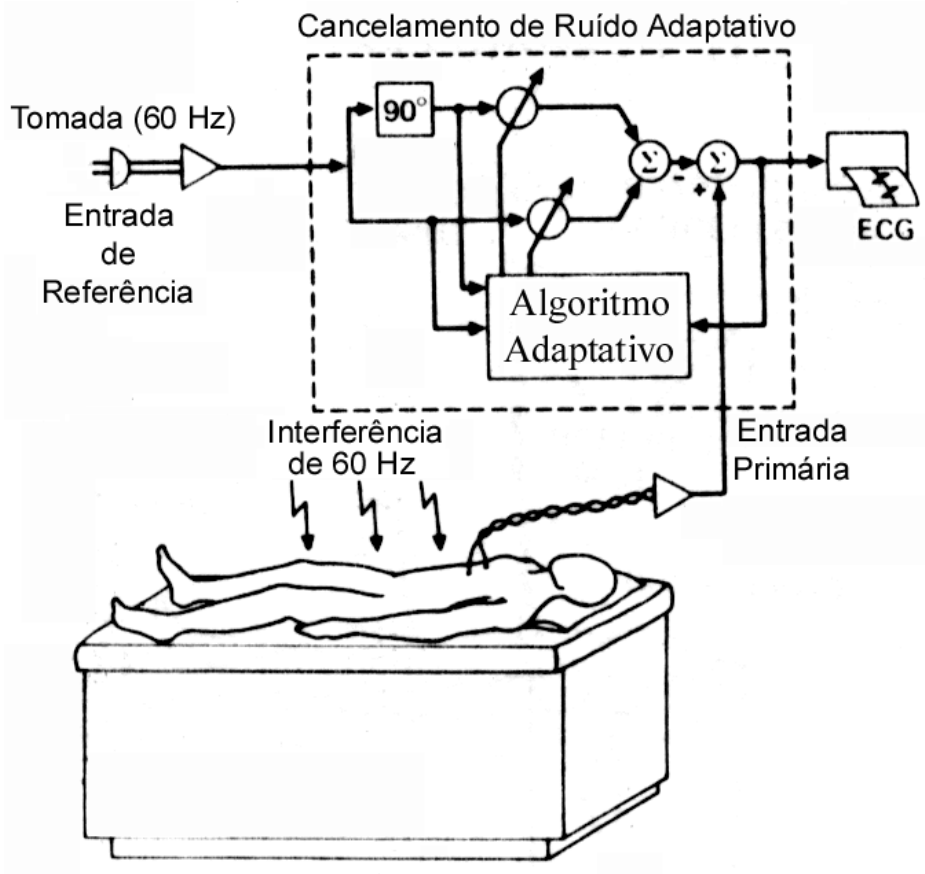

Fig. 1.4. - Configuração de um tipo de cancelamento da interferência da rede $(60 \mathrm{~Hz})$ em ECG (adaptado de WIDROW et al.,1975)

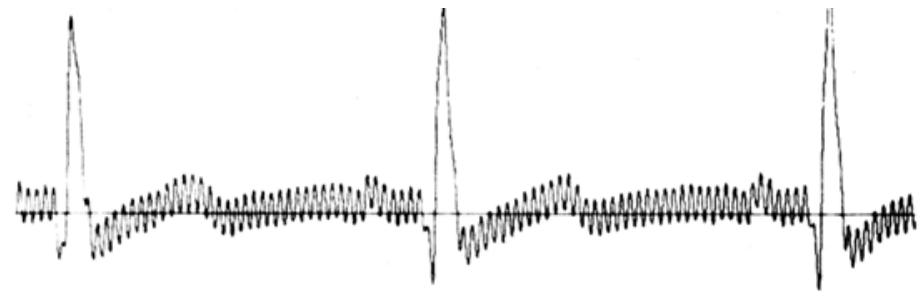

(a)

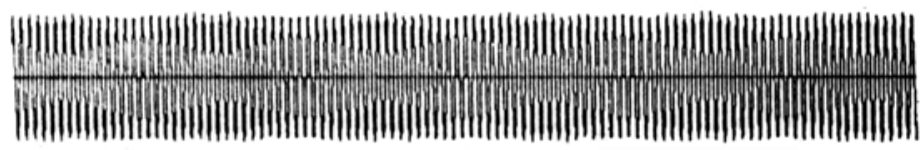

(b)
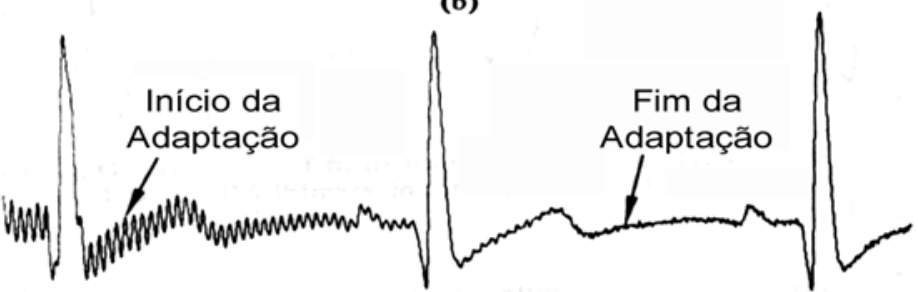

Fig. 1.5. - Cancelamento da interferência da rede em ECG a) ECG + Ruído da rede elétrica, b) Interferência da rede elétrica $(60 \mathrm{~Hz})$, c) Saída do filtro indicando período de adptação dos parâmetros (adaptado de WIDROW et al. ,1975) 